LAND-ATMOSPHERE INTERACTIONS AND THEIR RELATIONSHIPS TO THE ASIAN MONSOON IN THE TIBETAN PLATEAU 
Examining committee:

Prof.dr.ing. W. Verhoef Prof.dr.ir. A. Stein Prof.dr. J. Sobrino Prof.dr. E. Boegh Dr. A. Loew Prof.dr D. Han
University of Twente University of Twente University of Valencia Roskilde University Max-Planck-Inst. für Meteorologie University of Bristol

ITC dissertation number 247

ITC, P.O. Box 217, 7500 AE Enschede, The Netherlands

ISBN 978-90-365-3673-8

DOI 10.3990/1.9789036536738

Cover designed by Job Duim

Printed by ITC Printing Department

Copyright (c) 2014 by Lei Zhong

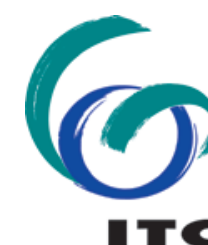

17C FACULTY OF GEO-INFORMATION SCIENCE AND EARTH OBSERVATION 


\title{
LAND-ATMOSPHERE INTERACTIONS AND THEIR RELATIONSHIPS TO THE ASIAN MONSOON IN THE TIBETAN PLATEAU
}

\author{
DISSERTATION \\ to obtain \\ the degree of doctor at the University of Twente, \\ on the authority of the rector magnificus, \\ prof.dr. H. Brinksma, \\ on account of the decision of the graduation committee, \\ to be publicly defended \\ on Thursday 8 May 2014 at $14.45 \mathrm{hrs}$
}

by

Lei Zhong

born on 20 April 1979

in Anhui, China 
This thesis is approved by

Prof.dr.Z. Su, promoter

Prof.dr. Y. Ma, promoter

Dr.M.S. Salama, assistant promoter 


\section{Acknowledgements}

I would like to express my deepest appreciation to my academic advisor, Prof. Bob Su, for his excellent guidance, encouragement and moral support for completing this study. I first met Bob in November 2004 when Prof.Yaoming $\mathrm{Ma}$ and I attended a CAS-ITC workshop in Beijing. I'm really impressed by Prof. Bob Su's personal charm through his speech in the workshop. During these years of my PhD career, I was always inspired by Bob's tremendous ideas over a wide range of topics and by his solid physics back ground. Thank you for pushing me forward all the time! This dissertation would not have been possible without his support and help.

I'm also truly indebted to Prof.Yaoming Ma for his endless guidance, support, understanding in various topics as an excellent advisor, and as a true friend. He taught me how the satellite data can be used in the atmospheric boundary layer study. He is so kind and gave me many chances and I really cherish them very much. I can never forget my first field experience with Prof.Yaoming Ma to the Tibetan Plateau. It was in 2005, during the fourth scientific expedition to Mt. Everest. Without his academic guidance, it is impossible for me to complete this dissertation and move forward to my academic career.

I would like also to express my sincere gratitude to my daily supervisor, Dr.Mhd. Suhyb Salama, for providing valuable insight and guidance over the past several years. He always spends a lot of time on the revision of my papers and the dissertation. I really appreciate his very kind help of technical support and constructive suggestions on my research. Without his guidance and support this achievement would not have been possible.

It is an honour talking to, and having fruitful discussions with, Prof. Kun Yang, Prof.Lide Tian, Dr. Xin Liu of Institute of Tibetan Plateau Research, Chinese Academy of Sciences, Prof.Yunfei Fu of University of Science and Technology of China and Prof.Jiemin Wang, Prof.Zeyong Hu, Prof.Jun Wen of Cold and Arid Regions Environmental and Engineering Research Institute, Chinese Academy of Sciences.

I'm also grateful to ITC, University of Twente for its financial support for me to pursue a PhD degree in the Netherlands. Many thanks go to Ms. Loes Colenbrander, Ms. Anke de Koning, Ms. Tina Tian, Ms. Tina Butt-Castro, Mr. Zheng Chang and Dr. Tiejun Wang for their very kind help which make my study in ITC much easier. My sincere thanks to Lichun, Joris, Christiaan, Rogier, Laura, Alain, Mariela, Chandra and other staff at WRS department for their invaluable suggestions and help. 
I'm indebted to Weiqiang Ma, Maoshan Li, Fanglin Sun and Minhong Song for their encourage and invaluable help on my research. I would like to thank Zhikun Zhu, Binbin Wang, Chao Xu, Yongjie Wang, Cunbo Han, Junping Du, Xuelong Chen, Lang Zhang, Yang Wang, Chunchun Meng for your friendship and help always.

Special thanks to Dr. Xia Li for her accompany and support. I'll always cherish the beautiful memories. My sincere thanks to the Chinese group in ITC, Guofeng Wu, Wenxiu Gao, Yanqiu Xing, Ningrui Du, Zhenshan Yang, Ouyang Wei, Pu Hao, Xin Tian, Yijian Zeng, Longhui Li, Changbo Qin, Xiaolong Yu, Xu Yuan, Donghai Zhen, Shaoning Lv, Hao Jiang, Guangyi Wang, Yu Song, Xin Shan, Qian Zhu, Fangfang Cheng, Jing Xiao, Qiuju Zhang, Yali Si. My life at Enschede was always enjoyable because they were around.

I'm obliged to my colleagues at School of Earth and Space Sciences, University of Science and Technology of China, for the friendly and comfortable working environment they provided.

Finally, my deepest thank to my parents, Jixue Zhong and Rongqiu Wang, and my elder brother Wei Zhong, for raising me in the love of science. I also want to express my appreciation to my mother-in-law Zhixia Wang, my father-in-law Zhongyi Hu for their moral support. My deepest gratitude goes to my wife Wei Hu who gave me endless support and love during my graduate study. She was always there cheering me on and standing by through the entire process. Also to my little sweetheart Keke who was born five months ago. Her arrival motivated me to be a successful father and scientist.

Lei Zhong(仲雷)

Hefei, China

J anuary, 2014 


\section{Table of Contents}

Acknowledgements
List of figures $\ldots \ldots \ldots \ldots \ldots \ldots \ldots \ldots \ldots$

Chapter 2 Estimation of Land Surface Temperature over the Tibetan Plateau Using AVHRR and MODIS Data .............................................. 15

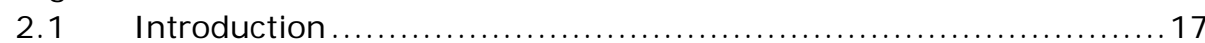

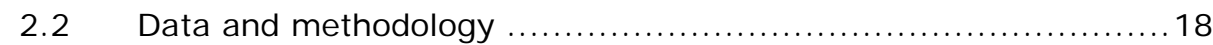

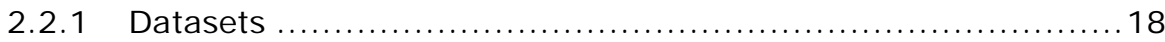

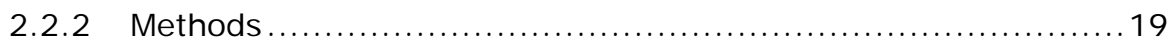

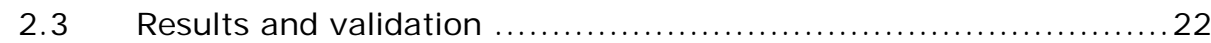

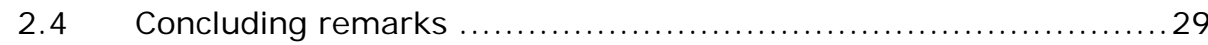

Chapter 3 Remote Sensing of Land Surface Heat Fluxes in the Middle Reaches of Yarlung-Zangbo River and Its Two Tributaries from AVHRR and MODIS Data .......................................................................

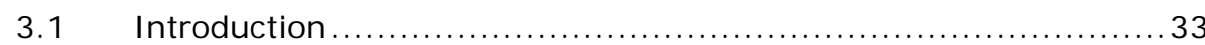

3.2 Study area and datasets ........................................... 34

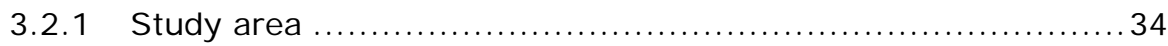

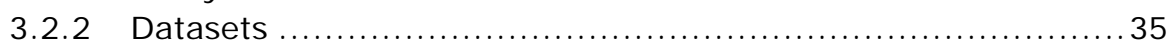

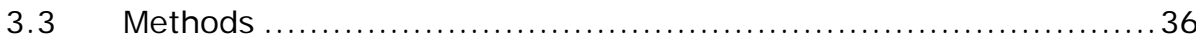

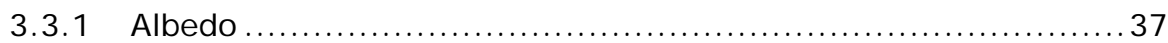

3.3.2 Normalized Difference Vegetation Index......................... 37

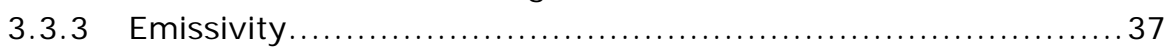

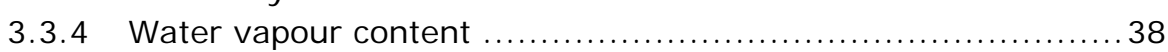

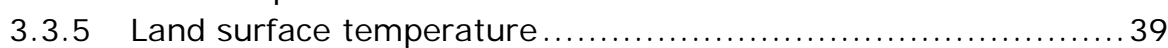

3.4 Results ............................................................... 40

3.4.1 Spatiotemporal variations of land surface parameters in the middle reaches of YZR and its two tributaries ................... 40

3.4.2 Spatiotemporal variations of land surface heat fluxes in the middle reaches of YZR and its two tributaries ....................43 43

3.5 Conclusions and discussions ..................................... 46 
Chapter 4 Assessment of Soil Water Deficit for the Middle Reaches of Yarlung-Zangbo River from Optical and Passive Microwave Images.......... 49

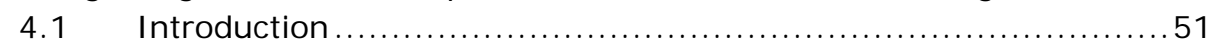

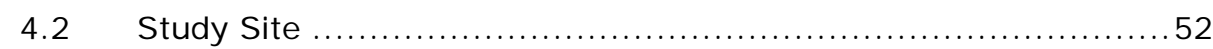

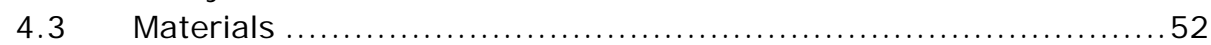

4.3.1 NOAA-16 AVHRR and Terra MODIS data ........................ 52

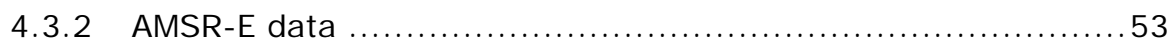

4.3.3 In-situ meteorological data ............................... 53

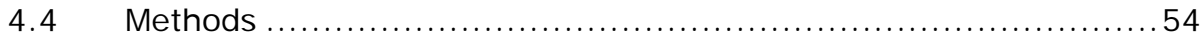

4.4.1 Comparison from soil moisture perspective ..................... 54

4.4.2 Determination of SWDI from AVHRR and MODIS data by using

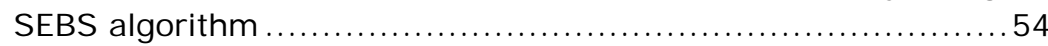

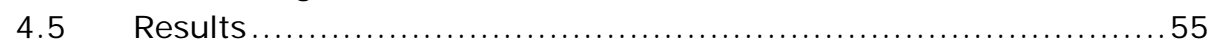

4.5.1 Comparison from soil moisture perspective ...................... 55

4.5.2 Determination of SWDI from AVHRR and MODIS data by using

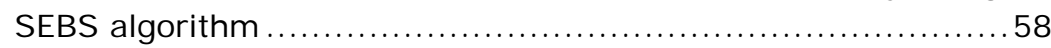

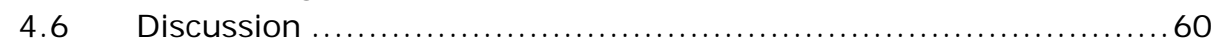

4.6.1 Comparison from soil moisture perspective ...................60 60

4.6.2 Determination of SWDI from AVHRR and MODIS data by using SEBS algorithm ................................................ 60

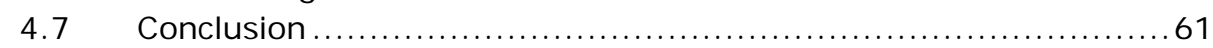

Chapter 5 Assessment of Vegetation Dynamics and Their Response to Variations in Precipitation and Temperature in the Tibetan Plateau ...........6 63

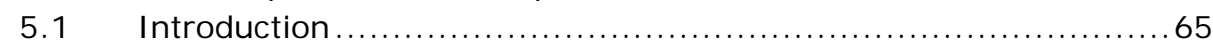

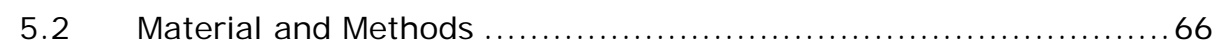

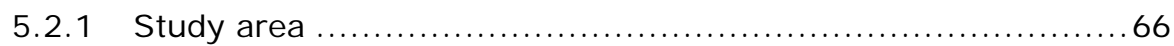

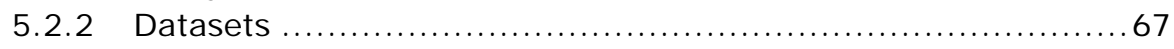

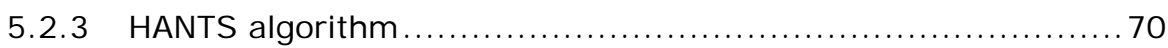

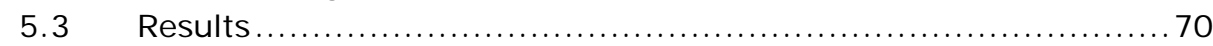

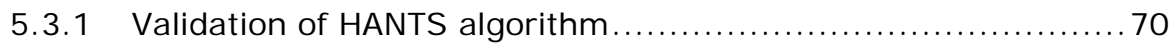

5.3.2 Spatial, seasonal and inter-annual changes in NDVI............. 71

5.3.3 NDVI development in different land cover types and its response

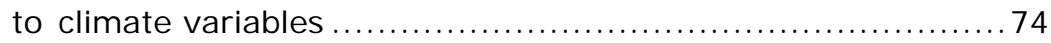

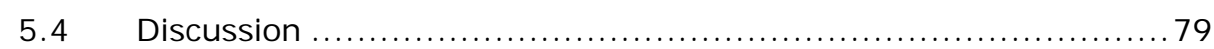

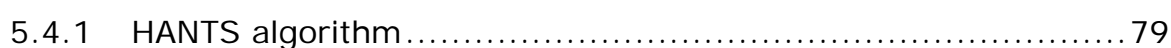

5.4 .2 Spatiotemporal variations of NDVI ............................... 79

5.4.3 The response of different land cover types to climate variables 80

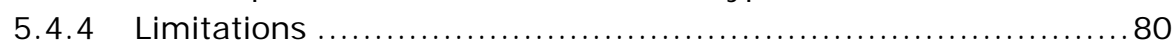

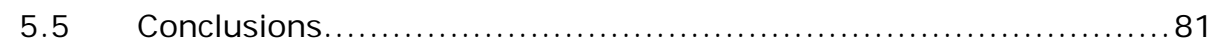

Chapter 6 Accelerated Changes of Environmental Conditions on the Tibetan

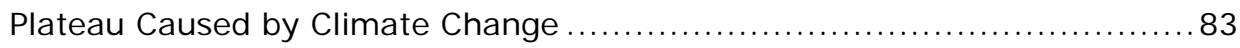

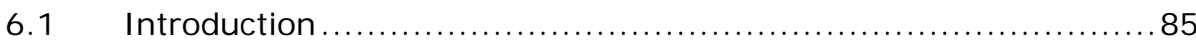

iv 


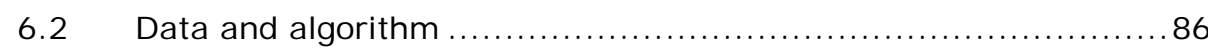

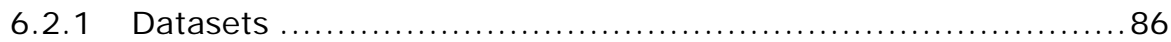

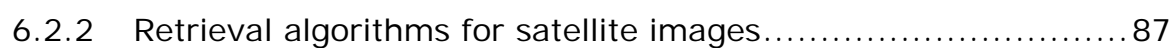

6.2 .3 Validation ....................................................... 87

6.3 Recent variation trends in land surface parameters across the

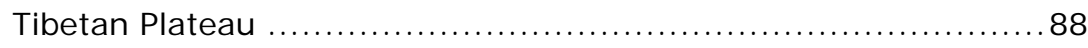

$6.4 \quad$ Conclusions and discussion....................................... 95

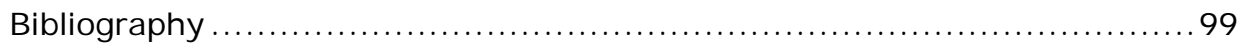

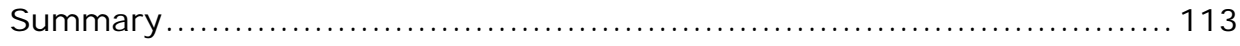

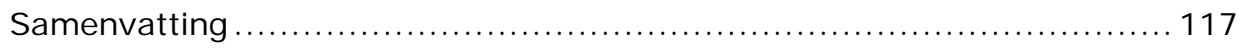

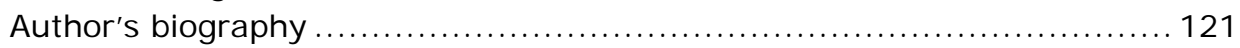

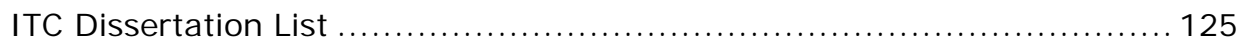




\section{List of figures}

Fig. 1-1 Location of the Tibetan Plateau

Fig. 1-2 The Location of the middle reaches of Yarlung-Zangbo River and its two tributaries in the TP is shown (left panel), with the TP (dark grey) being located in western part of China (light grey)(right panel).

Fig. 1-3 Map of land cover types in the middle reaches of Yarlung-Zangbo River and its two tributaries derived from global land cover 2000 (GLC 2000).

Fig. 1-4 The climate zoning map of the Tibetan Plateau.

Fig. 2-1 LST derived from AVHRR images: (a) and (b) are distribution patterns of land surface temperature; (c) and (d) are the corresponding frequency distributions.

Fig. 2-2 LST derived from MODIS images: (a) and (b) are distribution patterns of land surface temperature; (c) and (d) are the corresponding frequency distributions.

Fig. 2-3 Validation of derived AVHRR land surface temperature against field measurements: (a), (b), (c) and (d) represent winter, spring, summer and autumn cases, respectively.

Fig. 2-4 Validation of derived MODIS land surface temperature against field measurements: (a), (b), (c) and (d) represent winter, spring, summer and autumn cases, respectively.

Fig. 3-1 The Location of the middle reaches of $Y Z R$ and its two tributaries in the TP is shown (b), with the TP (dark grey) being located in western part of China (light grey)(a). Climatological annual precipitation ( $\mathrm{mm} / \mathrm{year}$ ) from TRMM 3B43 (c) and land cover map from GLC2000 (d) are also shown. Nine points in Fig. 1(b) represent the location of the meteorological stations. They are 1-Lhatze, 2-Rigaze, 3-Namling, 4-Gyangtse, 5-Nyemo, 6-Gonggar, 7Lhasa, 8-Maizhokunggar, 9-Tsedang.

Fig. 3-2 The derived land surface parameters in spring from satellite images. Panels (a)-(f) are LST, albedo, NDVI, Pv, emissivity and water vapour content derived from AVHRR, respectively. Panels $(\mathrm{g})-(\mathrm{h})$ are LST, albedo, NDVI, PV, emissivity and water vapour content derived from MODIS, respectively.

Fig. 3-3 The derived land surface parameters in autumn from satellite images. Panels (a)-(f) are LST, albedo, NDVI, Pv, emissivity and water 
vapour content derived from AVHRR, respectively. Panels (g)-(h) are LST, albedo, NDVI, Pv, emissivity and water vapour content derived from MODIS, respectively.

Fig. 3-4 The spatial distribution of land surface heat fluxes (unit $\mathrm{W} \mathrm{m}^{-2}$ ) in spring derived from AVHRR and MODIS images.

Fig. 3-5 The spatial distribution of land surface heat fluxes (unit $\mathrm{W} \mathrm{m}^{-2}$ ) in autumn derived from AVHRR and MODIS images.

Fig. 4-1 The derived the volumetric soil moisture (Unit: $\%, \mathrm{~cm}^{3} / \mathrm{cm}^{3}$ ) for middle reaches of the Yarlung-Zangbo River and its two tributaries (Lhasa River and Nianchu River) in April 2003 and October 2003.

Fig. 4-2 The derived SWDI and its spatial distribution of for middle reaches of the Yarlung-Zangbo River and its two tributaries (Lhasa River and Nianchu River) in different seasons.

Fig. 4-3 The relationship between the volumetric soil moisture (Unit: \%, $\mathrm{cm}^{3} / \mathrm{cm}^{3}$ ) and derived SWDI for the study area in April and October.

Fig. 5-1 Map of vegetation cover types in the Tibetan Plateau

Fig. 5-2 Proportions of land cover in the Tibetan Plateau (1 Alpine and Subalpine Meadow, ASM; 2 Alpine and Subalpine Plain Grass, ASPG; 3 Desert Grassland, DG; 4 Evergreen Needleleaf Forest, ENF; 5 Gravels, Gr; 6 Plain Grassland, PG; 7 Bare Rocks, BR; 8 Desert, D; 9 Glacier, Gl; 10 Meadow, M; 11 Evergreen Broadleaf Forest, EBF; 12 Lake, L; 13 Farmland, F; 14 River, R; 15 Slope Grassland, SG; 16 Swamp, S; 17 Bush, B; 18 Sparse Woods, SW; 19 Deciduous Broadleaf Forest, DBF; 20 Deciduous Needleleaf Forest, DNF; 21 Forest Mosaic/Degraded Forest, FM/DF)

Fig. 5-3 Comparison of original and reconstructed NDVI (Maduo: $98.217^{\circ} \mathrm{E}$, $34.917^{\circ} \mathrm{N}$, alpine and subalpine plain grass; Chaqia: $99.083^{\circ} \mathrm{E}, 36.783^{\circ} \mathrm{N}$, meadow)

Fig. 5-4 Average seasonal mean NDVI variations in the Tibetan Plateau

Fig. 5-5 Reconstructed time series of NDVI in the Tibetan Plateau

Fig. 5-6 Comparison of seasonal NDVI variations for different land cover types (land cover abbreviations as in Fig. 5-2) 
Fig. 5-7 Changes in seasonal NDVI, precipitation and temperature at different vegetation types

Fig. 6-1 Validation of derived PAL land surface temperature against field measurements. Not all time series data but cases in year 2000 are shown here.

Fig. 6-2 Temporal variations and spatial distribution of LST over the TP. (a) Time series of 10-day maximum LST of the TP from 1982 to 2000. (b) Variations of annual mean PAL LST from 1982 to 2000. The bold straight line represents the linear fit result. Dash-dot lines are confidential lines for the linear trend at $95 \%$ confidence level. (c) Spatial distribution of LST; (d) Spatial distribution of LST variance. The LST data in 1994 is not complete and it has been excluded.

Fig. 6-3 Air temperature and precipitation variations over the TP. (a) Time series of monthly mean air temperature at $2 \mathrm{~m}$ from ERA-40. (b) Variations of ERA-40 annual mean air temperature from 1982 to 2000. (c) Time series of monthly mean precipitation from ERA-40. (d) Variations of ERA-40 annual mean precipitation from 1982 to 2000. The bold straight line represents the linear fit result. Dash-dot lines are confidential lines for the linear trend at $95 \%$ confidence level.

Fig. 6-4 Monthly mean precipitation and variance. (a) and (b) are generated from 1982 to 1985. (c) and (d) are from 1986 to 1990. (e) and (f) are from 1991 to $1995 . \mathrm{g}$ ) and $(\mathrm{h})$ are from 1996 to 2000 . The white line represents contour of 3000 meters.

Fig. 6-5 NDVI albedo and wind speed variations over the TP. (a) Time series of 10-day maximum NDVI derived from PAL. (b) Variations of annual mean PAL NDVI from 1982 to 2000. (c) Time series of 10-day maximum albedo derived from PAL. (d) Variations of annual mean PAL albedo from 1982 to 2000. (e) Time series of monthly mean wind speed at $10 \mathrm{~m}$ from ERA-40. (f) Variations of ERA-40 annual mean wind speed from 1982 to 2000. The bold straight line represents the linear fit result. Dash-dot lines are confidential lines for the linear trend at $95 \%$ confidence level.

Fig. 6-6 Temporal variations and spatial distribution of sensible heat flux over the TP. (a) Time series of monthly mean surface sensible heat flux from GLDAS. (b) Variations of GLDAS annual mean sensible heat flux from 1982 to 2000. The bold straight line represents the linear fit result. Dash-dot lines are confidential lines for the linear trend at $95 \%$ confidence level. (c) Spatial distribution of sensible heat flux; (d) Spatial distribution of sensible heat flux variance. The white line represents contour of 3000 meters. 


\section{List of tables}

Table 1-1 Major land surface processes experiments in the world (19862008)

Table 2-1 Ground measurement sites.

Table 2-2 Published split window algorithms. (Algorithms 1-18 and 20 are for AVHRR images, and algorithm 19 is for MODIS images. $T_{4}$ and $T_{5}$ are the brightness temperatures of channels 4 and 5 for AVHRR; $T_{31}$ and $T_{32}$ the brightness temperatures of channels 3132 for MODIS; $\varepsilon$ and $\Delta \varepsilon$ are the average emissivity and emissivity difference; $\theta$ is the viewing zenith angle from nadir; $\tau$ is atmospheric transmittance; $w$ is water vapour content; and $\Delta I \downarrow$ is the effective downwelling sky radiance difference. A, B, C, D and L are coefficients in equations.)

Table 2-3 Comparison between the estimated land surface temperature from NOAA/AVHRR images and ground measurements. $\left(V_{m}=\right.$ measured values; $\mathrm{V}_{\mathrm{d}}=$ derived results; and the symbol '--.-' represents the cloud contaminated pixels.)

Table 2-4 Comparison between the estimated land surface temperature from EOS/MODIS images and ground measurements. $\left(V_{m}=\right.$ measured values; $\mathrm{V}_{\mathrm{d}}=$ derived results; and the symbol '----' represents the cloud contaminated pixels.)

Table 3-1 Satellite passing time

Table 4-1 The percentage of different SWDI values derived from satellite images

Table 5-1 The selected meteorological stations with their corresponding land cover types

Table 5-2 Interannual NDVI variation trend for different land cover types from 1998 to 2006

Table 5-3 Monthly maximum, minimum, difference between the maximum and minimum, and average NDVI values for different land cover types (land cover abbreviations as in Fig. 5-2) 
Table 5-4 Correlation coefficients of NDVI versus precipitation (P) and NDVI versus temperature $(T)$ of different vegetation types

Table 5-5 Annual mean NDVI, precipitation and temperature of different vegetation types 
Chapter 1

General Introduction 


\subsection{Scientific background}

The Asian monsoon is manifested as a land-atmosphere-ocean interaction between Asian continents and the surrounding oceans in the seasonal cycle. Land-atmosphere interaction which modulates the seasonal heating, are likely to be responsible for the interannual variability of the monsoon. From the beginning of 1980s, the international scientific community has realized that the land surface processes including land-atmosphere interaction are important factors in the Asian monsoon system. Since mid-1980s, organized by WCRP and IGBP, more than 50 land surface processes experiments have been carried out in different areas (Wang 1999, Ma 2006)(Table 1-1).

Table 1-1 Major land surface processes experiments in the world (1986-2008)

\begin{tabular}{|c|c|c|c|c|}
\hline Experiments & $\begin{array}{l}\text { Experimental } \\
\text { period }\end{array}$ & $\begin{array}{l}\text { Scale } \\
(\mathbf{k m} \times \mathbf{k m})\end{array}$ & Major objectives & References \\
\hline $\begin{array}{l}\text { HAPEX- } \\
\text { MOBILHY }\end{array}$ & 1986 & $100 \times 100$ & $\begin{array}{l}\text { Water and energy exchange, } \\
\text { regional hydrology }\end{array}$ & $\begin{array}{l}\text { Schmugge } \\
\text { and Andre } \\
\text { (1991) }\end{array}$ \\
\hline FIFE & 1988,1990 & $10 \times 10$ & $\begin{array}{l}\text { Water and energyexchange, } \\
\text { biometeorology, remote sensing }\end{array}$ & $\begin{array}{l}\text { Sellers and } \\
\text { Hall (1992) }\end{array}$ \\
\hline HEIFE AECMP'95 & $\begin{array}{l}\text { 1988, 1990- } \\
1992,1994, \\
1995\end{array}$ & $70 \times 90$ & $\begin{array}{l}\text { Water and energy exchange in } \\
\text { arid regions, regional hydrology, } \\
\text { biometeorology, remote sensing }\end{array}$ & $\begin{array}{l}\text { Wang et al. } \\
\text { (1993), Hu et } \\
\text { al. (1994) }\end{array}$ \\
\hline EFEDA & 1991, 1995 & $85 \times 130$ & $\begin{array}{l}\text { Desertification, biometeorology, } \\
\text { remote sensing }\end{array}$ & $\begin{array}{l}\text { Bolle et al. } \\
\text { (1993) }\end{array}$ \\
\hline HAPEX-Sahel & 1992 & $100 \times 100$ & Biometeorology, remote sensing & $\begin{array}{l}\text { Goutorbe et } \\
\text { al. (1994) }\end{array}$ \\
\hline BOREAS & 1993-1994 & $1000 \times 1000$ & Biometeorology, remote sensing & $\begin{array}{l}\text { Hall and } \\
\text { Sellers } \\
\text { (1993) }\end{array}$ \\
\hline $\mathrm{GCIP}$ & $1995-2000$ & $2000 \times 200$ & Meteorology and remote sensing & IGBP (1992) \\
\hline $\begin{array}{l}\text { GAME/Tibet and } \\
\text { TIPEX, GAME- } \\
\text { Siberia, GAME- } \\
\text { HUBEX GAME- } \\
\text { Tropic }\end{array}$ & 1996-2000 & $\begin{array}{l}200 \times 100 \\
(\text { meso-scale) } \\
2000 \times 1300 \\
\text { (plateau } \\
\text { area), } 100 \times \\
100 \text { for the } \\
\text { other three } \\
\text { area }\end{array}$ & $\begin{array}{l}\text { Water and energy exchange over } \\
\text { the experimental areas, regional } \\
\text { hydrology, snow cover, } \\
\text { precipitation, biometeorology, } \\
\text { remote sensing }\end{array}$ & $\begin{array}{l}\text { GAME ISP } \\
\text { (1998) }\end{array}$ \\
\hline $\begin{array}{l}\text { CEOP } \\
\text { (CAMP/Tibet) }\end{array}$ & 2001-2005 & $\begin{array}{l}36 \text { reference } \\
\text { areas }(250 \times \\
150)\end{array}$ & $\begin{array}{l}\text { Water and energy exchange over } \\
\text { the experimental areas, regional } \\
\text { hydrology, snow cover, } \\
\text { precipitation, biometeorology, } \\
\text { remote sensing }\end{array}$ & Koike (2002) \\
\hline I MGRASS & 1997, 1998 & $100 \times 150$ & $\begin{array}{l}\text { Water and energy exchange over } \\
\text { the grass land, regional } \\
\text { hydrology, precipitation, remote } \\
\text { sensing, biometeorology }\end{array}$ & Lu (1997) \\
\hline MAGS & 1998, 1999 & $1000 \times 1000$ & $\begin{array}{l}\text { Hydrological process, climatic } \\
\text { effect }\end{array}$ & JSC (1994) \\
\hline AMAZON & 1998-2000 & $3000 \times 2000$ & Biometeorology, remote sensing & $\begin{array}{l}\text { Sellers et al. } \\
\text { (1993) }\end{array}$ \\
\hline LOPEXS & 2004-2008 & $1000 \times 1000$ & $\begin{array}{l}\text { Land surface energy } \\
\text { components, remote sensing }\end{array}$ & $\begin{array}{l}\text { Wen et al. } \\
(2009)\end{array}$ \\
\hline
\end{tabular}

Referred to as the 'roof of the world' and the 'third pole of the earth' (Qiu 2008), the Tibetan Plateau (also known as the Qinghai-Xizang Plateau; TP 
hereinafter) is well known both for its high altitude (McVicar and Körner 2013) and unique geographical features (Ding et al. 2006; Ma et al. 2006; Ma et al. 2011; Zhong et al. 2012). Apart from being the 'source of rivers' and the 'ecological source' for South and Southeast Asia, it is also the 'starter' and 'regulating area' for the climate of China and indeed of the Eastern Hemisphere as a whole. Land-atmosphere interaction in this area, especially through energy and water cycles, has great influence on the Asian monsoon, east Asian atmospheric circulation and even global climate change ( $Y e$ and Gao 1979; Ye 1981; Ye and Wu 1998; Ma and Tsukamoto 2002; Zhong et al. 2010). The TP exerts its dynamic and thermal effects on the atmosphere mainly by the interaction between the underlying surface and the atmosphere through turbulent exchange of mass and energy. The simulation of Asian monsoon by a coupled ocean-atmosphere general circulation model (GCM) also suggests that without the Tibetan Plateau orography the monsoon precipitation cannot penetrate into the interior of the continent (Abe et al. 2003).

Land surface characteristics are key factors to influence the land-atmosphere mass and energy exchange. The physical quantities of the land surface which may possess anomalous atmospheric forcing or climate memory effects can be but not limited to: (1) Vegetation indices, such as Normalized Difference Vegetation Index (NDVI), vegetation coverage, (2) land surface temperature (LST), (3) albedo, (4) soil moisture, (5) water vapour content, (6) surface energy balance components. The above parameters are also among the most important land surface parameters for describing land surface features. Vegetation is regarded as an intermediate link in the pedosphere, atmosphere and hydrosphere of the earth system (Zhong et al. 2010). NDVI is one of the key parameters in global climatic change study. On the other hand, LST controls most physical, chemical and biological processes of the Earth surface (Qin and Karnieli 1999). Albedo represents the reflective ability of the earth to solar radiation and is widely used in surface energy balance, weather forecast and global climatic change study (Dickinson 1995). Surface emissivity is a measure of inherent efficiency of the surface in converting heat energy into radiant energy above the surface. Both surface emissivity and water vapour content are essential factors to derive the LST from satellite images (Zhong et al., 2012). Since all natural materials emit only a fraction of the energy emitted by a black body at the same temperature, the thermal radiance received by the sensors on board satellite is also determined by surface emissivity, and the total atmospheric water vapour, the latter is also an important component for the study of weather, hydrological cycles and the Earth's climate. These land surface parameters constitute the basis of energy and mass balance and Land-Atmosphere interactions. Their variations have significant impact on the energy and water cycles specifically for the high elevated Tibetan Plateau. 
To promote the quantitative understanding of land-atmosphere interaction in the TP, many field experiments have been conducted since the 1950s, such as the Qinghai-Xizang Plateau Meteorology Experiment (QXPMEX, May to August, 1979), the Second Tibetan Plateau Experiment of Atmospheric Sciences (TIPEX, 1996-2000), the GEWEX Asian Monsoon Experiment over the Tibetan Plateau (GAME-Tibet, 1996-2000), the Coordinated Enhanced Observing Period Asian-Australia Monsoon Project on the Tibetan Plateau (CAMP-Tibet, 2001-2005), Comprehensive Scientific Expedition in Mt. Everest Region by Chinese Academy of Sciences (April to June, 2005), Japan-China Meteorological Disaster Reduction Corporation Research Center Project (2005-2009). A large amount of valuable data have been collected, and many scientific results have been obtained (e.g. Bian et al., 2003; Choi et al., 2004; Gao et al., 2000; Hong et al., 2004; Ma and Tsukamoto, 2002; Ma et al., 2002, 2005; Tanaka et al., 2001; Ye and Gao, 1979).

Land surface quantities over the TP control the Asian monsoon and they are essential inputs for different climate models. However, due to a lack of adequate observational data and quantitative measures of land surface parameters over the TP, large uncertainties still exist in the relationship between variabilities of these quantities and the Asian monsoon.

The objective of this study is to quantify the spatial distribution of the land surface parameters over the TP, their long-term variations under the background of climate change and characterize their relationships with the atmosphere and specifically the Asian monsoon. The contribution of this work lays in:

i) Retrieve plateau-scale land surface parameters which are of great importance in land-atmosphere interaction;

ii) Reveal spatial distribution, seasonal changes, and inter-annual variation trends of the land surface parameters and especially, their responses to the Asian Summer Monsoon;

iii) Estimation of soil water deficit (SWD) and land-atmosphere energy transfer in an important agriculture center of the TP.

\subsection{Study area}

\subsubsection{Geographical Location}

Together with the Arctic and the Antarctic, the Tibetan Plateau and surrounding mountains, also called the 'Third Pole of the Earth', carry one of the largest ice masses of the Earth. Its ice fields contain the largest reserve of fresh water outside the polar regions (Yao et al. 2011). The Tibetan Plateau is the largest and highest region on earth and the source of the 10 major river systems that provide irrigation, power and drinking water for over 
1.3 billion people - nearly $20 \%$ of the world's population. The average height of the whole region is more than $4,000 \mathrm{~m}$ above sea level, for which the Tibetan Plateau is known as the 'roof of the world'. The highest peak, Mt. Everest, is 8,844.43 $\mathrm{m}$ above sea level and is also the highest in the world. The TP is located in the southeastern part of China with the main part in Qinghai Province and Tibet Autonomous Region (Fig.1-1). Adjacent to India, Nepal and Bhutan, the southern edge of the TP is from the Himalayas. The northern edge of the TP extends from the northern margins of Kunlun, Altun and Qilian Mountains, and is connected to the Tarim Basin which belongs to Asian central arid desert region and the Hexi Corridor with about $4000 \mathrm{~m}$ height difference. The western edge is Pamir and Karakoram Mountains, bordering with Kyrgyzstan, Tajikistan, Afghanistan, Pakistan and Kashmir. The eastern part borders with the southern and eastern foothill of the Yulong Snow Mountain, Snowy Mountains, Jiajin Mountain, Qionglai Mountain and Min Mountain. The eastern and northeastern parts of the TP are connected to the western section of the Qinling Mountains and the Loess Plateau. The TP in Chinese territory starts from the Western Pamirs in the west and extends to the Hengduan Mountains in the east. It covers about 31 degrees of longitude with a distance of $2945 \mathrm{~km}$ from east to west. The TP starts from the southern edge of the Himalayan Mountains and extends to the northern sides of Kunlun and Qilian Mountains. It covers about 13 degrees of latitude with a wide of $1532 \mathrm{~km}$ from the north to the south. The TP has a total area of about $2.571 \times 10^{6} \mathrm{~km}^{2}$, which accounts for $26.8 \%$ of Chinese territory (Zhang et al., 2002; Cao, 2006).

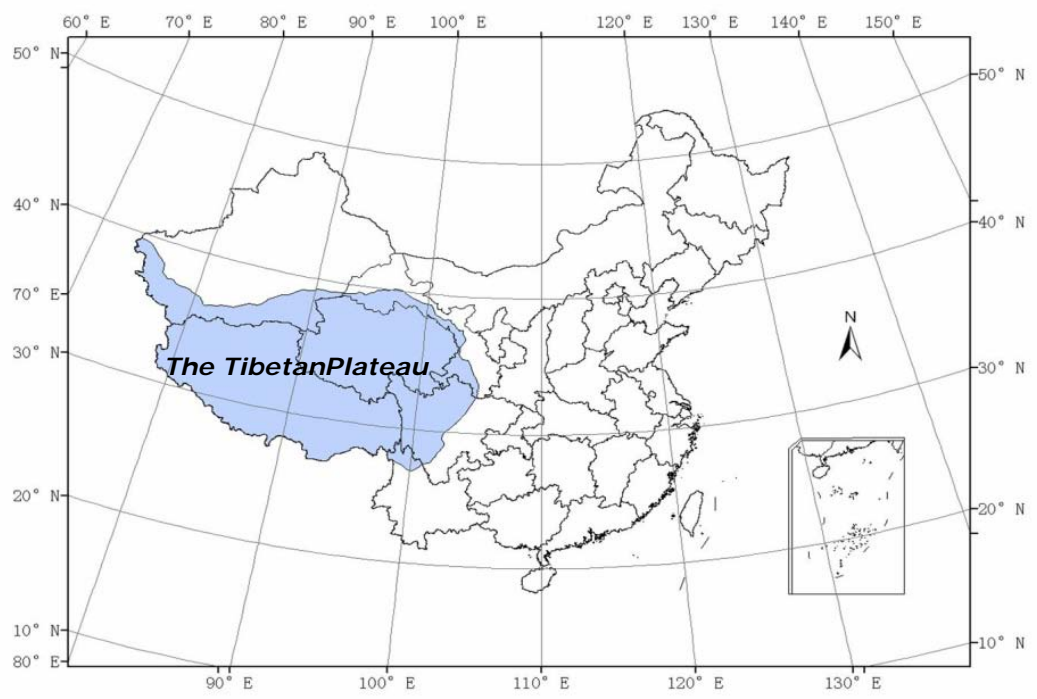

Fig. 1-1 Location of the Tibetan Plateau 
The middle reaches of Yarlung-Zangbo River (YZR) and its two tributaries (including lower reaches of Lhasa River and Nianchu River) is a study area of this work. YZR is a region in central Tibet Autonomous Region where the agricultural economy is most developed. The YZR and its two tributaries consist of three rivers' watershed, the Yarlung-Zangbo River, Lhasa River (LR) and Nianchu River (NR)(Fig. 1-2). YZR is the highest major river in the world. The middle reaches of YZR and its two tributaries have a territory about $60000 \mathrm{~km}^{2}$ which is $5 \%$ of Tibet Autonomous Region. However, it takes up $10 \%$ of cultivated area and has 50\% population in Tibet. It is a central agricultural region and forms a natural corridor for warm and wet air flow from the Indian Ocean. The precipitation usually decreases from the east to west and thus forms vegetation changing from semi-humid type to semi-arid type. According to global land cover 2000 database (ECJ RC 2003), there are 9 land cover types scattered through the study area (Fig.1-3). The three dominant land cover types are: alpine and subalpine meadow, alpine and subalpine plain grass and desert grassland. 


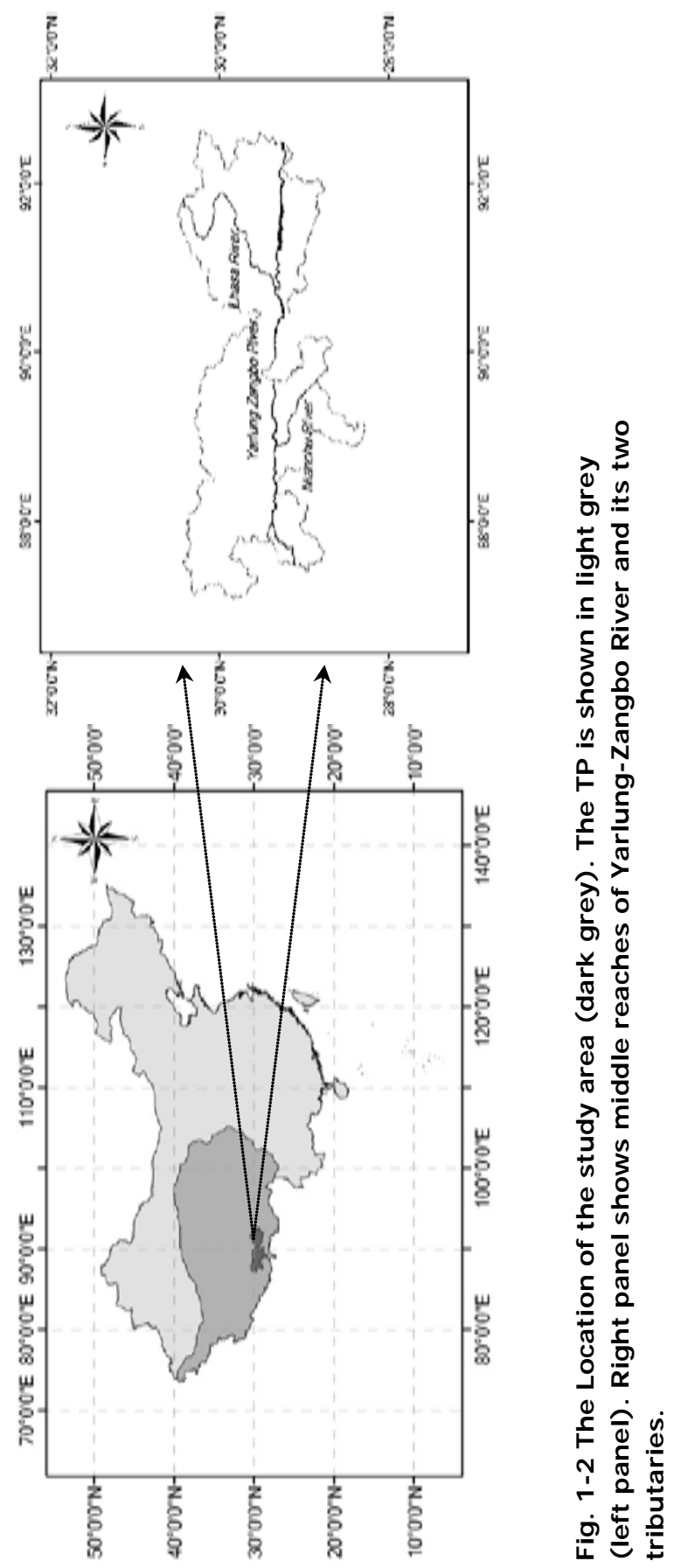




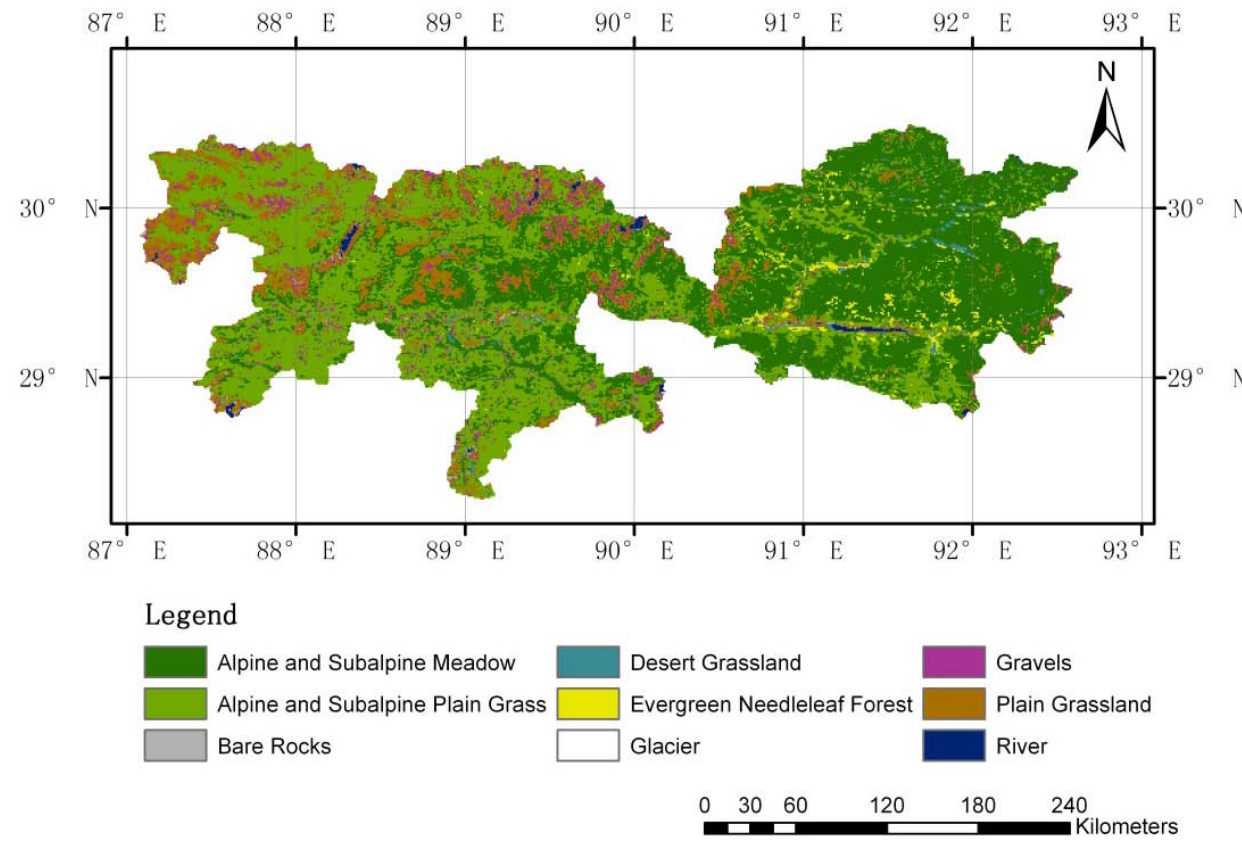

Fig. 1-3 Map of land cover types in the middle reaches of Yarlung-Zangbo River and its two tributaries derived from global land cover 2000 (GLC 2000).

\subsubsection{Natural Environment}

As the highest terrain, the northern, eastern and southern edges of the TP decline sharply to the basin and plains with height differences of about 3-4 $\mathrm{km}$. These huge differences in altitude are characteristics of the TP geomorphology. The edges of the TP are surrounded by high mountains and deep canyons. The internal of the TP is characterized by vast plateau, towering mountains, sporadic lake basins and broad basins. The main part of the TP is based on broad plateau surface. The general topography gradually inclines from the northwest to southwest, which decreasing from $5000 \mathrm{~m}$ to about $4000 \mathrm{~m}$ above sea level. The vertical and horizontal extensions of the huge mountains above the plateau constitute the skeleton of the plateau landscape. Numerous basins and lakes are embedded in the middle of the plateau surface. Accompanied with uplift processes of the TP, numerous lakes are formed with different sizes and features. The TP contains $37 \%$ of the total lakes in China that have an area larger than $500 \mathrm{~km}^{2}$. The Qinghai Lake is the largest lake in China. The other nine lakes are Namco, ShaiLincuo, Zhari Namco, TangraYumco, YamzhoYumco, Ngoring Lake, Ulam UL Lake, Har Lake and Zhaling Lake.

Overall, the TP has a resounding terrain with cold climate and widespread of glaciers and permafrost. The climate of the TP is characterized by a strong 
solar radiation, low temperature, great diurnal but smaller annual temperature range, distinct wet and dry seasons. However, as the variations of different terrain and altitude in the TP, the climatic conditions there are complex, but there are some certain regional variations. The temperature and moisture conditions in the TP change from the northwest to the southeast. The northwest of Plateau is cold and dry, while the southeastern part is relatively warm and humid. The regional difference is very clear. Based on the climate variations the TP can be divided into 13 different climatic zones (Fig.1-4). The rainy season in the TP usually starts from May and ends between late September and mid-October. The rainy season in southeastern TP starts earlier and ends later in comparison to the northwestern part of TP. The total precipitation during the rainy season takes up $90 \%$ of the annual amount, or even more. The seasonal variation of the TP is commonly characterized by what is called winter half year and summer half year. The winter half year spans from October to April whereby the entire TP is under the control of the westerly wind belt which is characterized by high wind speed and dry air flow. The summer half year, spans from May to September, during which the westerly circulation system shifts to the north with the establishment of the southwest monsoon. At the summer half year, a large amount of precipitation is brought to the TP. Therefore, the summer half year of the TP is also called the'rainy season'(Zheng et al., 1985). 


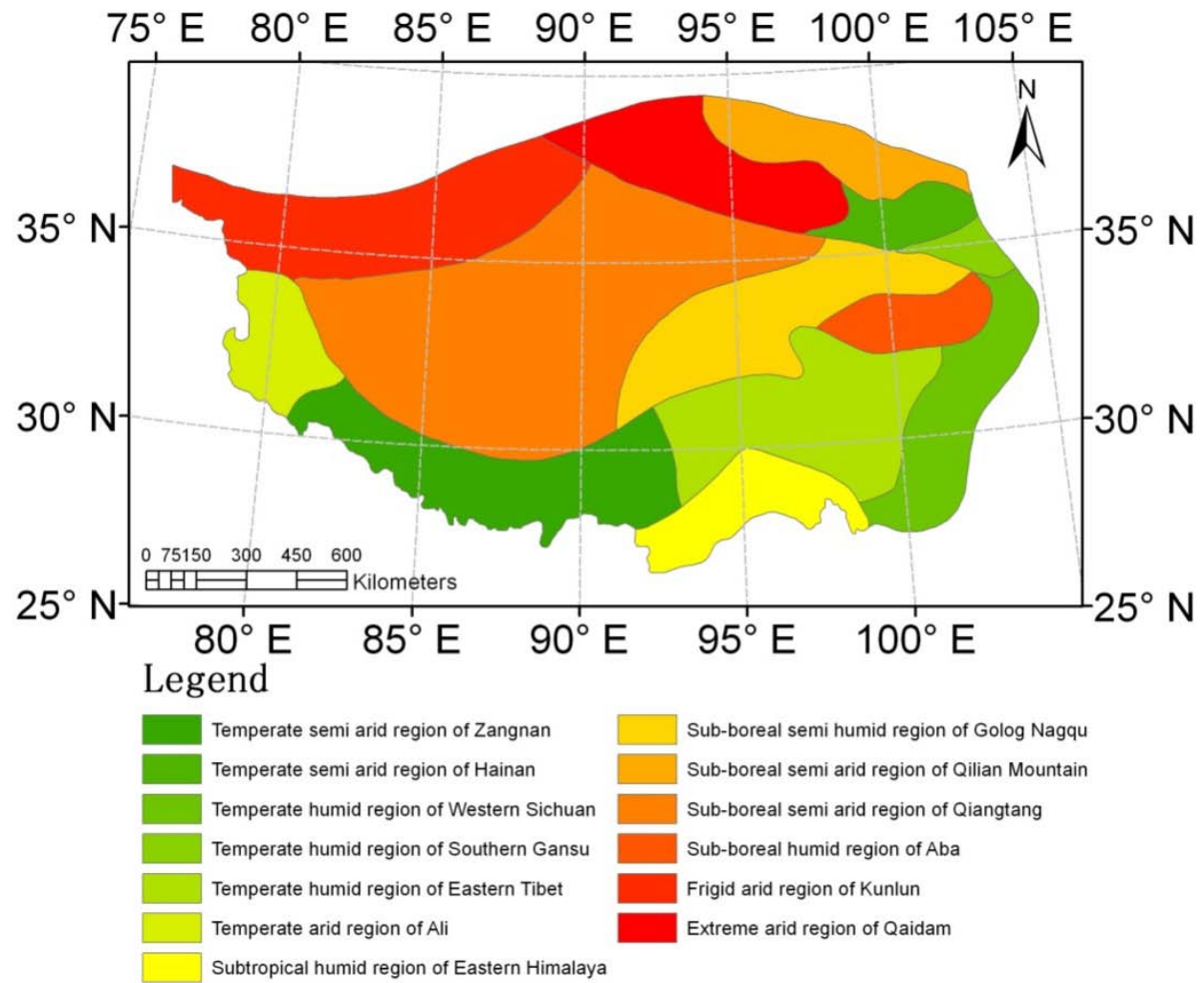

Fig. 1-4 The climate zoning map of the Tibetan Plateau

\subsection{Problem statement}

Higher accuracy of continuous data can be collected through establishing observation stations in the different areas of the inner plateau to determine surface parameters. At the same time, it must be noted that with respect to the vast area of the TP, these sites are sparsely scattered. Furthermore, the information acquired from sites can only be representative at point scale. Point scale observations cannot meet the information needs for regional or plateau scale studies. It is unrealistic to get the land surface parameters and land-atmosphere interaction information for entire TP through observation sites. And the special geographical environment and extreme climatic conditions on the Tibetan Plateau make the interpretation of field observations very difficult and many experiments were only conducted near the cities and in some regions with relatively convenient transportation. Moreover, observational sites are not only sparse but also uneven. In recent years, the development of remote sensing technology provided a possibility to collect data on global scale with high-resolution and repeated visiting time. Observational models can be applied quickly and easily to retrieve land 
surface parameters from RS data. After several decades of improvements, great developments have been made in the retrieval of land surface parameters and land-atmosphere energy exchanges from remote sensing data (McMillin, 1975; Prata, 1993; Zhu et al., 1993; Qin and Karnieli, 1999). Some fruitful works have also been done to estimate land surface parameters over the TP based on satellite data by different scholars (Zhong and Wu, 1985; Ma and Tsukamoto, 2002; Ma et al., 2003; Gao et al., 2004; Ma et al., 2006; Ma et al., 2006; Ma et al., 2007; Wang et al., 2007; Ma et al., 2010). But at the same time, it must be noted that the scientific results, so far, are mainly concentrated on meso-scale experiment area in the northern TP. Land surface parameters for the entire TP, which accounts for $25 \%$ of the Chinese territory, were, before this work, virtually missing. Although there are some global products from MODIS, some studies, such as Zhong et al. (2012), have proved that there are large discrepancies for MODIS products in the Tibetan Plateau area. For example, the absolute error (AE) for LST and albedo are $3.3^{\circ} \mathrm{C}$ and 0.027 , respectively. Furthermore, existing studies focused primarily on the inversion algorithm itself (Julien et al., 2006), and the satellite retrieval results only cover a relatively short time series and are not sufficient to understand the surface parameters' spatial distribution, their seasonal changes and inter-annual variation trends. Last but not least, as a major and important agricultural center, the land surface water deficit and land-atmosphere energy transfer in YZR and its two tributaries are of great concern for local people and the government. Remote sensing of soil water deficit and land surface heat fluxes has significant meaning for crop growth monitoring, crop yield assessment, disaster monitoring and understanding energy and water cycles in local area and even for surrounding regions.

\subsection{Statement of Objectives}

In this work we fill the abovementioned gap by providing spatially distributed, long time series information on land surface parameters for the entire TP.

We used multi-sources data that include EO, model reanalysis and in situ data: SPOT VEGETATION (S10), NOAA/NASA Pathfinder Advanced Very High Resolution Radiometer AVHRR Land (PAL), Moderate Resolution Imaging Spectroradiometer(MODIS), ECMWF 40 Year Re-analysis (ERA-40), Global Land Data Assimilation System (GLDAS) and in-situ meteorological data.

Our contributions are:

(1) Retrieve plateau-scale land surface parameters which are of great importance in land-atmosphere interaction;

(2) Reveal spatial distribution, their seasonal changes, inter-annual variation trends of the surface parameters and especially, their responses to the Asian Summer Monsoon; 
(3) Estimation of soil water deficit (SWD) and land-atmosphere energy transfer in an important agriculture center of the TP.

Specific objectives of the thesis can be listed as the followings.

> To retrieve plateau-scale LST by applying different split window algorithms (SWA).

$>$ To estimate land surface heat fluxes and soil water deficit conditions for the middle reaches of Yarlung-Zangbo River and its two tributaries from satellite images.

$>$ To reveal vegetation dynamics over the entire TP and their responses to temperature and precipitation.

$>\quad$ To identify the spatial patterns and long-term variation trends for LST, NDVI and albedo at Plateau scale.

\subsection{Structure of the Thesis}

Structure of the thesis is as follows.

Chapter 1 covers scientific background, study area, problem statement, research objectives and the general structure of the thesis.

In Chapter 2, we retrieve land surface temperature (LST) over the TP from the NOAA's Advanced Very High Resolution Radiometer (AVHRR) and the Moderate Resolution Imaging Spectroradiometer(MODIS) data using two split window algorithms (SWAs).

In Chapter 3, land surface parameters in $\mathrm{YZR}$ and its two tributaries are derived from AVHRR-16 L1B and MODIS L1B data. Thereafter land surface heat fluxes are retrieved from SEBS model in combining with in-situ meteorological data.

In Chapter 4 we analyze the surface energy balance of the YZR and its two tributaries in spring and autumn and derive the surface SWD conditions using data from AVHRR and MODIS and then compared to AMSR-E data.

In Chapter 5, a time series of 315 SPOT VEGETATION scenes, covering the period between 1998 and 2006, has been processed with the Harmonic Analysis of Time Series (HANTS) algorithm in order to reveal the governing spatiotemporal pattern of variability. Then using a $1 \mathrm{~km}$ resolution land cover map from GLC2000, seven meteorological stations, presenting monthly data on near surface air temperature and precipitation, were selected for correlation analysis between NDVI and climate conditions. 
In Chapter 6, The NOAA/NASA Pathfinder AVHRR Land (PAL) dataset is used to retrieve the land surface temperature (LST), Normalized Difference Vegetation Index (NDVI) and albedo, from 1982 to 2000. Simultaneously, meteorological parameters and land surface heat fluxes are acquired from the European Centre for Medium-Range Weather Forecasts (ECMWF) 40 Years Re-Analysis data (ERA-40) and Global Land Data Assimilation System (GLDAS), respectively. The spatial patterns and long-term variation trends for land surface parameters are quantitatively identified.

In the last section, we summarize the results and conclusions of Chapter 2 to Chapter 6 and provide a discussion of future work. 


\section{Chapter 2}

\section{Estimation of Land Surface Temperature over the Tibetan Plateau Using AVHRR and MODIS Data*}

${ }^{*}$ This chapter is based on

Zhong, L., Y. Ma, Z. Su, and M. S. Salama, 2010, Estimation of Land Surface Temperature over the Tibetan Plateau Using AVHRR and MODIS Data. Advances in Atmospheric Sciences, 27: 1110-1118. 


\begin{abstract}
Estimation of large-scale land surface temperature from satellite images is of great importance for the study of climate change. This is especially true for the most challenging areas, such as the Tibetan Plateau (TP). In this chapter, two split window algorithms (SWAs), one for the NOAA's Advanced Very High Resolution Radiometer (AVHRR), and the other for the Moderate Resolution Imaging Spectroradiometer(MODIS), were applied to retrieve land surface temperature (LST) over the TP simultaneously. AVHRR and MODIS data from 17 January, 14 April, 23 July, and 16 October 2003 were selected as the cases for winter, spring, summer, and autumn, respectively. Firstly, two key parameters (emissivity and water vapour content) were calculated at the pixel scale. Then, the derived LST was compared with in situ measurements from the Coordinated Enhanced Observing Period (CEOP) Asia-Australia Monsoon Project (CAMP) on the TP (CAMP/Tibet) area. These were in good accordance with each other, with an average percentage error (PE) of $10.5 \%$ for AVHRR data and $8.3 \%$ for MODIS data, meaning the adopted SWAs were applicable in the TP area. The derived LST also showed a wide range and a clear seasonal difference. The results from AVHRR were also in agreement with MODIS, with the latter usually displaying a higher level of accuracy.
\end{abstract}

Key words: Land surface temperature, AVHRR, MODIS, the Tibetan Plateau 


\subsection{Introduction}

Land surface temperature (LST) plays an important role in the interaction between land and atmosphere, being one of the key parameters in studies of global climate change. LST is also an important factor controlling most physical, chemical and biological processes of the Earth (Qin and Karnieli, 1999). Traditional measurement methods are able only to obtain LST at point or local scales, and the requirement for LST at the regional and even global scale in environmental studies and resource management makes remote sensing of LST an important research subject (Yang and Yang, 2006). With the availability of Advanced Very High Resolution Radiometer (AVHRR) and Moderate Resolution Imaging Spectroradiometer(MODIS) data, various algorithms have been proposed for the remote sensing of LST. These algorithms are, however, empirical in nature and therefore limited to a specific application and region.

Referred to as the 'Roof of the World' and the 'Third Pole of the Earth' (Qiu, 2008), the TP has significant thermal and dynamical influences on atmospheric circulation and it is also thought to play an important role in the progress of the Asian summer monsoon and global climate change. With the implementation of the Global Energy and Water Cycle Experiment (GEWEX) and the Asia Monsoon Experiment on the TP (GAME/Tibet)(Koike et al., 1999) and the Coordinated Enhanced Observing Period (CEOP) Asia-Australia Monsoon Project on the TP (CAMP/Tibet), land-surface-atmosphere interactions have been observed at the patch scale around measurement sites.

Remote sensing provides an effective method to retrieve larger-scale land surface parameters. Ma et al. $(2003,2006)$ derived land surface parameters and surface flux in the experimental area of GAME/Tibet from the United States National Oceanic and Atmospheric Administration advanced very high resolution radiometer (NOAA AVHRR) and Landsat ETM data. However, the results were limited to the meso-scale area and they were not sufficient to understand LST variations at the plateau scale. Oku and Ishikawa (2004) estimated LST over the TP area with altitudes of over $4000 \mathrm{~m}$ using Geostationary Meteorological Satellite Visible/Infrared Spin-Scan Radiometer (GMS VISSR) images.

On the whole, studies which have estimated LST over the most challenging area of the TP have been scarce. It is not only necessary but also important to find the proper algorithms to derive the LST over the TP. In this chapter, two different Split Window Algorithms (SWAs), one for AVHRR-16 L1B data, the other for MODIS LIB data, will be applied to retrieve LST. The data and methodology adopted in the study are introduced in the second section. The 
results are then presented in the third section, together with validation from ground truth measurements. Some concluding remarks are made in the final section.

\subsection{Data and methodology}

\subsubsection{Datasets}

The NOAA has an ongoing operational program of polar-orbiting meteorological satellites with the AVHRR instrument on board to monitor global meteorological change (Cracknell, 1997). The NOAA-AVHRR has two thermal channels operating in the wavelength ranges 10.5-11.3 and 11.5$12.5 \mu \mathrm{m}$, respectively. Although the spatial resolution of its high-resolution picture transmission (HRPT) format is relatively low $\left(1.1 \times 1.1 \mathrm{~km}^{2}\right.$ under nadir), the NOAA-AVHRR has the advantages of a frequent revisiting time (about two images per day), and easy access. These two features have made it an important source of remote sensing data for the monitoring of the Earth's resources (Qin et al., 2001).

MODIS is an Earth observation system (EOS) instrument. It views the entire surface of the Earth every one to two days, acquiring data in 36 spectral bands. The thermal channels 31 and 32, ranging in wavelengths of 10.7811.28 and 11.77-12.27 $\mu \mathrm{m}$, respectively, have a spatial resolution of $1 \mathrm{~km}$. MODIS is particularly useful because of its global coverage, radiometric resolution, dynamic ranges, and accurate calibration in multiple thermal infrared bands designed for retrievals of SST, LST and atmospheric properties (Mao et al., 2005a).

Because of the challenging climate conditions over the TP, meteorological stations are not only sparse but also uneven. There are few in situ data that can be used to validate derived LST. Taking this in situ data quality into account, the data from four observation sites in CAMP/Tibet area were used to validate the satellite estimation (Table $2-1$ ).

Table 2-1 Ground measurement sites

\begin{tabular}{cccccc}
\hline Sites & $\begin{array}{c}\text { Latitude } \\
\left({ }^{\circ} \mathrm{N}\right)\end{array}$ & $\begin{array}{c}\text { Longitude } \\
\left({ }^{\circ} \mathrm{E}\right)\end{array}$ & $\begin{array}{c}\text { Altitude } \\
(\mathrm{m})\end{array}$ & Land cover & $\begin{array}{c}\text { Vegetation } \\
\text { Height }(\mathrm{cm})\end{array}$ \\
\hline ANNI & 31.25442 & 92.17244 & 4480.0 & $\begin{array}{c}\text { Grass } \\
\text { Sparse } \\
\text { grass }\end{array}$ & $<5$ \\
BJ & 31.36866 & 91.89871 & 4509.2 & $\begin{array}{c}\text { Sparse } \\
\text { grass }\end{array}$ & $<5$ \\
D105 & 33.06429 & 91.94256 & 5038.6 & Grass & $15-30$ \\
NPAM & 31.92623 & 91.71468 & 4619.5 & &
\end{tabular}




\subsubsection{Methods}

For AVHRR L1B data, several preprocessing steps are necessary, such as calibration, infrared limb darkening correction, geometric correction, image mosaic and subset. For MODIS L1B data, Bowtie processing, calibration, geometric correction, image mosaic and subset are required.

The retrieval of LST from AVHRR and MODIS data was achieved mainly through the application of SWAs. A SWA was first introduced to estimate ocean surface temperature (McMillin, 1975), with Price (1984) being one of the main pioneers thereafter in applying the split window technique for LST retrieval. Since then, after twenty years of development, there are now about 20 proposed SWAs (Table 2-2). Of these, Ma's algorithm (Ma and Tsukaoto, 2002 ) is the only algorithm put forward for the experimental area in the northern TP, and this was adopted in the present study to derive LST from AVHRR. Mao et al. (2005a) proposed a practical SWA to derive LST from MODIS, a method approved as a simple and highly accurate approach. However, whether this method is suitable for the TP is as yet unknown. Therefore, Mao's method was applied in order to try to derive LST from MODIS data over the TP. 
Table 2-2 Published split window algorithms (Algorithms 1-18, 20 are for AVHRR images and algorithm 19 is for MODIS images. $T_{4}$ and $T_{5}$ are brightness temperature of channel 4 and channel 5 for AVHRR; $T_{31}$ and $T_{32}$ are brightness temperature of channel 31 and channel 32 for MODIS; $\varepsilon$ and $\Delta \varepsilon$ are the average emissivity and emissivity difference; $\theta$ is viewing zenith angle from nadir; $\tau$ is atmospheric transmittance; $W$ is water vapour content; $\Delta I \downarrow$ is effective downwelling sky radiance difference; A, B, C, D and L are coefficients in equations. )

\begin{tabular}{|c|c|c|}
\hline NO. & Author & Algorithms \\
\hline 1. & Price (1984) & $T_{\text {sfc }}(x, y)=\left\{T_{4}(x, y)+3.33\left[T_{4}(x, y)-T_{5}(x, y)\right]\right\} \cdot\left(5.5-\varepsilon_{4}\right) / 4.5-0.75 T_{5}(x, y) \Delta \varepsilon$ \\
\hline 2. & Becker and $\mathrm{Li}(1990)$ & $\begin{array}{l}T_{\text {sfc }}(x, y)=1.274+\left[1+0.15616(1-\varepsilon) / \varepsilon-0.482 \Delta \varepsilon / \varepsilon^{2}\right] \cdot\left[T_{4}(x, y)+T_{5}(x, y)\right] / 2 \\
\left.\left[6.26+3.98(1-\varepsilon) / \varepsilon+38.33 \Delta \varepsilon / \varepsilon^{2}\right] \cdot\left[T_{4}(x, y)-T_{5}(x, y)\right]\right] / 2\end{array}$ \\
\hline 3. & Vidal (1991) & $T_{\text {sft }}(x, y)=T_{4}(x, y)+2.78\left[T_{4}(x, y)-T_{5}(x, y)\right]+50\left(\varepsilon_{4}-\varepsilon_{5}\right) / \varepsilon-300(\Delta \varepsilon / \varepsilon)$ \\
\hline 4. & Prata and Platt (1991) & $T_{\text {sfc }}(x, y)=\left\{T_{4}(x, y)+2.46\left[T_{4}(x, y)-T_{5}(x, y)\right]+40(1-\varepsilon)-273.16\right\} / \varepsilon$ \\
\hline 5. & Sobrino et al. (1991) & $\begin{array}{l}T_{\mathrm{scc}}(x, y)=T_{4}+A\left(T_{4}(x, y)-T_{5}(x, y)\right)+B \\
A=\left(C_{5} D_{4}+D_{4} D_{5} w\right) /\left(D_{5} C_{4}-D_{4} C_{5}\right) \\
B=\left[\left(1-1 / \varepsilon_{5}\right)\left(1-2 k_{5} w\right) C_{5} D_{5} L_{5}-\left(1-1 / \varepsilon_{4}\right)\left(1-2 k_{4} w\right) C_{4} D_{5} L_{4}\right] / \\
D_{5} C_{4}-D_{4} C_{5} \\
C_{i}=\varepsilon_{i} \tau_{i} \cos (\theta) \\
D_{i}=k_{i}\left[1+2 \tau_{i}\left(1-\varepsilon_{i}\right) \cos (\theta)\right] \\
L_{i}=T_{i} / n_{i}\end{array}$ \\
\hline 6. & Kerr et al. (1992) & $\begin{array}{l}T_{\text {sfc }}(x, y)=P_{\mathrm{v}}(x, y)\left\{T_{5}(x, y)+2.6\left[T_{4}(x, y)-T_{5}(x, y)\right]-2.4\right\}+\left[1-P_{\mathrm{v}}(x, y)\right] \\
\cdot\left\{T_{4}(x, y)+2.1\left[T_{4}(x, y)-T_{5}(x, y)\right]\right\}+3.1\end{array}$ \\
\hline 7. & $\begin{array}{c}\text { Ottlé and Vidal-Madjar } \\
\text { (1992) }\end{array}$ & $T_{\text {sfc }}(x, y)=a_{0}+a_{1} T_{4}(x, y)+a_{2} T_{5}(x, y)$ \\
\hline 8. & Ulivieri et al. (1992) & $T_{\text {sfc }}(x, y)=T_{4}(x, y)+1.8\left[T_{4}(x, y)-T_{5}(x, y)\right]+48(1-\varepsilon)-75 \Delta \varepsilon$ \\
\hline 9. & Prata (1993) & $\begin{array}{l}T_{\text {stc }}(x, y)=(3.42 / \delta) T_{4}(x, y)-(2.42 / \delta) T_{5}(x, y)+[(1-\delta) / \delta] \\
\cdot\left(\left\{B_{4}\left[T_{4}(x, y)\right]-\Delta I \downarrow\right\} \cdot\left\{\partial B_{4} / \partial T_{\text {sc }}\right\} T_{4}^{-1}-T_{4}(x, y)\right) \\
\delta=\varepsilon_{4}+2.42 \tau_{5} \Delta \varepsilon\end{array}$ \\
\hline 10. & Sobrino et al. (1994) & $\begin{array}{l}B_{4}\left[T_{4}(x, y)\right]=\left(\alpha_{1}+\alpha_{2} R\right) \cdot B_{4}\left[T_{4}(x, y)\right]+\left(\alpha_{3}+\alpha_{4} R\right) \cdot B_{5}\left[T_{4}(x, y)\right]+\left(\alpha_{5}+\alpha_{6} R\right) \\
R=\tau_{5} / \tau_{4} ; \alpha_{i}=\alpha_{i 0}+\alpha_{i 1}\left(1-\varepsilon_{4}\right)+\alpha_{i 2} \Delta \varepsilon\end{array}$ \\
\hline 11. & $\begin{array}{l}\text { França and Cracknell } \\
\text { (1994) }\end{array}$ & $\begin{array}{l}T_{\text {sfc }}(x, y)=T_{4}+A\left(T_{4}(x, y)-T_{5}(x, y)\right)+B \\
A=\left(C_{5} D_{4}+D_{4} D_{5} w\right) /\left(D_{5} C_{4}-D_{4} C_{5}\right) \\
B=\left[\left(1-1 / \varepsilon_{5}\right)\left(1-2 W_{5}\right) C_{5} D_{5} L_{5}-\left(1-1 / \varepsilon_{4}\right)\left(1-2 W_{4}\right) C_{4} D_{5} L_{4}\right] / D_{5} C_{4}-D_{4} C_{5} \\
C_{i}=\varepsilon_{i} \tau_{i} \cos (\theta) ; D_{i}=W_{i}\left[1+2 \tau_{i}\left(1-\varepsilon_{i}\right) \cos (\theta)\right] ; L_{i}=T_{i} / n_{i}\end{array}$ \\
\hline 12. & Coll et al. (1994) & $\begin{array}{l}T_{\text {sfc }}(x, y)=T_{4}(x, y)+\left\{1.0+0.58\left[T_{4}(x, y)-T_{5}(x, y)\right]\right\}\left[T_{4}(x, y)-T_{5}(x, y)\right] \\
+0.51+40(1-\varepsilon)+\beta \Delta \varepsilon \\
\beta=(0.1 w+1.118) T_{4}(x, y)-68 w-163\end{array}$ \\
\hline
\end{tabular}




\begin{tabular}{|c|c|c|}
\hline 13. & Becker and Li (1995) & $\begin{array}{l}T_{\text {sfc }}(x, y)=(-7.491-0.407 W)+\left[1.0290+(0.2106-0.0307 W \cos \theta)\left(1-\varepsilon_{4}\right)\right. \\
-(0.03696-0.737 W) \Delta \varepsilon]\left[T_{4}(x, y)+T_{5}(x, y)\right] / 2+[4.25+0.56 W \\
\left.+(3.41+1.59 w)\left(1-\varepsilon_{4}\right)-(23.85-3.89 W) \Delta \varepsilon\right]\left[T_{4}(x, y)+T_{5}(x, y)\right] / 2\end{array}$ \\
\hline 14. & Ulivieri et al. (1996) & $\begin{array}{l}T_{\mathrm{sfc}}(x, y)=T_{4}(x, y)+2.78\left[T_{4}(x, y)-T_{5}(x, y)\right]+50(1-\varepsilon) / \varepsilon \\
-300(\Delta \varepsilon / \varepsilon)\end{array}$ \\
\hline 15. & François and Ottlé(1997) & $T_{\text {sftc }}(x, y)=T_{4}(x, y)+a\left[T_{4}(x, y)-T_{5}(x, y)\right]+b\left[T_{4}(x, y)-T_{5}(x, y)\right]^{2}+c$ \\
\hline 16. & François and Ottlé(1996) & $T_{\mathrm{sfc}}(x, y)=a^{\prime}(W) T_{4}(x, y)+b^{\prime}(W) T_{5}(x, y)+c^{\prime}(W)$ \\
\hline 17. & Coll and Caselles(1997) & $\begin{array}{l}T_{\text {sfc }}(x, y)=T_{4}(x, y)+\left\{1.34+0.39\left[T_{4}(x, y)-T_{5}(x, y)\right]\right\}\left\{T_{4}(x, y)-T_{5}(x, y)\right] \\
+0.56+a(1-\varepsilon)-\beta \Delta \varepsilon\end{array}$ \\
\hline 18. & $\begin{array}{c}\text { Sobrino and } \\
\text { Raissouni(2000) }\end{array}$ & $\begin{array}{l}T_{\text {sfc }}(x, y)=T_{4}(x, y)+1.40\left[T_{4}(x, y)-T_{5}(x, y)\right]+0.32\left[T_{4}(x, y)-T_{5}(x, y)\right]^{2} \\
+0.83+(57-5 W)(1-\varepsilon)-(161-30 W) \Delta \varepsilon\end{array}$ \\
\hline 19. & Mao et al. (2005a) & $\begin{aligned} T_{\mathrm{s}}=A_{0} & +A_{1} T_{31}-A_{2} T_{32} \\
& A_{0}=E_{1} a_{31}-E_{2} a_{32} A_{1}=1+A+E_{1} b_{31} A_{2}=A+E_{2} b_{32} \\
& A=D_{31} / E_{0} E_{1}=D_{32}\left(1-C_{31}-D_{31}\right) / E_{0} \\
& E_{2}=D_{31}\left(1-C_{32}-D_{32}\right) / E_{0} E_{0}=D_{32} C_{31}-D_{31} C_{32} \\
& C_{i}=\varepsilon_{i} \tau_{i}(\theta) D_{i}=\left[1-\tau_{i}(\theta)\right]\left[1+\left(1-\varepsilon_{i}\right) \tau_{i}(\theta)\right]\end{aligned}$ \\
\hline 20. & Ma et al. (2002) & $\begin{array}{l}T_{\text {stc }}(x, y)=T_{4}(x, y)+1.56\left[T_{4}(x, y)-T_{5}(x, y)\right]+0.28\left[T_{4}(x, y)-T_{5}(x, y)\right]^{2} \\
+(48-5 W)(1-\varepsilon)\end{array}$ \\
\hline
\end{tabular}

Estimations of two key parameters (emissivity, $\varepsilon$, and water vapour content, $W$ ) were needed prior to deriving LST. Because the surface at the pixel scale in satellite images is usually heterogeneous, the emissivity for the pixel scale must be estimated using a theoretical approach, which models a given surface by considering it as being made up of a mixture of bare soil, vegetation and water body (Sobrino et al., 1990; Mao et al., 2005a, b):

$$
\varepsilon_{i}=P_{\mathrm{w}} R_{\mathrm{w}} \varepsilon_{\mathrm{iw}}+P_{\mathrm{v}} R_{\mathrm{v}} \varepsilon_{\mathrm{iv}}+\left(1-P_{\mathrm{v}}-P_{\mathrm{w}}\right) R_{\mathrm{s}} \varepsilon_{\text {is }}
$$

where $\varepsilon_{i}$ is the surface emissivity of band $i$ ( $i=4,5$ for AVHRR, $i=31,32$ for MODIS); $\varepsilon_{\mathrm{iw}}, \varepsilon_{\mathrm{iv}}$ and $\varepsilon_{\mathrm{is}}$ are the surface emissivity for water body, vegetation and bare soil of band $i$, respectively; $P_{\mathrm{v}}$ is the vegetation coverage for a pixel, calculated by the method of Carlson and Ripley (1997), $P_{\mathrm{v}}=\left[\left(\mathrm{NDVI}_{-}-\mathrm{NDVI}_{\mathrm{s}}\right) /\left(\mathrm{NDVI}_{\mathrm{v}}-\mathrm{NDVI}_{\mathrm{s}}\right)\right]^{2}$, where $\mathrm{NDVI}_{\mathrm{v}}$ and $\mathrm{NDVI}_{\mathrm{s}}$ represent the NDVI of vegetation and soil, respectively; $P_{\mathrm{w}}$ is the water coverage for a pixel, derived by the method of Mao (2005a), 
$P_{\mathrm{w}}=\mathrm{QDN} / \mathrm{DNI}$, where QDN represents reflectance of a mixed pixel and DNI represents the least reflectance of a land pixel obtained by samples from an image; and $R_{\mathrm{w}}, R_{\mathrm{v}}$ and $R_{\mathrm{s}}$ are the radiation ratios of water body, vegetation and bare soil, respectively.

The water vapour content for AVHRR was derived by applying the splitwindow covariance-variance ratio (SWCVR) technique (Sobrino et al., 1999):

$$
\begin{gathered}
w=0.26-14.253 \cos \theta \ln R_{54}-11.649\left(\cos \theta \ln R_{54}\right)^{2} \\
R_{54}=\frac{\sum_{k=1}^{N}\left(t_{4 k}-t_{40}\right)\left(t_{5 k}-t_{50}\right)}{\sum_{k=1}^{N}\left(t_{4 k}-t_{40}\right)^{2}}
\end{gathered}
$$

where $W$ represents water vapour content $\left(\mathrm{g} \mathrm{cm}^{-2}\right) ; \theta$ is the observation angel; $N$ represents adjacent pixels; $t_{4 k}$ and $t_{5 k}$ are the brightness temperature for $k^{\text {th }}$ pixel, directly measured by the satellite in AVHRR bands 4 and 5; and $t_{40}$ and $t_{50}$ are the mean brightness temperatures of $N$ pixels.

The water vapour content can be directly derived from the MODIS image (Kaufman and Cai, 1992):

$$
\begin{gathered}
w=\left[\left(\alpha-\ln \tau_{\mathrm{w}}\right) / \beta\right]^{2} \\
\tau_{\mathrm{w}}=\frac{\rho_{19}}{\rho_{2}}
\end{gathered}
$$

Because the transmittance of MODIS band $31 / 32$ and water vapour content of atmosphere are approximately satisfied as a linear relationship (Mao et al., 2005a), the transmittance of MODIS band $31 / 32$ at the pixel scale can be estimated from the water vapour content of atmosphere.

\subsection{Results and validation}

The data of 17 January, 14 April, 23 July, and 16 October 2003 taken from AVHRR-16 L1B and MODIS L1B were selected as the cases for winter, spring, summer, and autumn, respectively. The selection was based on the combination of field measurements and satellite images. Firstly, on the basis 
of the available in situ measurements, some rainy days were excluded. For these four days, there was no precipitation at observation sites during the satellite passing time. Next, the satellite images were examined one by one, with those images with a lot of cloud cover excluded. It must be pointed out that it is impossible to find a satellite image without any cloud cover, especially for our large study area.

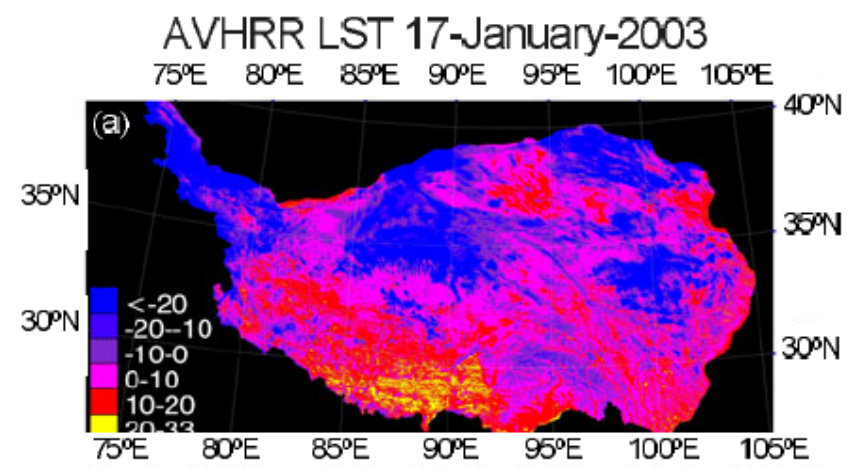

AVHRR LST 23-July-2003

$75^{\circ} \mathrm{E} \quad 80^{\circ} \mathrm{E} \quad 85^{\circ} \mathrm{E} \quad 90^{\circ} \mathrm{E} \quad 95^{\circ} \mathrm{E} \quad 100^{\circ} \mathrm{E} \quad 105^{\circ} \mathrm{E}$
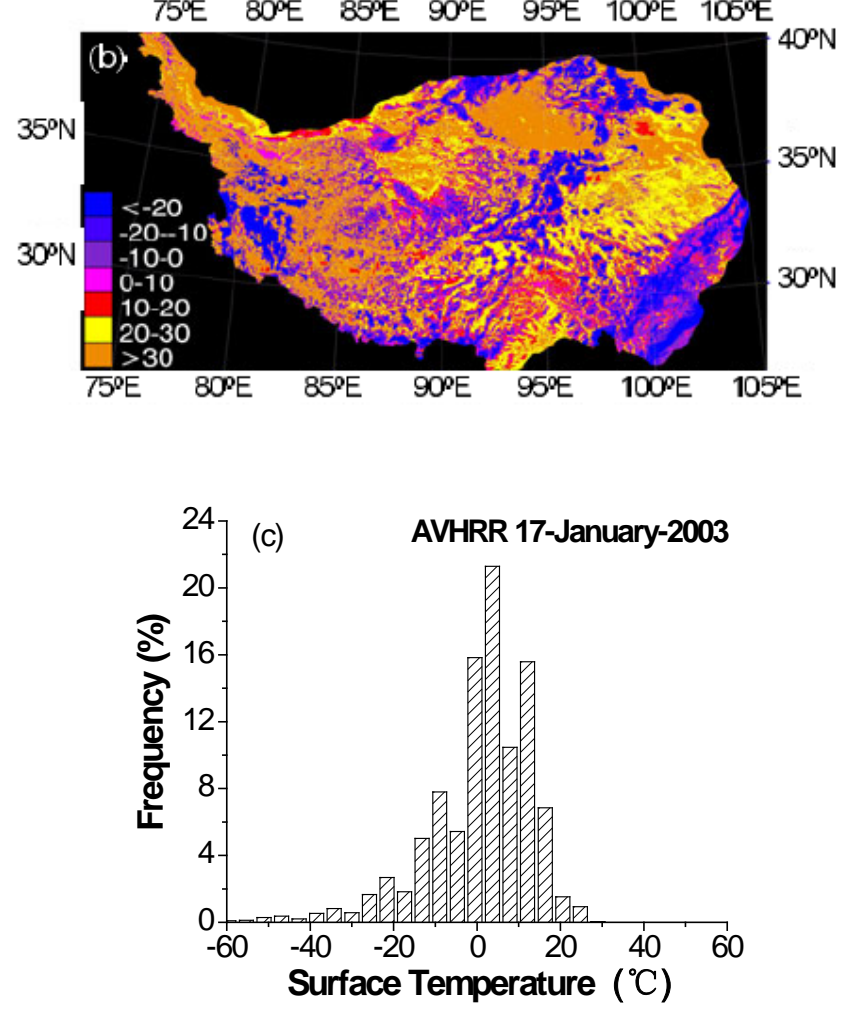


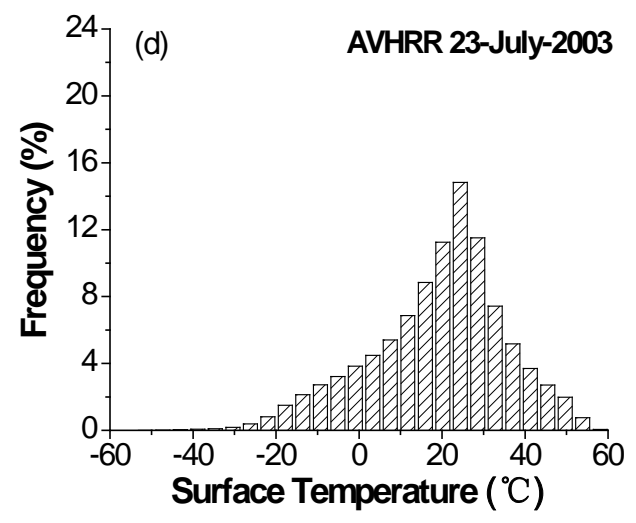

Fig. 2-1 The LST derived from AVHRR images. (a), (b) are distribution patterns of land surface temperature. (c), (d) are the corresponding frequency distributions.

MODIS LST 17-January-2003

$75^{\circ} \mathrm{E} \quad 80^{\circ} \mathrm{E} \quad 85^{\circ} \mathrm{E} \quad 90^{\circ} \mathrm{E} \quad 95^{\circ} \mathrm{E} \quad 100^{\circ} \mathrm{E} \quad 105^{\circ} \mathrm{E}$

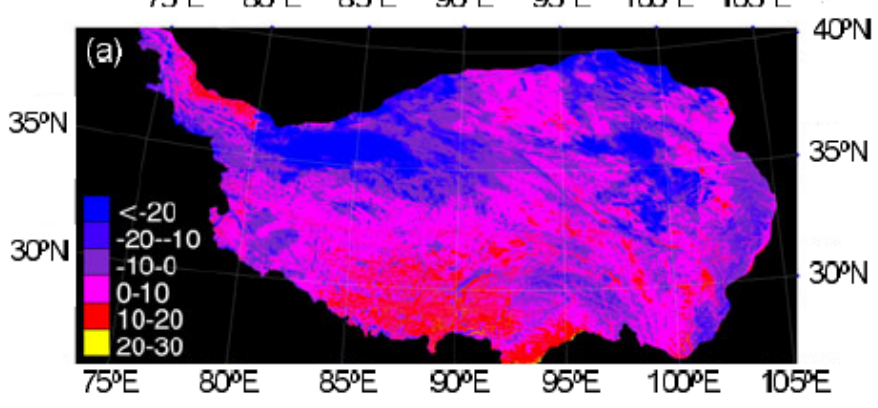

MODIS LST 23-July-2003

$5^{\circ} \mathrm{E} \quad 8^{\circ} \mathrm{E} \quad 8^{\circ} \mathrm{E} \quad 9^{\circ} \mathrm{E} \quad 9^{\circ} \mathrm{E} \quad 100^{\circ} \mathrm{E} \quad 105^{\circ} \mathrm{E}$

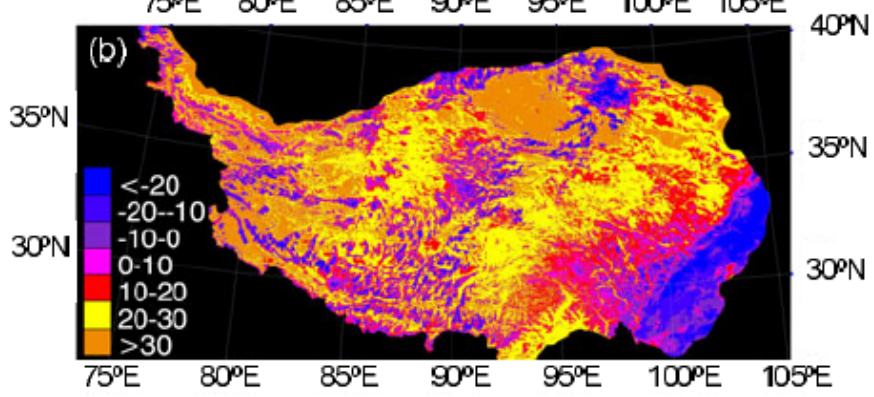



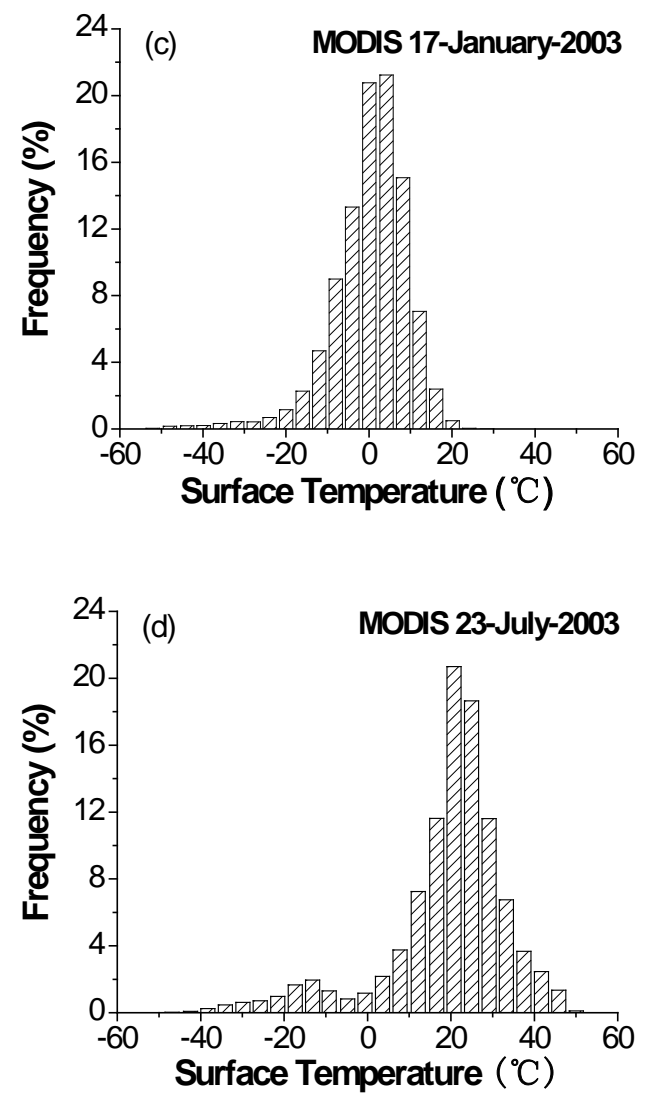

Fig. 2-2 The LST derived from MODIS images. (a), (b) are distribution patterns of land surface temperature. (c), (d) are the corresponding frequency distributions.

Figure 2-1 and Figure 2-2 show the LST derived from AVHRR and MODIS images. Only the winter case (17 January) and summer case (23 July) are displayed. Because of the variety in the underlying surface, complex topography and large coverage from west to east, and from north to south, the distribution patterns of derived LST over the TP are a little complicated. The derived LST shows a wide range, and this is in good accordance with land surface status. One high value center can be easily found at Qaidam Basin, where a desert is located. The center is especially obvious in the summer images (Figs. 2-1b and 2-2b), and a clear seasonal contrast can be seen by comparing Figs. 2-1 and 2-2.

From winter to summer, LST increased greatly, with the yellow parts expanding in the image (Figs. 2-1a, 2-1b, 2-2a, and 2-2b). This phenomenon can also be seen in the frequency distribution histograms (Figs. 2-1c, 2-1d, 
$2-2 c$, and 2-2d). The histogram usually moves toward the right, which indicates an increasing of LST. In general, the derived LST from AVHRR was in accordance with that derived from MODIS. However, because the local crossing time of MODIS is usually at midday, with AVHRR crossing one to two hours later, much more cloud was present in the AVHRR images than in the MODIS ones. Therefore the dark blue parts in the AVHRR images were much larger than those in the MODIS images (Figs. 2-1b and 2-2b).

Four observation sites in CAMP/Tibet area, ANNI, BJ, D105 and NPAM, were used to make the validation. The derived LST from satellite data were compared with field measurements at ANNI, BJ, D105 and NPAM. The percentage error (PE) was applied to measure quantitatively the difference between the derived results $\left(V_{\text {derived }}\right)$ and the in situ values $\left(V_{\text {measured }}\right)$ :

$$
\mathrm{PE}=\frac{\left|V_{\text {derived }}-V_{\text {measured }}\right|}{V_{\text {measured }}}
$$

The differences are shown in Figs. 2-3 and 2-4, together with a 1:1 line. As can be seen from Tables 2-3 and 2-4, and Figs. 2-3 and 2-4, the derived LST from both satellite images was close to in situ measurements. The minimum LST PE derived from AVHRR was $4.1 \%$, the largest $22.4 \%$, and the mean $10.5 \%$. The minimum LST PE derived from MODIS was $0.3 \%$, the largest $18.4 \%$, and the mean $8.3 \%$.

The retrieval results from MODIS were superior to those from AVHRR. Many reasons might account for this besides the image quality itself, such as the different SWAs, or the different algorithms for water vapour content. Although the derived results were generally in agreement with field measurements, the discrepancies were extremely large for the AVHRR results on 17 January at NPAM and ANNI, as were the MODIS results on 17 January at NPAM and on 23 July at D105. These were due to 1 ) the pixel scale itself is usually not homogeneous and the component temperature was not taken into account; 2) the impact of topography on LST calculation having been omitted; and 3) cloud having a tremendous influence on the estimation. 
Table 2-3 The comparison between the estimated land surface temperature from NOAA/ AVHRR images and the ground measurements. $\left(V_{m}=\right.$ measured values; $V_{d}=$ derived results; the symbol'----'represents the cloud contaminated pixels.)

\begin{tabular}{|c|c|c|c|c|c|c|c|c|c|c|c|c|}
\hline \multirow{2}{*}{ Sites } & \multicolumn{3}{|c|}{ 17-J anuary-2003 } & \multicolumn{3}{|c|}{ 14-April-2003 } & \multicolumn{3}{|c|}{ 23-July-2003 } & \multicolumn{3}{|c|}{ 16-October-2003 } \\
\hline & $\mathrm{V}_{\mathrm{m}}$ & $V_{d}$ & $\mathrm{PE}$ & $V_{m}$ & $V_{d}$ & $\mathrm{PE}$ & $\mathrm{V}_{\mathrm{m}}$ & $V_{d}$ & $\mathrm{PE}$ & $V_{m}$ & $V_{d}$ & $\mathrm{PE}$ \\
\hline D105 & 7.3 & $\cdots$ & $\cdots$ & 28.9 & 26.6 & $8 \%$ & 35.6 & 32.1 & $9.8 \%$ & 13.0 & 13.6 & $4.6 \%$ \\
\hline NPAM & 10.8 & 8.7 & $19.4 \%$ & 11.5 & --- & --- & 28.7 & 25.8 & $10.1 \%$ & 21.1 & 19.6 & $7.1 \%$ \\
\hline ANNI & 12.5 & 9.7 & $22.4 \%$ & 8.6 & $\cdots$ & $-\cdots$ & 28.1 & 26.4 & $6 \%$ & 29.5 & 28.3 & $4.1 \%$ \\
\hline BJ & -9.2 & $--\cdot$ & $--\cdot$ & 18.1 & 21.5 & $18.8 \%$ & 30.7 & 28.5 & $7.2 \%$ & 30.0 & 27.5 & $8.3 \%$ \\
\hline
\end{tabular}

Table 2-4 The comparison between the estimated land surface temperature from EOS/MODIS images and the ground measurements $\left(V_{m}=\right.$ measured values; $V_{d}=$ derived results; the symbol'----'represents the cloud contaminated pixels.)

\begin{tabular}{|c|c|c|c|c|c|c|c|c|c|c|c|c|}
\hline \multirow{2}{*}{ Sites } & \multicolumn{3}{|c|}{ 17-J anuary-2003 } & \multicolumn{3}{|c|}{ 14-April-2003 } & \multicolumn{3}{|c|}{ 23-July-2003 } & \multicolumn{3}{|c|}{ 16-October-2003 } \\
\hline & $\mathrm{V}_{\mathrm{m}}$ & $V_{d}$ & $\mathrm{PE}$ & $\mathrm{V}_{\mathrm{m}}$ & $V_{d}$ & $\mathrm{PE}$ & $\mathrm{V}_{\mathrm{m}}$ & $V_{d}$ & PE & $\mathrm{V}_{\mathrm{m}}$ & $V_{d}$ & $\mathrm{PE}$ \\
\hline D105 & 6.8 & --- & $-\ldots$ & 25.2 & 25 & $0.8 \%$ & 16.7 & 14.1 & $15.6 \%$ & 10.5 & --- & --- \\
\hline NPAM & 12.5 & 10.2 & $18.4 \%$ & 31.6 & 33.8 & $7.0 \%$ & 32.4 & --- & --- & 27.8 & 25.1 & $9.7 \%$ \\
\hline ANNI & 5.2 & 5.6 & $7.7 \%$ & 27.7 & 24.9 & $10.1 \%$ & 26.1 & 26.0 & $0.3 \%$ & 20.6 & 19.4 & $5.8 \%$ \\
\hline BJ & 5.5 & $-\ldots$ & $-\ldots$ & 26.3 & 27.9 & $6 \%$ & 22.6 & 24.2 & $7 \%$ & 20.4 & 22.6 & $10.7 \%$ \\
\hline
\end{tabular}



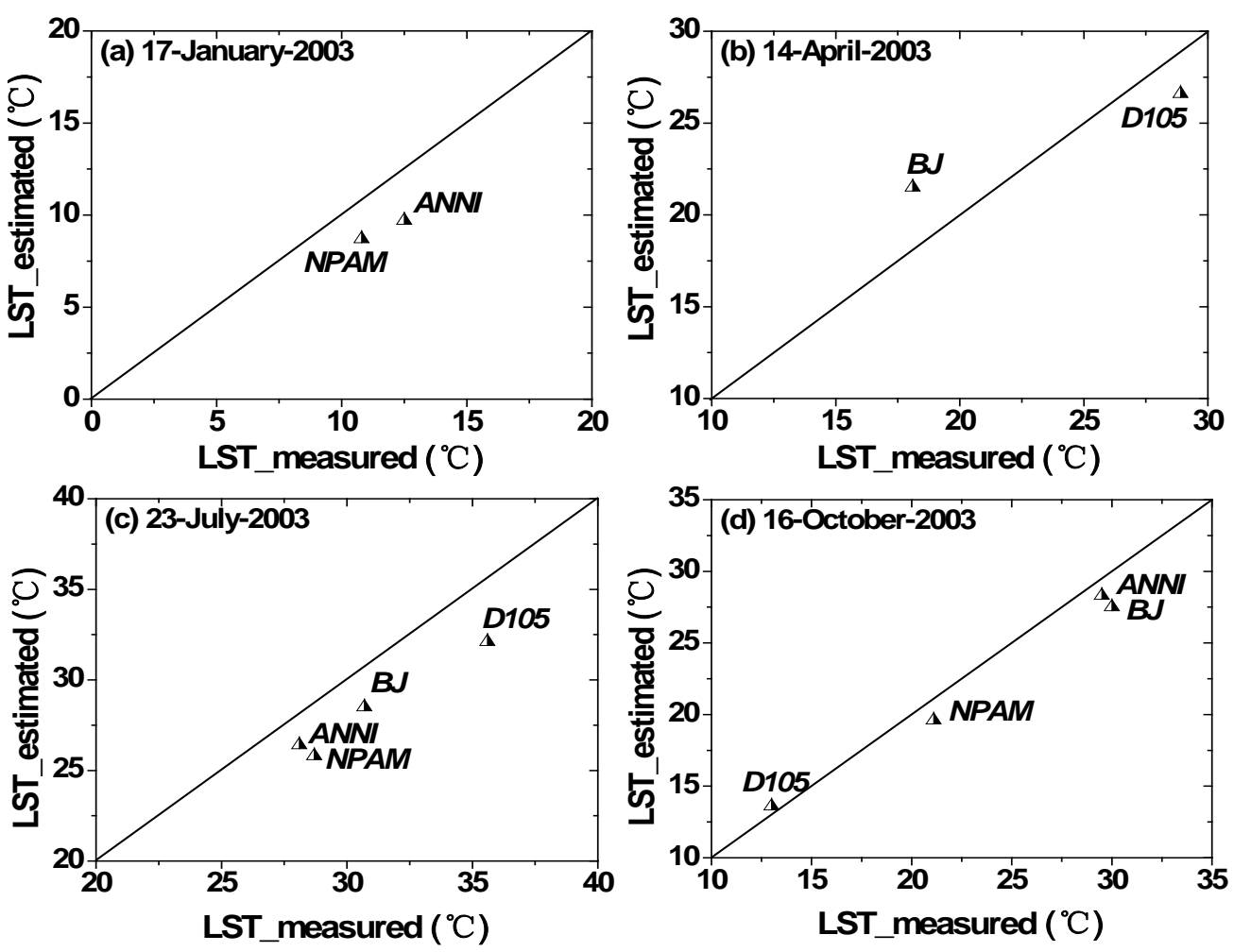

Fig. 2-3 Validation of derived AVHRR land surface temperatureagainst field measurements. (a), (b), (c) and (d) represent winter, spring, summer and winter cases respectively. 

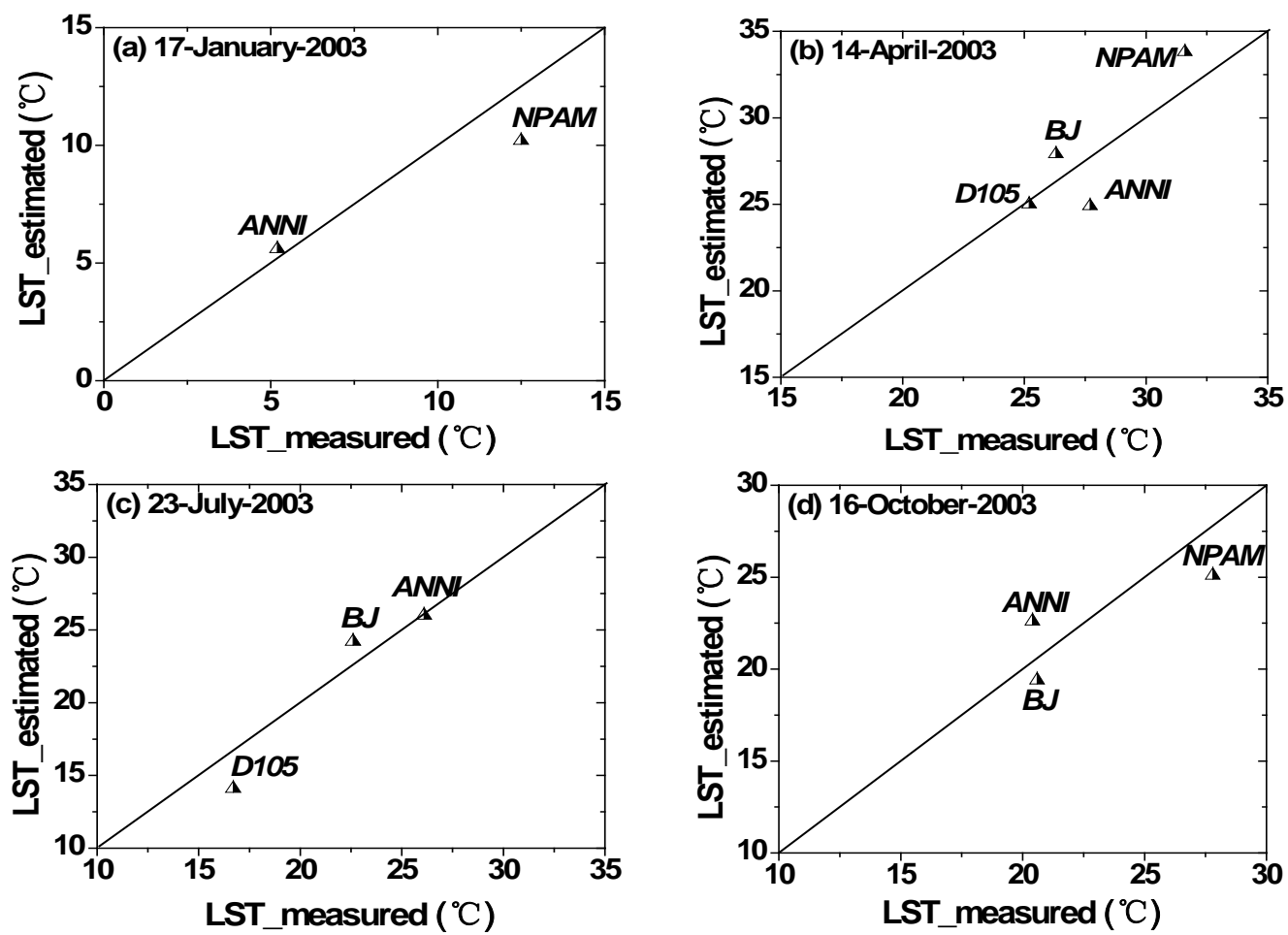

Fig. 2-4 Validation of derived MODIS land surface temperature against field measurements. (a), (b), (c) and (d) represent winter, spring, summer and winter cases respectively.

\subsection{Concluding remarks}

In this chapter, two different SWAs, one for AVHRR and the other for MODIS, were applied to estimate the LST from AVHRR and MODIS data over the TP. Two essential parameters, surface emissivity and water vapour content, were retrieved at the pixel scale. The derived LST were validated with field measurements and showed a good approximation. The following main conclusions can be drawn:

(1) The derived LST in different seasons from AVHRR and MODIS over the study area were in good accordance with the land surface status. LST showed a wide range because of the diversity in land surface type, such as forest, grassland, meadow, marshland, desert, river, and lake. One high value center, located at Qaidam Basin, was clearly identified in the derived LST images.

(2) The derived LST showed a clear seasonal difference over the TP. The LST was usually much higher in summer than in winter, except for those areas with cloud cover. 
(3) In general, the derived results from AVHRR images were in agreement with those from MODIS images because the imaging time was on the same day. However, due to two hours difference between the imaging times, there was much more cloud cover in the AVHRR images.

(4) The derived LST was also in good accordance with in situ measurements, with an average PE of $10.5 \%$ for AVHRR data and $8.3 \%$ for MODIS data. The results from MODIS were usually superior to those from AVHRR.

(5) The two SWAs were appropriate for retrieving LST over the TP, not only because of their high level of accuracy, but also for their simplicity and practicability.

What must be pointed here is that the retrieval accuracy could have been improved if the component temperature and topography were taken into account. Furthermore, more field measurement sites are still needed to validate the large-scale estimation results. Lastly, cloud has a tremendous impact on optical remote sensing. Therefore, the technique of harmonic analysis of time series would be a good choice to remove the influence of cloud cover. 


\section{Chapter 3}

\section{Remote Sensing of Land Surface Heat Fluxes in the Middle Reaches of Yarlung-Zangbo River and Its Two Tributaries from AVHRR and MODIS Data*}

\footnotetext{
${ }^{*}$ This chapter is based on

Zhong, L., Y. Ma, W. Ma, Y. Fu, Z. Su, M. S. Salama, D. Chu, and C. Bianba, 2012, Remote sensing of land surface parameters in the middle reaches of Yarlung-Zangbo River and its two tributaries from AVHRR and MODIS data. Journal of the Meteorological Society of Japan, 90C: 75-86.

Zhong, L., Y. Ma, W. Ma, D. Chu, and C. Bianba, 2011, Land surface heat fluxes in the middle reaches of Yarlung-Zangbo river and its two tributaries derived from AVHRR and MODIS data. Journal of Glaciology and Geocryology, 33: 309-317. (In Chinese with English abstract)
} 


\section{ABSTRACT}

The middle reaches of Yarlung-Zangbo River (YZR) and its two tributaries (including lower reaches of Lhasa River and Nianchu River) is a region in central Tibet Autonomous Region where the agricultural economy is most concentrative and developed. Remote sensing of land surface parameters (albedo, land surface temperature, NDVI) and land surface heat fluxes has significant meaning for crop growth monitoring, crop yield assessment, disaster monitoring and understanding energy and water cycles in local area and even for surrounding regions. In this chapter, AVHRR-16 L1B data and MODIS LIB data, which have the same spatial resolution, will be applied to retrieve land surface parameters and land surface heat fluxes, respectively. The satellite images taken on 14 April and 16 October, 2003 are selected as representative cases for April and Autumn. Based on the derived land surface parameters from satellite images and meteorological data from 9 meteorological stations in the study area, the land surface heat fluxes are estimated by applying Surface Energy Balance System (SEBS). Results show that the energy balance components have clear spatial distribution and temporal variations. By comparing the estimation results from these two different satellites, it is found that the heat fluxes have similar spatial distribution trends in general. However, because of the different satellite passing time, the heat flux values from MODIS are larger than those from AVHRR.

Keywords: Land surface heat fluxes; AVHRR; MODIS; SEBS; YarlungZangbo River and its two tributaries 


\subsection{Introduction}

Located in the western part of China, with an average elevation about 4000 $\mathrm{m}$, the Tibetan Plateau (TP hereinafter) covers about one quarter of Chinese territory. Its dynamic and thermal effects, together with land-atmosphere energy and water exchanges have great impacts on climate changes in China, Asia and even the whole globe ( Ma et al., 2006). The TP takes its dynamic and thermal effects mainly by the interaction between the underlying surface and the atmosphere through turbulent exchange of mass and energy (Zhong et al., 2006).The point-level land-atmosphere energy exchange characteristics can be acquired by the observation at traditional meteorological stations. The developments of remote sensing technology provide a possibility to upscale the point results to local or region scale. Remote sensing is becoming a powerful tool for obtaining a wide range of real-time surface parameters and surface heat fluxes information. So far, scientists have carried out many effective works in the TP which has a very tough environment. Some useful results about the surface parameters and land-atmosphere energy transfer in the TP have been achieved (Zhong and Wu, 1985; Ma et al., 2002; Ma et al., 2002; Xu et al., 2002; Yang et al., 2003; Gao et al., 2004; Yang et al., 2004; Ma et al., 2006; Ma et al., 2008; Ma et al., 2010).For the remote sensing of land surface parameters, Zhong and $\mathrm{Wu}$ (1985) firstly discussed the principles and methods to derive surface reflectance in the TP from AVHRR data. Xu et al. (2002) proposed a dynamic surface albedo retrieval method and derived the land surface albedo in the TP by applying international advanced bidirectional reflectance model. Gao et al. (2004) improved and developed a three-dimensional look-up table algorithm to retrieve surface temperature, soil moisture and vegetation water content from passive microwave remote sensing. The study of land-atmosphere energy transfer characteristics, Yang et al. (2003, 2004) improved the surface fluxes parameterization schemes and established a single-source model to simplify the surface water and heat transfer processes in the TP with sparse vegetation. Based on different satellite data, combined with surface observation data, Ma et al (2002a, 2002b, 2003, 2006, 2008, 2010) proposed two surface fluxes parameterization schemes for the heterogeneous underlying surfaces in the TP, thus providing a strong basic concept and parameters for the numeric simulation studies and remote sensing of surface energy and water cycles in these areas. However, most existing studies mainly focus on the meso-scale experimental area in the northern TP. Therefore, they are not enough to understand the energy and water cycle characteristics of the Yarlung-Zangbo River (YZR) and its two tributaries (including lower reaches of Lhasa River and Nianchu River). Remote sensing of land surface parameters, such as albedo, land surface temperature, vegetation index, and surface heat fluxes, has significant meaning for the study of energy and water cycles in YZR and its two tributaries and even for surrounding regions. Surface parameters are key factors for remote sensing 
evapouration model. They are also the basis for the study of the surface energy balance and mass balance. Remote sensing of surface parameters and surface fluxes in the agricultural areas of the central Tibet has significant theoretical and practical meaning for crop condition monitoring, crop yield assessment, and disaster monitoring.

\subsection{Study area and datasets}

\subsubsection{Study area}

The middle reaches of Yarlung-Zangbo River (YZR) and its two tributaries (Lhasa River and Nianchu River) is a main agricultural region in central Tibet Autonomous Region producing $56.8 \%$ of the TP agricultural production (Wei et al. 2004). It is not only a climate-sensitive area, but also an ecologically fragile region in TP.

The study area is comprised of the YZR, Lhasa River (LR) and Nianchu River (NR) watersheds (Fig. 3-1a, 3-1b). YZR is the highest major river in the world (You et al. 2007). The river flows from west to east through the South Tibet Valley (3-5 km wide). The middle reaches of YZR and its two tributaries is a central agricultural region and natural water vapour corridor for warm and wet air flow from the Indian Ocean (Zheng and Li 1999). Climatologically the precipitation decreases from east to west and vegetation type follows this gradient (Fig. 3-1c, 3-1d). The typical rooting depth of vegetation in the study area is about $0-10 \mathrm{~cm}$ ( $\mathrm{Li}$ and Koike 2003; He et al. 2009).

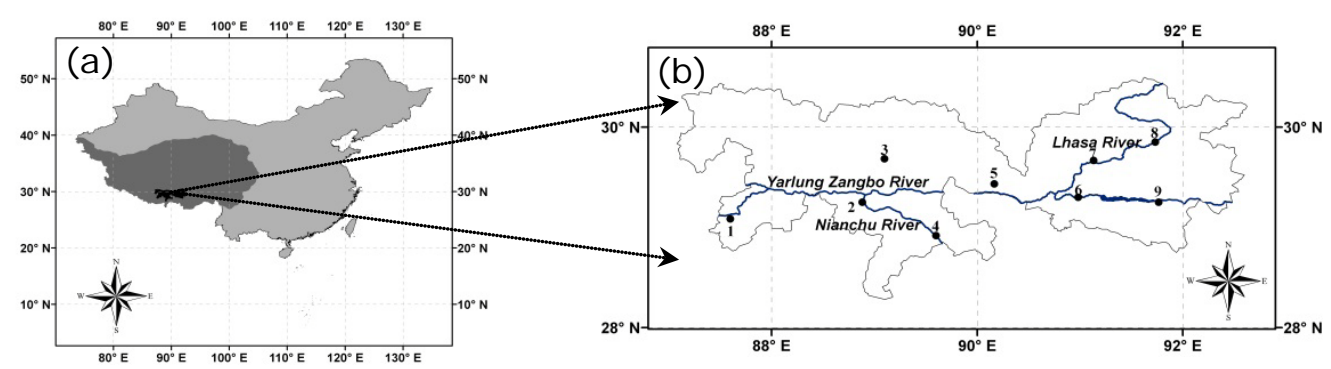




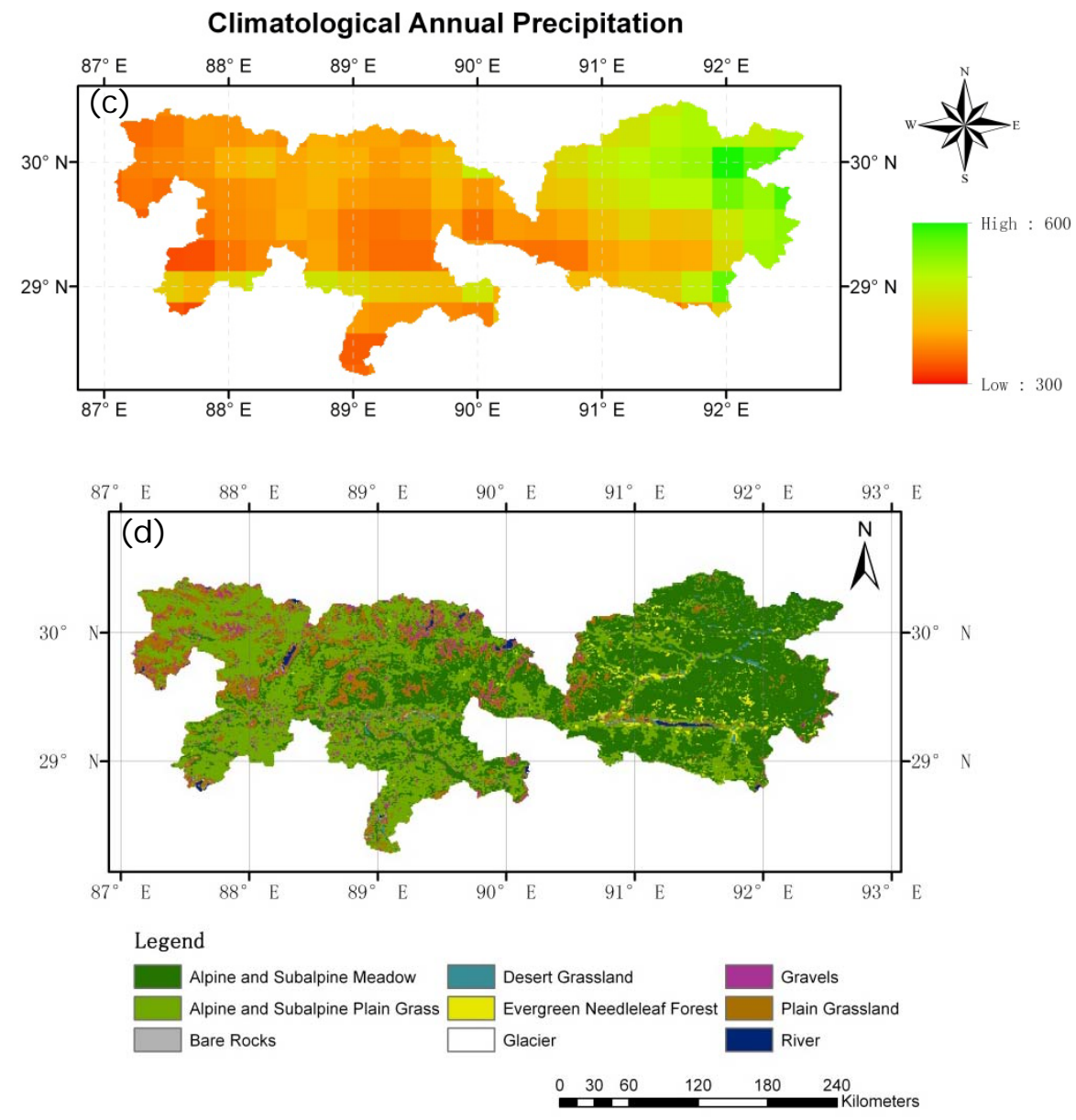

Fig. 3-1 The Location of the middle reaches of YZR and its two tributaries in the TP is shown (b), with the TP (dark grey) being located in western part of China (light grey)(a). Climatological annual precipitation $(\mathrm{mm} /$ year) from TRMM 3B43 (c) and land cover map from GLC2000 (d) are also shown. Nine points in Fig. 3-1(b) represent the location of the meteorological stations. They are 1-Lhatze, 2-Rigaze, 3-Namling, 4-Gyangtse, 5-Nyemo, 6-Gonggar, 7Lhasa, 8-Maizhokunggar, 9-Tsedang.

\subsubsection{Datasets}

The Advanced Very High Resolution Radiometer (AVHRR) and Moderate Resolution Imaging Spectroradiometer (MODIS) are used to retrieve land surface parameters and land surface heat fluxes. These two satellites with similar spatial resolution are used to make an inter-comparison. Simultaneously, because of their different satellite overpass time in a day, the variations of land surface parameters at different time can also be revealed. The AVHRR is a six channel scanning radiometer providing three 
channels in the visible-near infrared region and three thermal infrared channels. NOAA-AVHRR has a spatial resolution of $1.1 \times 1.1 \mathrm{~km}$ at nadir and high revisit time of about two images a day and easy access. MODIS is a key instrument aboard the Terra (EOS AM) and Aqua (EOS PM) satellites. Terra's orbit around the Earth is timed so that it passes from north to south across the equator in the morning, while Aqua passes south to north over the equator in the afternoon. Terra MODIS and Aqua MODIS are viewing the entire Earth's surface every 1 to 2 days, acquiring data in 36 spectral bands. It has a varying spatial resolution, from $250 \mathrm{~m}$ (for bands 1-2), $500 \mathrm{~m}$ (for bands 3-7) to $1 \mathrm{~km}$ (for bands 8-36). MODIS bands 1-7 are all aggregated to $1 \mathrm{~km}$. TERRA MODIS L1B (MOD021KM.hdf) and NOAA AVHRR16 L1B data in 2003, which cover the whole study area, are collected. For AVHRR data, image calibration, solar elevation angle correction for visible and nearinfrared bands, limb darkening correction for infrared band, geometric correction, image mosaic and subset, and atmospheric correction are required. For MODIS data, bowtie processing, calibration, geometric correction, image mosaic and subset, and atmospheric correction are needed (Zhong 2007). Simplified Method for Atmospheric Correction (SMAC) was applied to perform the atmospheric correction. SMAC is a fast and accurate technique for the atmospheric correction of satellite measurements in the solar spectrum. The main advantage of the method is that it is several hundred times faster than more detailed radiative transfer models like MODTRAN and that it does not require precalculated look-up tables (Rahman and Dedieu 1994). Almost cloud-free images taken on 14 April and 16 October 2003 are selected as the cases for spring, and autumn, respectively. The satellite overpass time is listed in Table 3-1.

Some other in-situ meteorological parameters are also essential for SEBS. There are a total of nine meteorological stations located in the study area (Fig. 3-1a). They are 1-Lhatze, 2-Rigaze, 3-Namling, 4-Gyangtse, 5-Nyemo, 6-Gonggar, 7-Lhasa, 8-Maizhokunggar, 9-Tsedang. The conventional observational items, such as wind speed, air temperature, humidity, air pressure, solar radiation, sunshine hours, will be used in the study.

Table 3-1 Satellite overpass time (local time)

\begin{tabular}{lll}
\hline Instruments & 14 Apr. 2003 & 16 Oct. 2003 \\
\hline AVHRR & $12: 57$ & $13: 27$ \\
MODIS & $10: 55$ & $10: 50$ \\
\hline
\end{tabular}

\subsection{Methods}

Based on the surface energy balance principle, the Surface energy balance system (SEBS) model was developed by Su (2002) to estimate atmospheric turbulent fluxes and the evapourative fraction (the ratio of latent heat flux 
and the available energy) using spectral satellite observations together with the meteorological data. By applying Bulk Atmospheric Similarity(BAS) and Monin-Obukhov Similarity(MOS) theory, the advantage of SEBS model is that it can be used for the estimation of land surface heat fluxes at both local and regional scale. So far, SEBS has been widely used for the estimation of the surface energy fluxes at different scales (Su et al., 2001; Su et al., 2003; Timmermans and Kwast, 2005). Another advantage of SEBS is that it adopts a physical model, which takes full consideration of underlying surface heterogeneity into account, to determine the roughness length for heat transfer. The land surface characteristics which are needed as the input for the SEBS model can be derived by the following methods.

\subsubsection{Albedo}

Liang (2000) applied an approach that decouples surface reflectance spectra from real-time radiative transfer simulations so that many different surface reflectance spectra and the atmospheric conditions can be effectively incorporated. His conversion formulae for calculating total shortwave albedo for AVHRR and MODIS is applied in this study. For AVHRR we use the expression:

$\alpha_{\text {short }-A V H R R}=-0.3376 \alpha_{1}^{2}-0.2707 \alpha_{2}^{2}+0.7074 \alpha_{1} \alpha_{2}+0.2915 \alpha_{1}+0.5256 \alpha_{2}+0.0035$

where $\alpha_{\text {short-AVHRR }}$ is AVHRR shortwave albedo; $\alpha_{1}$ and $\alpha_{2}$ are narrowband albedo for AVHRR band 1 and band 2. For MODIS equation, it becomes:

$\alpha_{\text {short-MODIS }}=-0160 \alpha_{1}+0.291 \alpha_{2}+0.243 \alpha_{3}+0.116 \alpha_{4}+0.112 \alpha_{5}+0.081 \alpha_{7}-0.0015$

where $\alpha_{\text {short-MODIS }}$ is MODIS shortwave albedo; $\alpha_{1}, \alpha_{2}, \alpha_{3}, \alpha_{4}, \alpha_{5}$, and $\alpha_{7}$ are narrowband albedo for MODIS band 1 to band 5 , and band 7 .

\subsubsection{Normalized Difference Vegetation Index}

Normalized Difference Vegetation Index (NDVI), defined below, is widely used as an indicator of vegetation growth status, spatial density distribution and phenology of vegetation.

$$
N D V I=\left(\alpha_{2}-\alpha_{1}\right) /\left(\alpha_{2}+\alpha_{1}\right)
$$

where $\alpha_{1}$ and $\alpha_{2}$ are narrowband albedo for AVHRR/MODIS band 1 and band 2.

\subsubsection{Emissivity}

The emissivity is estimated by a theoretical approach, which models a given surface by considering it as being made up of a mixture of bare soil, vegetation and water body (Sobrino et al. 1990; Mao et al. 2005a; Mao et al. 
2005b).

$$
\varepsilon_{i}=P_{w} R_{w} \varepsilon_{i w}+P_{v} R_{v} \varepsilon_{i v}+\left(1-P_{v}-P_{w}\right) R_{s} \varepsilon_{i s}
$$

where $\varepsilon_{i}$ is the surface emissivity of band $i$ ( $i=4,5$ for AVHRR, $i=31,32$ for MODIS); $\varepsilon_{i w}, \varepsilon_{i v}$ and $\varepsilon_{i s}$ are the surface emissivity for water body, vegetation and bare soil of band $i ; P_{v}$ is vegetation coverage for a pixel and it can be calculated by the method of Carlson and Ripley (1997), $P_{v}=\left[\frac{N D V I-N D V I_{\text {min }}}{N D V I_{\text {max }}-N D V I_{\text {min }}}\right]^{2}, P_{w}$ is water coverage for a pixel and it can be derived by the method of Mao (2005a), $R_{w}, R_{v}$ and $R_{s}$ are radiation ratio of water body, vegetation and bare soil.

\subsubsection{Water vapour content}

The water vapour content for AVHRR will be derived by applying Split-Window Covariance-Variance Ratio (SWCVR) technique (Sobrino et al. 1999).

$$
\begin{gathered}
W=0.26-14.253 \cos \theta \ln R_{54}-11.649\left(\cos \theta \ln R_{54}\right)^{2} \\
R_{54}=\frac{\sum_{k=1}^{N}(t 4 k-t 40)(t 5 k-t 50)}{\sum_{k=1}^{N}(t 4 k-t 40)^{2}}
\end{gathered}
$$

where $\theta$ is the observation angel; $k$ represents the adjacent pixels and $N$ represents the number of pixels; $t 4 k$ and $t 5 k$ are the brightness temperature for $k^{\text {th }}$ pixel directly measured by the satellite in AVHRR band 4 and band 5; t40 and $t 50$ are the mean brightness temperature of $N$ pixels. The water vapour content can be directly derived from MODIS image (Kaufman and Cai 1992).

$$
W=\left[\left(\alpha-\ln \tau_{w}\right) / \beta\right]^{2}
$$

where $W$ represents water vapour content $\left(\mathrm{g} \mathrm{cm}^{-2}\right) ; \alpha$ and $\beta$ are constants ( $\alpha=0.02, \beta=0.651$ ); $\tau_{w}$ is the ratio of absorption band (band 19) to window band of atmosphere (band 2)

$$
\tau_{w}=\frac{\rho_{19}}{\rho_{2}}
$$

Because the transmittance of MODIS band $31 / 32$ and water vapour content of atmosphere are approximately satisfied as a linear relationship, the 
transmittance of MODIS band $31 / 32$ at pixel scale can be estimated from the water vapour content of atmosphere (Mao et al. 2005b).

\subsubsection{Land surface temperature}

The retrieval of LST from AVHRR and MODIS data is achieved mainly through the application of SWAs (Split Window Algorithms). After twenty years' development, there are about 20 SWAs which have been proposed. However, these algorithms and methods are based on different considerations and are suitable for certain conditions (Qin and Karnieli 1999). Ma and Tsukaoto(2002) put forward an algorithm for the experiment area in the northern TP. This method will be investigated to derive LST from AVHRR data.

$$
T_{s f c}=T_{4}+1.56\left[T_{4}-T_{5}\right]+0.28\left[T_{4}-T_{5}\right]^{2}+(48-5 W)(1-\varepsilon)
$$

Where $T_{4}$ and $T_{5}$ are brightness temperature of band 4 and band 5 for AVHRR; $W$ is water vapour content and $\varepsilon$ is average emissivity of band 4 and band 5 .

Mao (2005b) proposed a practical SWA to derive LST from MODIS. The method was approved as a simple but with high accuracy. However, whether this method is suitable for YZR and its two tributaries is not known yet. Therefore, Mao's method will be investigated for its applicability in the study area by applying it to derive LST from MODIS data.

$$
T_{s}=A_{0}+A_{1} T_{31}-A_{2} T_{32}
$$

The coefficients in equation 3-10 are given here below:

$$
\begin{gathered}
A_{0}=E_{1} a_{31}-E_{2} a_{32}, \\
A_{1}=1+A+E_{1} b_{31}, \\
A_{2}=A+E_{2} b_{32}, \\
A=D_{31} / E_{0}, \\
E_{1}=D_{32}\left(1-C_{31}-D_{31}\right) / E_{0}, \\
E_{2}=D_{31}\left(1-C_{32}-D_{32}\right) / E_{0}, \\
E_{0}=D_{32} C_{31}-D_{31} C_{32}, \\
C_{i}=\varepsilon_{i} \tau_{i}(\theta), \\
D_{i}=\left[1-\tau_{i}(\theta)\right]\left[1+\left(1-\varepsilon_{i}\right) \tau_{i}(\theta)\right]
\end{gathered}
$$

where $\theta$ is the viewing zenith angel from nadir; $\varepsilon_{i}$ and $\tau_{i}$ are surface emissivity and atmospheric transmittance for band $i$ respectively. 


\subsection{Results}

\subsubsection{Spatiotemporal variations of land surface parameters in the middle reaches of YZR and its two tributaries}

To better explain the spatial variation characteristics of land surface parameters, the study area is divided into western and eastern part by longitude $90^{\circ} \mathrm{E}$. It is also divided into northern and southern part by YZR. Figures 3-2 and 3-3 show the land surface parameters derived from AVHRR and MODIS images. Only the spring and autumn cases are displayed. Among all land surface parameters, the dominant spatial patterns of LST are much more complicated. High LST values are found in the valleys (Figs. 3-2a, 3-2g, 3-3a and 3-3g). Pixels with extremely low values are mainly contaminated by cloud cover. The LST in southern part is usually much higher than the northern part. LST is influenced by a combination of natural and anthropogenic factors, such as latitude, altitude, precipitation, soil moisture, land cover type, urbanization, land use, etc. Some spatial patterns of LST can be identified with reference to land cover classes according to GLC2000. Alpine and subalpine meadow (ASM) and alpine and subalpine plain grass (ASPG) are two dominant land cover types in the study area (Fig. 3-1d), constituting up to $42.5 \%$ and $38.9 \%$ of the total area, respectively. The LST of ASM is usually much lower than that of ASPG (Figs. 3-2a, 3-2g, 3-3a and $3-3 \mathrm{~g}$ ). The spatial distributions of NDVI and vegetation coverage show some similar patterns, and they are in good accordance with the land cover map of Fig. 3-1d. The vegetation density in eastern part is much higher than that in western part (Figs. 3-2c, 3-2d, 3-2i, 3-2j, 3-3c, 3-3d, 3-3i and 3-3j) and seems to diminish from north to south. Except for some disturbance from clouds, the Albedo shows a west-high east-low mode. This is especially obvious from MODIS images (Figs. 3-2h and 3-3h). The surface emissivity and water vapour content are displayed in Figs. 3-2e, 3-2f, 3-2k, 3-2l, 3-3e, 3-3f, 3-3k and 3-3l. The emissivity is usually much higher in eastern part than western part. This corresponds to the distribution of vegetation density. It is also remarkable to find the shape of atmospheric water vapour belt following the trend of YZR and its two tributaries. The relatively high surface temperature and sufficient water resources from Rivers make ample atmospheric water vapour formed. Another potential water vapour resource is from the Indian Ocean. From spring (April) to autumn (October), both NDVI and $P_{v}$ values become larger. This is due to growth phase of most of vegetation in western part, i.e. have not started to grow in the pre-monsoon season. In the post-monsoon season, although the vegetation becomes withered and yellow, the land surface is still covered by vegetation. Accordingly, surface albedo declines together with atmospheric water vapour content increasing from spring to autumn. 

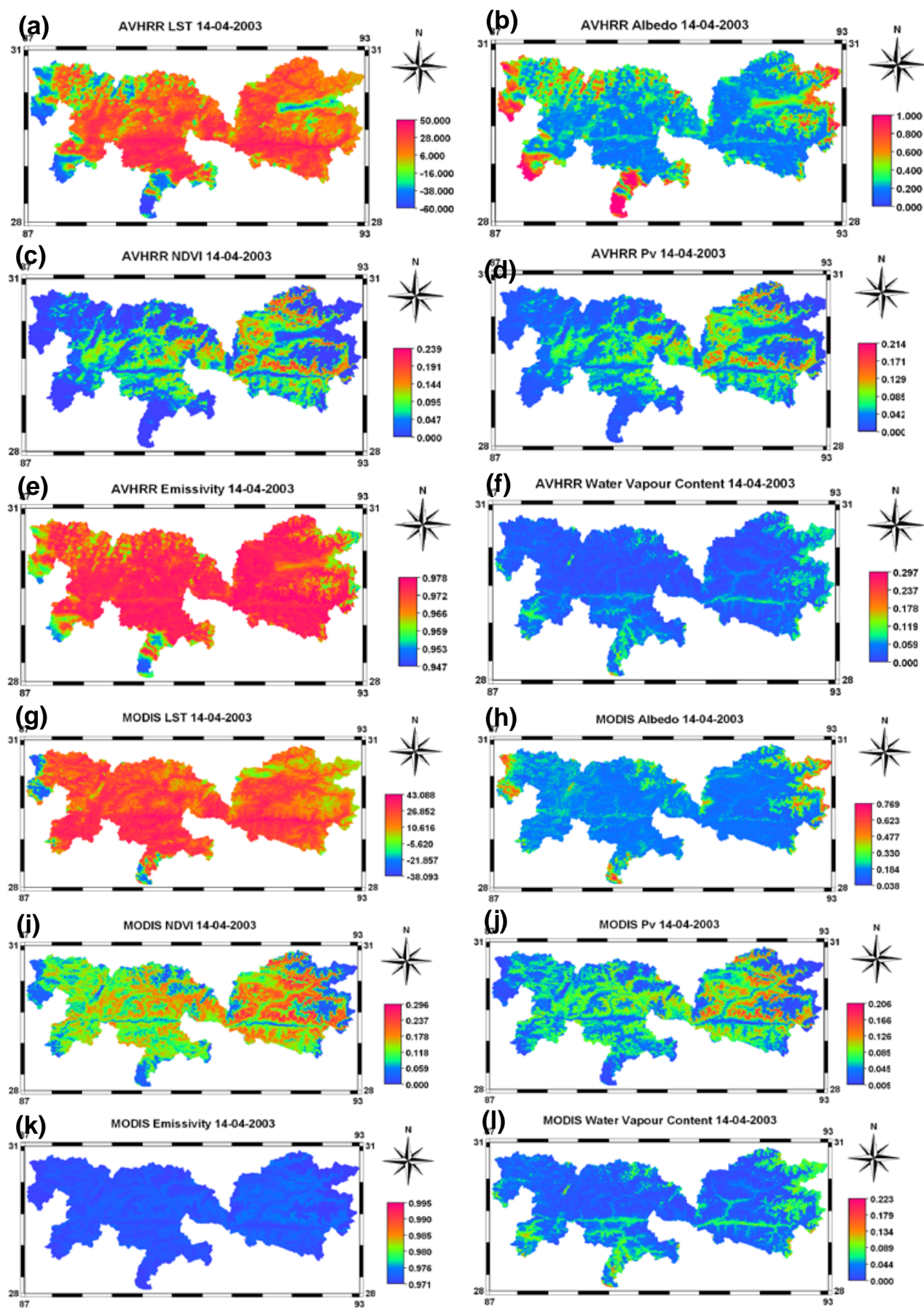

Fig. 3-2 The derived land surtace parameters in spring from satellite images. Panels (a) - (f) are LST, albedo, NDVI, Pv, emissivity and water vapour content derived from AVHRR, respectively. Panels $(g)-(h)$ are LST, albedo, NDVI, Pv, emissivity and water vapour content derived from MODIS, respectively. 

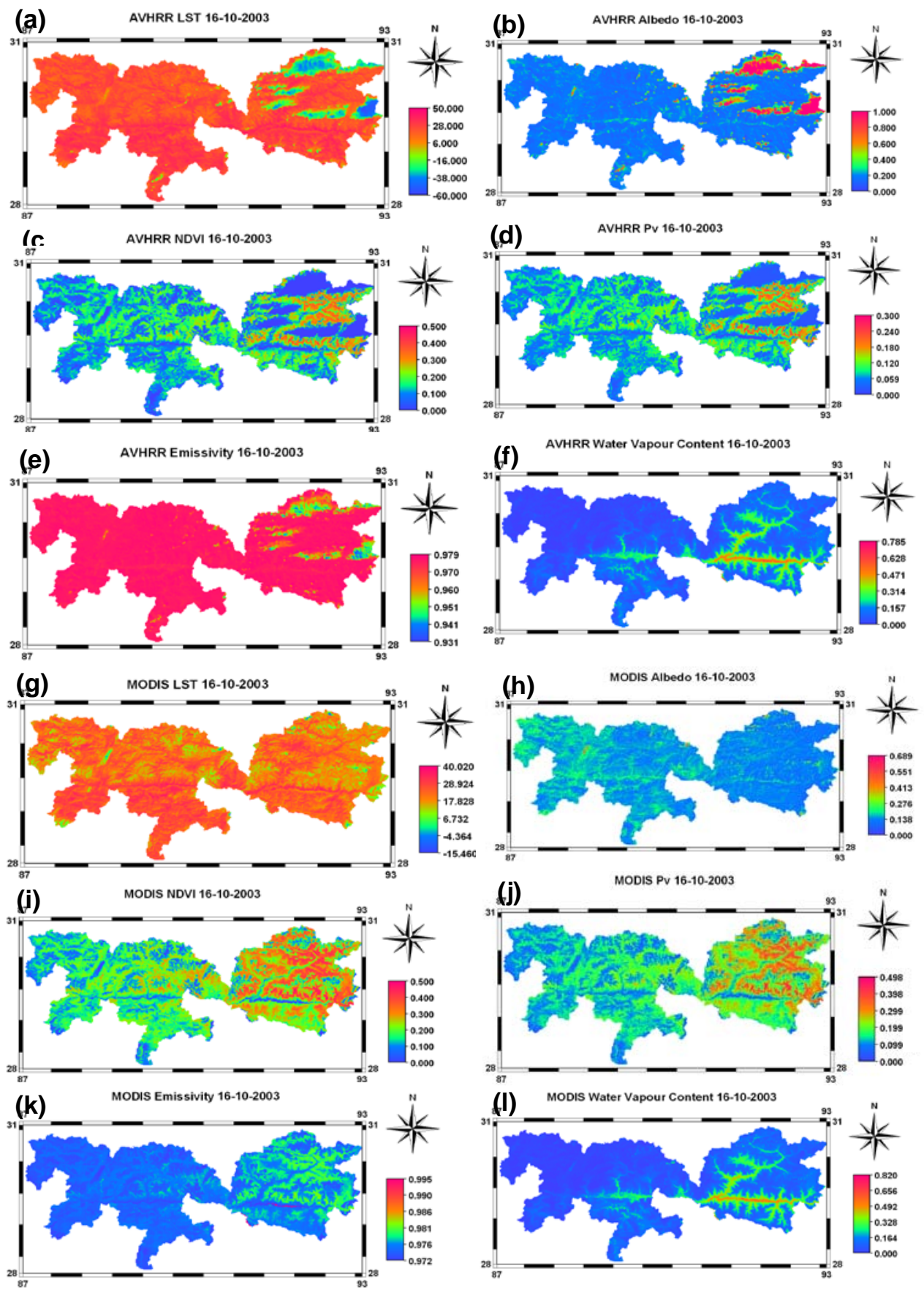

Fig. 3-3 The derived land surface parameters in autumn from satellite images. Panels (a)- (f) are LST, albedo, NDVI, PV, emissivity and water vapour content derived from AVHRR, respectively. Panels (g)-(h) are LST, albedo, NDVI, Pv, emissivity and water vapour content derived from MODIS, respectively. 


\subsubsection{Spatiotemporal variations of land surface heat fluxes in the middle reaches of YZR and its two tributaries}

The surface flux estimation results show that the spatial distribution of net radiation flux, sensible heat flux, latent heat flux and soil heat flux in the study area corresponds well with that of the surface parameters (NDVI, PV and surface albedo)(Figs.3-4, 3-5). In the eastern part with relatively higher vegetation cover, the net radiation flux and the latent heat flux are much higher while the sensible heat flux is much lower. If the study area is divided into two parts by $Y Z R$, it can be seen the sensible heat flux in the southern part is much higher than those in the northern part. However, the southern latent heat flux is a little lower. If we make a comparison between these two kinds of satellite data, it can be found that the AVHRR data is influenced greatly by the cloud cover because the satellite passing time for AVHRR is in the mid-afternoon when the convective clouds over the TP develop vigorously. This is especially obvious in the results derived from AVHRR on 16 October (Fig. 3-5). Some abnormal results from SEBS model can be found in the northeastern part of $Y Z R$ and its two tributaries because of the deeply convective clouds. There are no value for net radiation flux and soil heat flux while negative values can be found for sensible heat flux and latent heat flux. Due to the limitation of the satellite data quality itself, the estimation results from AVHRR are not as clear and complete as those from MODIS. In addition, the calibration uncertainties can also induce some differences between SEBS results. The calibration for AVHRR instrument is done prior to launch. Actually, the calibration parameters will vary with the length of launch time. However, in-orbit calibration is applied for MODIS instruments. There are 3 in-orbit scalers, including solar diffuse panel, stability monitoring instrument for solar diffuse panel and radiometric calibration device, for the calibration of solar reflective bands. These scalers can provide high-precision calibration results. The changing calibration parameters can be detected and corrected through alternative scaling techniques. Furthermore, AVHRR band 1 and band 2 are broad bands which contain several strong water vapour absorption zones and this will reduce AVHRR retrieval accuracy. In comparison with estimate results from AVHRR and MODIS data, it can be seen their spatial patterns are consistent on the same day but the MODIS results are greater than the AVHRR results (Figs. 3-4, 3-5). The reason is that the shortwave solar radiation or the net radiation flux at 13:00 is greater than those at 15:00 which is validated by the in-situ measurements (for instance, Lhasa station). If we make a comparison between results in spring time and autumn time for the same instrument, it can be found that the AVHRR energy balance components in spring are greater than those in fall. The MODIS spring net radiation flux, sensible heat flux and soil heat flux are also larger than those in fall. The MODIS latent heat flux in fall is greater than that in spring. It needs to be pointed out that regardless of the spring and autumn, the 
surface latent heat fluxes are much higher (more than $200 \mathrm{~W} \mathrm{~m}^{-2}$ ). This is mainly owing to the following facts. As the spring is turning green season for crops, the land surface is relatively wet. The satellite passing time is after noon when the solar radiation is intense and thus the evapotranspiration is relatively very strong. Although some crops have been harvested in autumn, but for some other land covers, such as grass, vegetation has not yet become brown, there is considerable evapotranspiration for those areas.

YZR and its two tributaries is the center for Tibetan people. Since 1950s, the population in this area has doubled. With the increasing population pressure, the scale and intensity of human development and utilization of valley land resources increases greatly. The relationship between human and land has become unsustainable ( $\mathrm{Li}$ et al., 1997). The over-exploitation of the valley land, for example, overgrazing, leads to the destruction of native vegetation and soil structure. Thus it will accelerate the wind erosion intensity over sandy or sandy gravel land surface resulting in an increase of a series of sand activities process, such as wind erosion, sand flow, the quicksand accumulation. Coupled with the influences of local special terrain and vegetation status, the middle reaches of YZR basin, especially for the YZR and its two tributaries region, the desertification trend is more and more serious. There is a total area of 112000 hectares of bare sandy land including dunes and this amount takes up 2/3 of local cultivated area. The distribution pattern for aeolian landform in YZR valley is like patchy. It is generally a zonal distribution pattern along the valley trend. It can be clearly seen from the spatial distribution map of estimated land surface heat fluxes in spring (Fig.3-4) that the sensible heat flux is much higher while the latent heat flux is lower in valley and its flanking areas. The dry seasons for YZR and its two tributaries last from November to next April. The average river runoff at those time periods is less than $5 \%$ of the annual amount. The minimum runoff is in February with an average amount of $1 \%$ to $2 \%$ of the annual mean. The time periods from April to June are usually sowing, germination and tillering stage which needs large and concentrated quantities of water for local spring crops. The contradiction of less supply and large demand of water resources cause the spring drought. After a wet period from J une to September, the study area comes to a normal water season in October. It can be seen that the areas with high sensible heat flux values decrease greatly especially for the valley sides. Simultaneously, the sensible heat flux decrease and the latent heat flux increase in the valley center. 

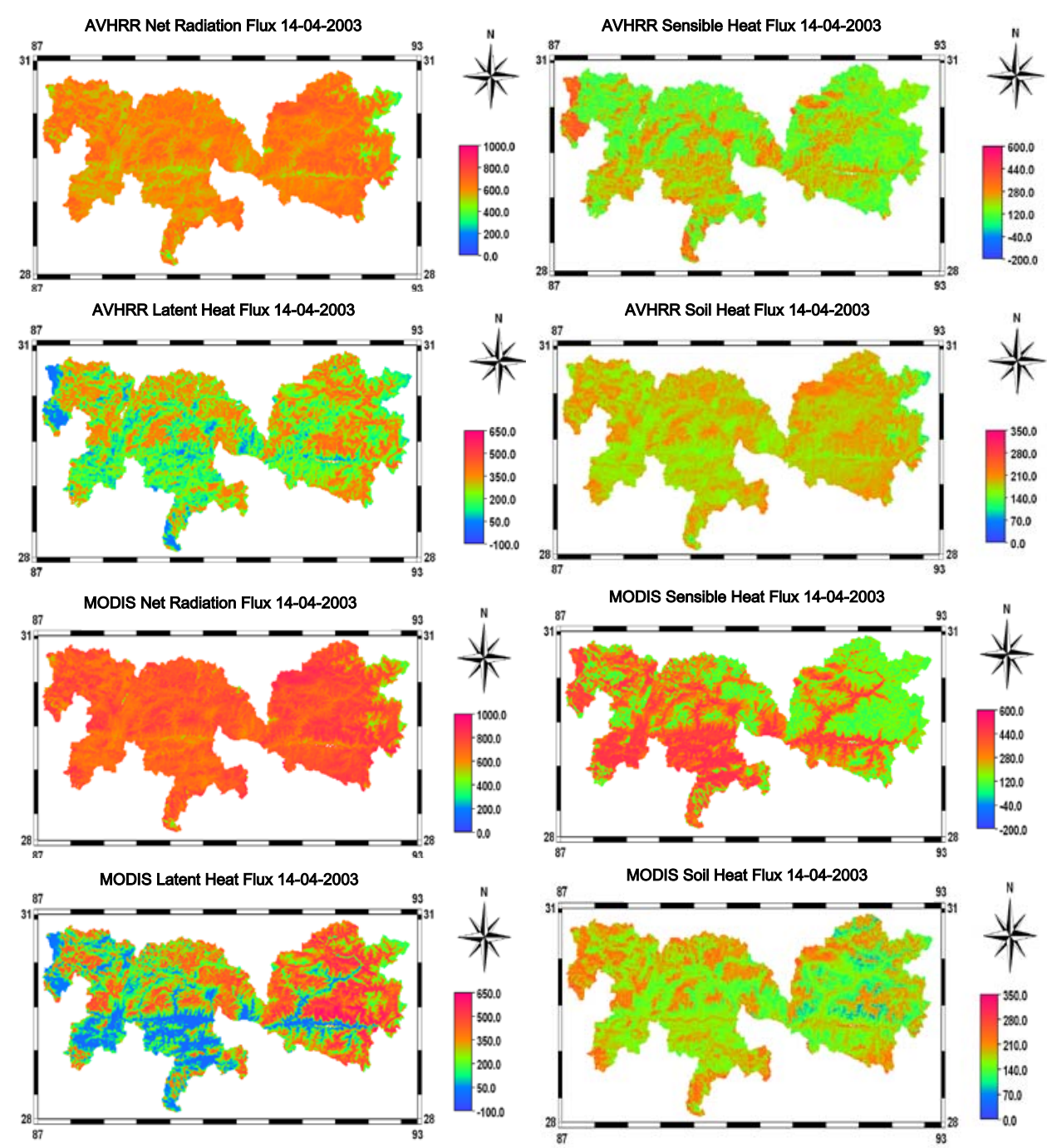

Fig. 3-4 The spatial distribution of land surface heat fluxes (unit $\mathrm{W} \mathrm{m}^{-2}$ ) in spring derived from AVHRR and MODIS images 

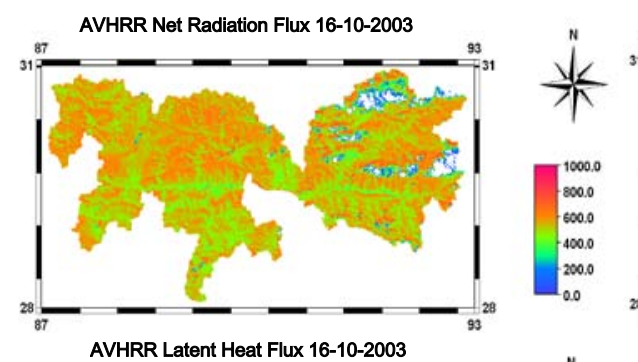

AVHRR Sensible Heat Flux 16-10-2003
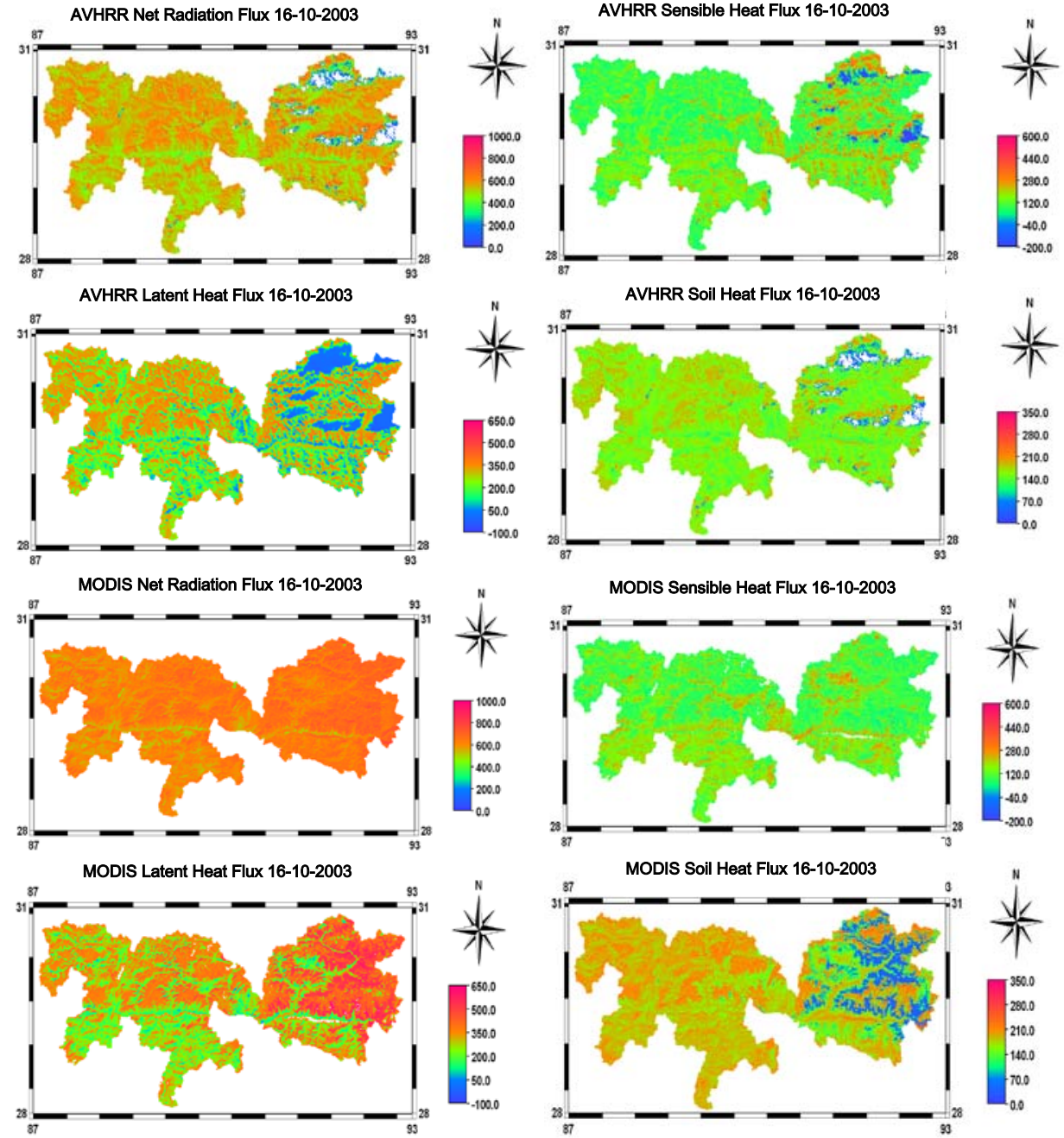

Fig. 3-5 The spatial distribution of land surface heat fluxes (unit $\mathbf{W ~ m}^{-2}$ ) in autumn derived from AVHRR and MODIS images

\subsection{Conclusions and discussions}

Based on AVHRR and MODIS images, the land surface characteristics in YZR and its two tributaries are retrieved firstly. Then combined with the in-situ data from meteorological stations in the study area, the land surface heat fluxes in spring and autumn are estimated by using SEBS model. Some conclusions can be drawn as followings.

(1) As called the "water vapour channel", the valleys in the study area are found to have higher LST. Because of abundant water resource supply, it is also proved to have larger atmospheric water vapour content. 
(2) The LST in southern part is usually much higher than the northern part. The vegetation density in eastern part is much higher than that in western part. The emissivity is usually much higher in eastern part than western part. This is in good correspondence to vegetation density distributions. Except some disturbance from clouds, the albedo shows a west-high and east-low mode.

(3) Most of the land surface parameters show a clear seasonal difference. From spring (April) to autumn (October), both NDVI and vegetation coverage values increase with the decreasing of surface albedo.

(4) Although the underlying surface is inhomogeneous with complex terrain, the estimation surface fluxes results show there are clear spatial distributions and temporal variations for the net radiation flux, sensible heat flux, latent heat flux and soil heat flux in YZR and its two tributaries. Furthermore, the spatial distributions of energy balance components correspond well with the spatial patterns of land surface parameters.

(5) In the eastern part with better vegetation cover, the latent heat flux is higher while the sensible heat flux is lower. For the net radiation, the eastern part usually has much higher values than western part. If the study area can be divided into two parts by YZR, it can be identified that the sensible heat flux in southern part is usually much higher than the northern part. The latent heat flux in southern part is usually much lower than the northern part.

(6) The comparison between estimation results from AVHRR and MODIS show that the spatial distributions of derived heat fluxes from both satellites on the same day show some similarities. However, because of the different satellite passing time, estimations from MODIS data are higher than those from AVHRR.

(7) The comparison between spring results and autumn results show that the energy balance components estimated from AVHRR in spring are higher than those in autumn. For MODIS data, the net radiation flux, sensible heat flux and soil heat flux in spring are higher than those in autumn while the latent heat flux in spring is lower than that in autumn.

(8) The phenomenon of desertification in YZR and its two tributaries has become more and more serious. The distribution pattern for aeolian landform in YZR valley is like patchy. It is generally a zonal distribution pattern along the river valley. It can be clearly seen from the spatial distribution map of estimated land surface heat fluxes in spring that the 
sensible heat flux is much higher while the latent heat flux is lower in valley and its flanking areas.

Although there are several meteorological stations in the study area, the conventional observational items, such as wind, air temperature, humidity and air pressure are not enough for the validation. Establishing more comprehensive observation stations for the study area are in urgent need. There are no in-situ flux measurements which can be used for the validation, but it is still comparable by using flux estimation results from two different satellite sensors. Thus it is helpful to qualitatively understand the spatial distribution and temporal variations of land surface heat fluxes. The next priority is the study on drought monitoring and evapotranspiration estimation which are of great concern for local government and people. 


\section{Chapter 4}

\section{Assessment of soil water deficit for the middle reaches of Yarlung-Zangbo River from optical and passive microwave images}

\footnotetext{
* This chapter is based on

Zhong, L., Y. Ma, Y. Fu, X. Pan, W. Hu, Z. Su, M.S. Salama and L. Feng, 2014, Assessment of soil water deficit for the middle reaches of Yarlung-Zangbo River from optical and passive microwave images, Remote Sensing of Environment, 142: DOI : 10.1016/j.rse.2013.11.008.
} 


\section{ABSTRACT}

The middle reaches of Yarlung-Zangbo River (YZR) and its two tributaries (Lhasa River and Nianchu River) is a main agricultural region in central Tibet Autonomous Region. Soil water deficit (SWD) estimation has significant relevance to local crop growth monitoring, crop yield assessment and disaster monitoring. It also has great theoretical importance for understanding the local energy and water balance status. In this paper, AVHRR and MODIS data on 14 April 2003, 16 October 2003 under nearly clear weather conditions are selected as the spring and autumn cases. Land surface parameters, such as land surface temperature, surface albedo, Normalized Difference Vegetation Index, emissivity, have been derived from different algorithms for AVHRR and MODIS data. In combination with meteorological data, the soil water deficit index is determined by applying Surface Energy Balance System. The $\mathrm{R}$ square values between SWDI and AMSR-E soil moisture are ranging from 0.457 to 0.607 , with spring SWD being much more severe than that in autumn. The limited river runoff (less than $5 \%$ of the annual total) is the dominant factor for spring SWD. This study also reveals that the derived spring SWD from AVHRR and MODIS data is quite different on the same day. This phenomenon is caused by different satellite overpass times which influence the melting frozen soil. This also confirms the soil moisture may have diurnal variations. The spatial variations of SWD conditions in the middle reaches of YZR and its two tributaries have been clearly identified.

Keywords: Surface Energy Balance System; Soil moisture; the Tibetan Plateau 


\subsection{Introduction}

Globally, soil water deficit (SWD) is considered to be one of the world's most common phenomena. Especially in recent years, water shortage is becoming more serious with increasing social and economic development (Jang et al. 2009). Under the background of climate change (McVicar et al. 2012; Sun et al. 2012; Donohue et al. 2013), water scarcity has been recognized as one of the most urgent problems that requires pressing solutions (Rosegrant et al. 2009; Van Loon and Van Lanen 2013).

SWD is the difference between field capacity and the actual soil water content in the root zone. In other words, SWD is often caused by a reduction in the availability of soil water (Wanjura and Upchurch 2000) inadequate to meet the evapotranspiration demand (Padhi et al. 2012). Actually, SWD is directly linked to evapotranspiration. While drought is a complex phenomenon whose severity is specific regionally due to local energy and water balance status (Shahabfar et al. 2012). It is a natural hazard, caused by large-scale climatic variability, and cannot be prevented by local water management (Van Loon and Van Lanen 2013). It refers to an anomaly when compared to a long-term climatology. Four major types of drought which are broadly defined and agreed upon in the scientific literature (McVicar and Jupp 1998). They are meteorological drought, agricultural drought, hydrologic drought and socioeconomic drought. Some linkages exist between SWD and drought. Both drought and SWD are all related to energy transfer and water cycle processes. More or less SWD usually can be found in drought-prone regions. However, the converse is not necessarily true.

The severity of SWD can be assessed with meteorological based indices (e.g., the standardized precipitation index)(Su et al. 2003) or other methods, such as lysimeter and the neutron probe detection method. However, all these indexes are based on the in-situ measurements, and hence represent a 'point' in the landscape. A lot of manpower, material and financial resources need to be invested to get the limited point-level SWD information. It is quite challenging to acquire local or regional SWD situations using the above methods.

SWD is directly linked to evapotranspiration. In recent decades, a wide variety of models have been developed using satellite data to estimate evapotranspiration ( $M a$ et al. 2013), such as the Surface Energy Balance Algorithm for Land (SEBAL; Bastiaanssen et al. 1998), the Surface Energy Balance Index (SEBI; Menenti and Choudhury 1993), the Simplified Surface Energy Balance Index (S-SEBI; Roerink et al. 2000). Although these models have successfully assessed the surface heat fluxes and monitored the SWD on a small scale, they usually lose strength for larger scales at which the 
underlying surface conditions are no longer homogenous any more. Overall, various remote sensing models are built on the premise of certain conditions. The above existing methods often lose their applicability in the Qinghai-Tibet Plateau area because of the complex terrain and characteristic environmental conditions there.

The development of Surface Energy Balance System (SEBS)(Su 2002; Su et al. 2003) provides a possibility for SWD monitoring in the study area. For the specific region of $Y Z R$ and its two tributaries, previous studies focused on the analysis of the land-atmosphere interaction based on the in-situ measurements (e.g., You et al. 2007; Song et al. 2011). As for satellite remote sensing, many studies focused on the retrieval algorithms of land surface parameters (e.g., Ma et al. 2010; Zhong et al. 2011a; Ma et al. 2012; Zhong et al. 2012). Hence, it's necessary to evaluate the applicability of soil water deficit index (SWDI) derived from energy balance aspect for the YZR and its two tributaries. Monitoring surface SWD conditions using remote sensing method facilitate the quantitative understanding of the regional energy and water cycles and supports scientific management and rational use of local water resources.

The purpose of this study is to verify the validity of SEBS-derived SWDI and reveal its spatio-temporal pattern in the study area. Two questions are answered through this study. Firstly, how to identify the validity of SWDI estimated by SEBS? Soil moisture derived from AMSR-E is used to make a comparison with SWDI. Secondly, what's the spatio-temporal pattern of SWDI in YZR and its two tributaries? AVHRR and MODIS data with similar spatial resolution are used to reveal the patterns. These two questions form the basis for the structure presented in the Methods (section4.4), Results (section 4.5) and Discussion (section 4.6) sections below.

\subsection{Study Site}

The study site is the same as the previous Chapter.

\subsection{Materials}

\subsubsection{NOAA-16 AVHRR and Terra MODIS data}

AVHRR and Terra MODIS radiance data are used to retrieve land surface parameters, such as LST, surface albedo, NDVI, Leaf Area Index (LAI) and emissivity. All these derived parameters are used as the inputs for SEBS. The images acquired on 14 April and 16 October 2003 are selected to represent spring and autumn, respectively. 


\subsubsection{AMSR-E data}

Volumetric soil moisture derived from Advanced Microwave Scanning Radiometer (AMSR-E) is used to validate the SWDI results from SEBS. The AMSR-E on the Aqua Earth observation satellite was launched in May 2002. The sensor is 12 channels (six frequencies), with 4 bands relevant to soil moisture retrieval. Orbit characteristics are somewhat similar to its predecessor, Scanning Multichannel Microwave Radiometer, although the AMSR-E swath width is nearly twice as wide at $1445 \mathrm{~km}$ (Owe et al. 2008). The data represent the volumetric soil moisture (of a soil layer about $5 \mathrm{~cm}$ deep) retrieved using the Land Parameter Retrieval Model (Owe et al. 2008) from AMSR-E C band data. The data has a spatial resolution of 0.25 degree.

\subsubsection{In-situ meteorological data}

Nine meteorological stations located in the study area (Fig. 3-1a). The conventional observational items, such as wind speed, air temperature, humidity, air pressure, solar radiation, sunshine hours, are used in the study. The meteorological data are recorded at a frequency of every 6 hours. The wind speed is measured at $10 \mathrm{~m}$ while other variables are recorded at $2 \mathrm{~m}$ above the land surface. To adjust wind speed data obtained from instruments placed at elevations other than the standard height of $2 \mathrm{~m}$, a logarithmic wind speed profile may be used (Allen et al. 1998; Su 2002).

$$
U_{2}=U z * 4.87 /[\ln (67.8 * z-5.42)]
$$

where $U_{2}$ is wind speed at $2 \mathrm{~m}$ above ground surface, $U z$ is measured wind speed at $\mathrm{Z} \mathrm{m}$ above ground surface, $\mathrm{Z}$ is the height of measurement.

The sunshine hours are used to calculate the average daily net radiation by using a simplification of the equation presented by Allen et al. (1998). The net radiation was estimated by the following equation.

$$
R_{n}=(1-\alpha) \cdot R_{\text {swd }}+\varepsilon \cdot R_{l w d}-\varepsilon \cdot \sigma \cdot T_{0}^{4}
$$

where $\alpha$ is the albedo, $\varepsilon$ is the emissivity of the surface, $\sigma$ is the StefanBolzmann constant, $T_{0}$ is land surface temperature, $R_{\text {swd }}$ is the downward solar radiation which can be calculated by the Iqbal's methods (1983), $R_{l w d}$ is the downward longwave radiation which can be calculated as $R_{l w d}=\varepsilon_{a} \sigma T_{a}^{4}$. 


\subsection{Methods}

\subsubsection{Comparison from soil moisture perspective}

As the study area is located at mid-latitudes where the daily AMSR-E swath does not fully cover the area (Ashcroft and Wentz 2003), the products (both ascending and descending) retrieved in one month have been averaged. These products have basic filters applied that mask freezing conditions. The AMSR-E soil moisture have been validated with in-situ soil moisture measurements in the TP and the soil moisture measurements are in good agreement with the meteorological data and consistent in space and time (Dente et al. 2012). This means the AMSR-E soil moisture can be used to make a comparison with SWD.

\subsubsection{Determination of SWDI from AVHRR and MODIS data by using SEBS algorithm}

According to Su et al. (2003), after a series of iteration, SWDI can be written as

$$
S W D I=\frac{H-H_{w e t}}{H_{d r y}-H_{w e t}}
$$

where $H$ represents the actual surface sensible heat flux. It can be derived from bulk atmospheric similarity approach (Su 2002). The SWDI is the logical complement of the Normalised Difference Temperature Index (NDTI) (McVicar and Jupp 2002). $H_{d r y}$ and $H_{\text {wet }}$ in equation 4-3 are the surface sensible heat flux under the dry limit and wet limit, respectively. In the circumstance of dry limit, surface latent flux $\lambda E$ tends to be zero and soil moisture limits actual evapotranspiration. The surface energy balance equation can be written as $R_{n}=H_{d r y}+G_{0}$. Thus $H_{d r y}=R_{n}-G_{0}$, where $R_{n}$ and $G_{0}$ are net radiation flux and soil heat flux. Under the wet limit condition, the surface energy balance equation can be written as $R_{n}=H_{\text {wet }}+\lambda E_{\text {wet }}+G_{0}$. Then $H_{\text {wet }}=R_{n}-\lambda E_{\text {wet }}-G_{0} . H_{\text {wet }}$ can be calculated by the method proposed by Menenti (1984). To estimate land surface parameters from AVHRR and Terra MODIS data, some pre-processing are performed (Zhong 2007). To obtain accurate land surface parameters as inputs to SEBS, different retrieval algorithms for AVHRR and MODIS data are used (Zhong et al. 2010; Zhong et al. 2011b; Zhong et al. 2012). Based on the retrieved land surface parameters and conventional meteorological data, SEBS is applied to get the SWDI. To better explain the spatial variation characteristics of land surface parameters, the study area is divided into western and eastern parts by longitude $90^{\circ} \mathrm{E}$. It is also divided into northern and southern parts by $\mathrm{YZR}$. 


\subsection{Results}

\subsubsection{Comparison from soil moisture perspective}

As the SWD conditions have a direct linkage to soil moisture status, high SWDI values are related to dry region with low soil moisture and vice versa. It should be noted here that a decoupling may exist between the AMSR-E soil moisture and SEB-based SWDI. This is due to that AMSR-E signal responds to the top $5 \mathrm{~cm}$ whereas surface-energy-balance measurement can be impacted by transpiration or diffusion of deeper soil water. Assuming no vertical decoupling of soil moisture through the soil column, the AMSR-E C-band derived volumetric soil moisture is used to make a comparison with SWD monitoring results. As shown by Figure 4-1, the soil moisture is usually much higher in the east than the west. Soil moisture is also higher in the north than the south. Correspondingly, as revealed by AVHRR and MODIS results (Figure 4-2), the western and southern parts usually have much higher soil water deficit, with higher SWDI values. This is consistent with the spatial distributions of AMSR-E derived soil moisture status. From April to October, the soil moisture increases (Figure 4-1). The SWDI values decrease in the same time period as a response. As shown by Figure 4-3a-4-3d, there is a negative correlation between SWDI and volumetric soil moisture. Generally, with increasing soil moisture, SWDI values usually show a decreasing trend, which means the alleviation of soil water deficit. All these phenomena confirm the validity and robustness of our SWD monitoring results. 

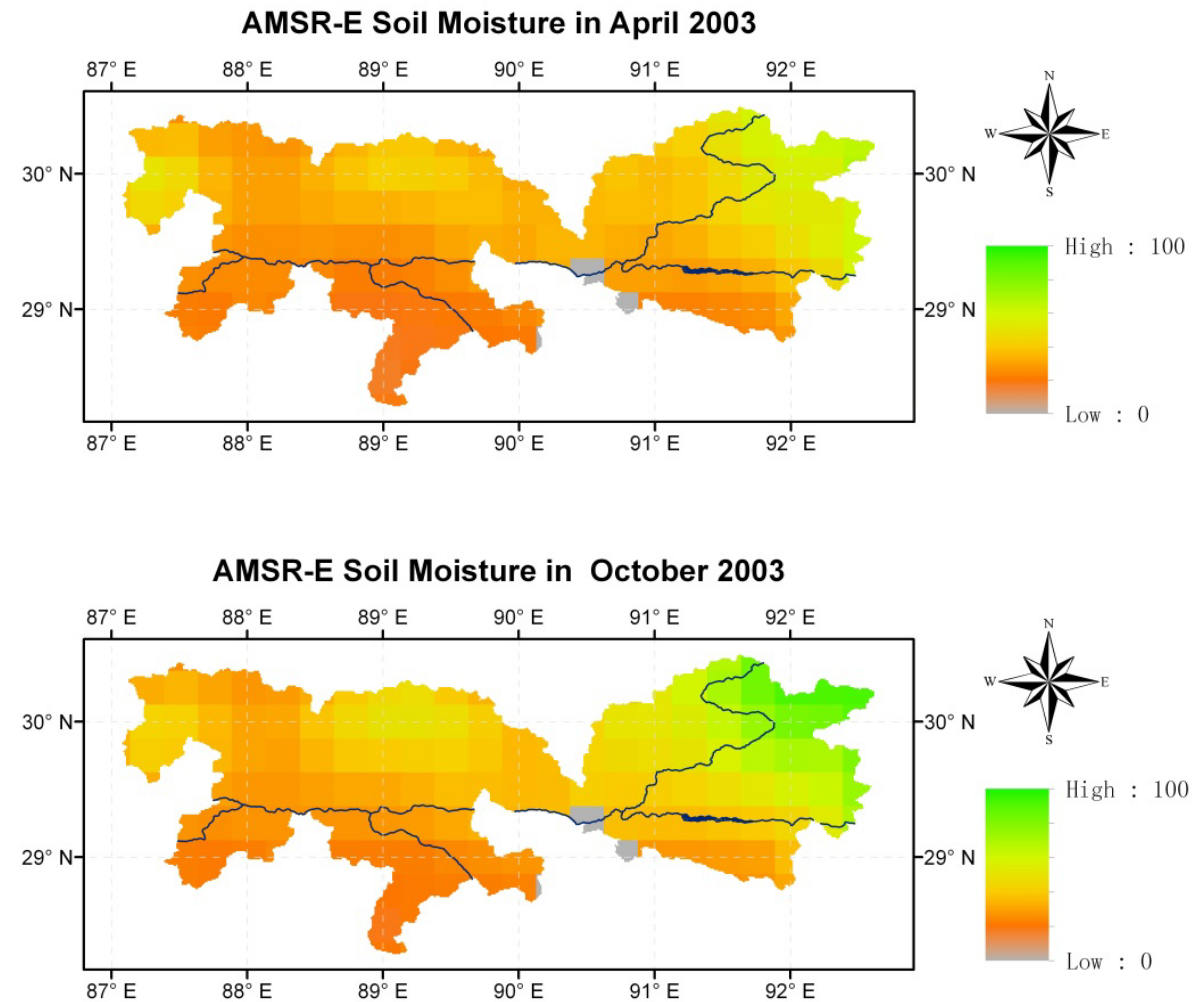

Fig. 4-1 The derived the volumetric soil moisture (Unit: $\mathrm{m}^{3} / \mathrm{m}^{3}$ ) for middle reaches of the Yarlung-Zangbo River and its two tributaries (Lhasa River and Nianchu River) in April 2003 and October 2003. 


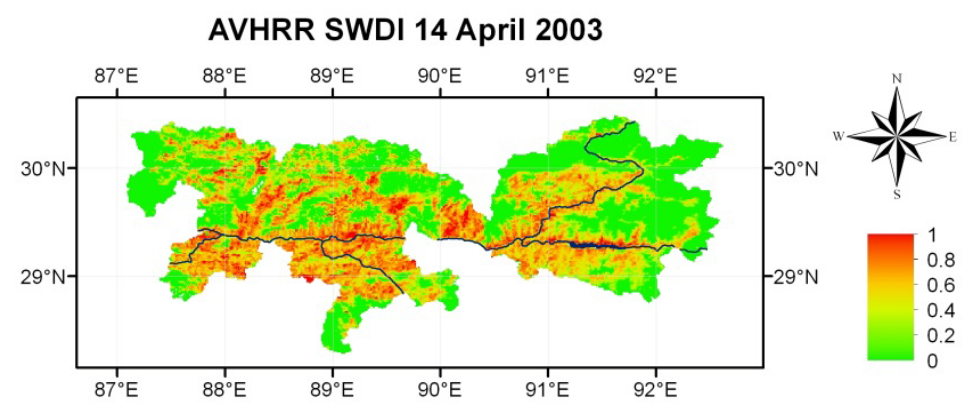

MODIS SWDI 14 April 2003

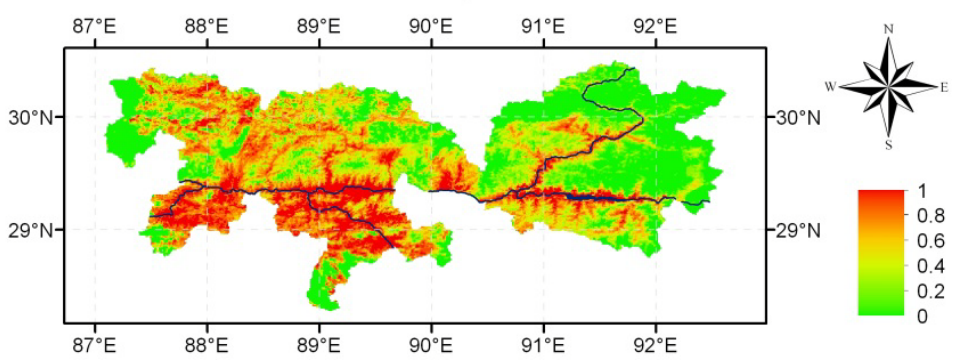

AVHRR SWDI 16 October 2003

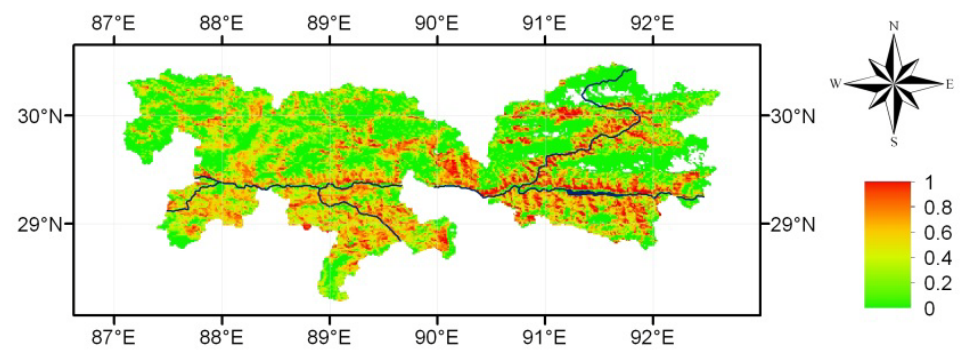

MODIS SWDI 16 October 2003

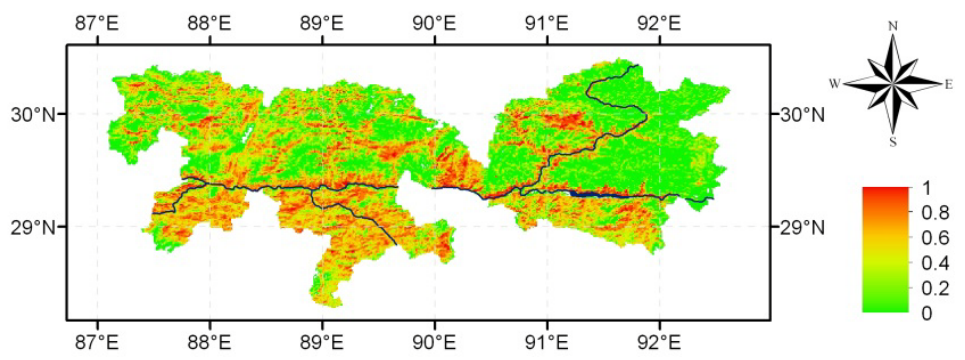

Fig. 4-2 The derived SWDI and its spatial distribution of for middle reaches of the Yarlung-Zangbo River and its two tributaries (Lhasa River and Nianchu River) in different seasons. 

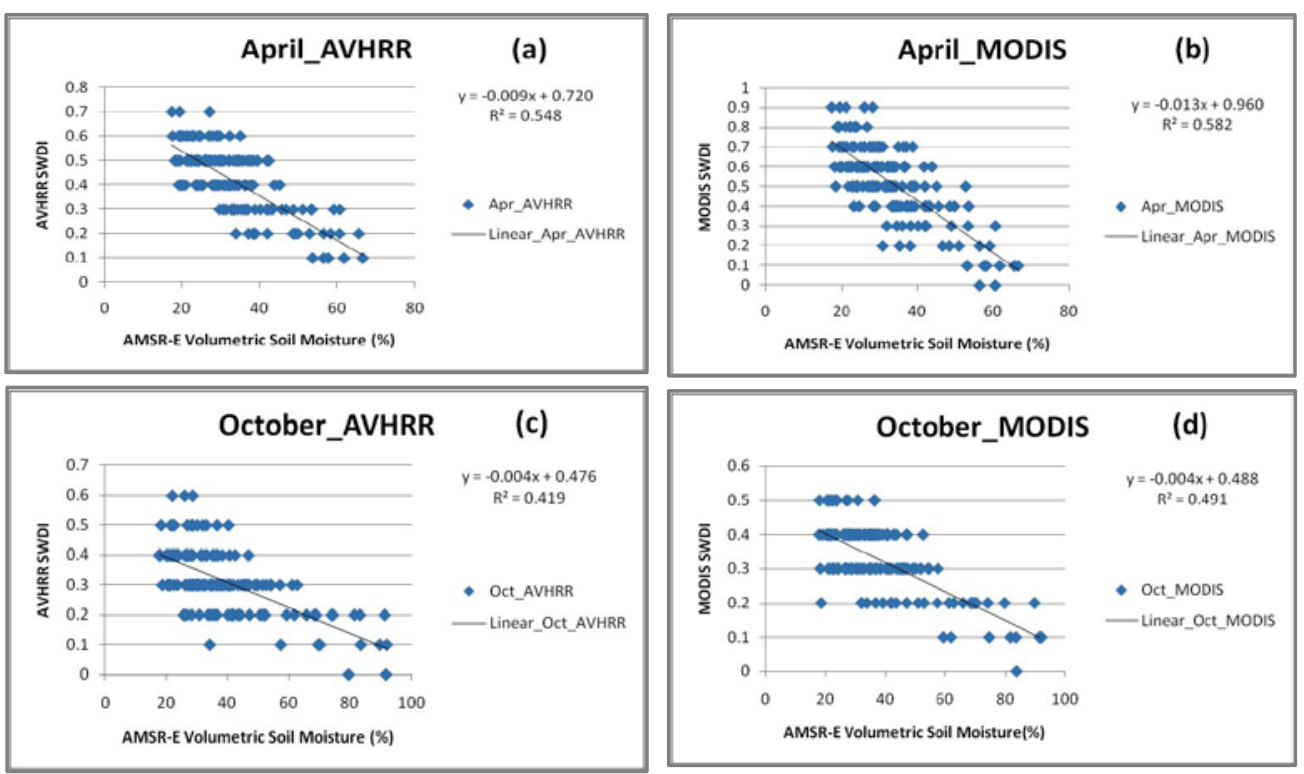

Fig. 4-3 The relationship between the volumetric soil moisture (Unit: $\mathrm{m}^{3} / \mathrm{m}^{3}$ ) and derived SWDI for the study area in April and October.

\subsubsection{Determination of SWDI from AVHRR and MODIS data by using SEBS algorithm}

The SWDI distributions on 14 April, 2003 and 16 October, 2003 are derived from both AVHRR and MODIS images by applying SEBS algorithm (Figure 42 ). The aeolian sand landform usually exists along the river valley and has a patchy distribution which is consistent with derived spatial patterns (Figure 42 ). For the same season, the SWD conditions are much more serious to the southern part of YZR than the northern part.

As seen from Fig. 4-2, the SWD conditions are much more serious on 14 April than 16 October. The dry seasons for YZR and its two tributaries last from November to next April ( $W u$ 1993). The average river runoff during this period is less than $5 \%$ of the annual total, minimum runoff in February $1 \%$ to $2 \%$ of the annual total (Wu 1993). April to J une usually comprises the sowing, germination and tillering agricultural stages which needs large and concentrated quantities of water for successful local spring crop production (Zhong et al. 2011a). The contradiction of less supply and large demand of water resources causes the spring SWD (i.e., water shortage). After the wet period is experienced from June to September, limited to no SWD is experienced in October. That means the April SWD conditions are alleviated by the time of the October image. 
There are differences between AVHRR and MODIS monitoring results. For the same day in spring, these differences are especially obvious. The area with medium soil water deficit $(0.6<\mathrm{SWDI} \leq 0.8)$ and high soil deficit (SWDI $>0.8)$ are much larger in MODIS image (Table 4-1). However, the region with low soil water deficit $(0.4<$ SWDI $\leq 0.6)$ and no soil deficit $(S W D I \leq 0.4)$ are much smaller than that of AVHRR image. The phenomenon manifests that the spring SWD is much more severe in MODIS image. It shows that the SWD conditions may have diurnal change related to diurnal soil moisture variations. This is due to the different satellite overpass time. As shown in Table 3-1, Terra MODIS images are usually acquired in the morning while NOAA-16 images are observed in the afternoon. With the surface temperature rising above zero degree Celsius, the seasonally frozen soil begins to melt and this will increase the soil moisture and alleviate SWD conditions to some extent. However, things are different in autumn. As shown by Table 4-1 and Figure 4-2, the differences between SWDI values derived from AVHRR and MODIS are not as large as they were in spring. The proportions for no soil water deficit (SWDI 0.4$)$, low soil water deficit $(0.4<$ SWDI $\leq 0.6)$, medium soil water deficit $(0.6<$ SWDK 0.8$)$ and high soil water deficit (SWDI $>0.8)$ are $69.8 \%, 18 \%, 9.7 \%$ and $2.5 \%$ respectively, for AVHRR. Those values for MODIS are $71.5 \%, 22 \%, 6.3 \%$ and $0.2 \%$, respectively. As the study area enters season with annual average runoff in October, the soil moisture is not influenced by the melting of seasonally frozen soil. In contrast, the daily SWD conditions in spring are dominated by the natural freeze-thaw diurnal soil moisture patterns.

Table 4-1 The percentage of different SWDI values derived from satellite images

\begin{tabular}{ccccc}
\hline Data & $\begin{array}{c}\text { No soil water } \\
\text { deficit } \\
\text { SWDI } \leq 0.4\end{array}$ & $\begin{array}{c}\text { Low soil water } \\
\text { deficit } \\
0.4<\text { SWDI } \leq 0.6\end{array}$ & $\begin{array}{c}\text { Medium soil } \\
\text { water deficit } \\
0.6<\text { SWDI } \leq 0.8\end{array}$ & $\begin{array}{c}\text { High soil water } \\
\text { deficit } \\
\text { SWDI }>0.8\end{array}$ \\
\hline $\begin{array}{c}\text { AVHRR } \\
\begin{array}{c}14 \text { Apr. 2003 } \\
\text { MODIS }\end{array}\end{array}$ & $61 \%$ & $23.4 \%$ & $14 \%$ & $1.6 \%$ \\
$\begin{array}{c}14 \text { Apr. 2003 } \\
\text { AVHRR }\end{array}$ & $50.2 \%$ & $15.8 \%$ & $17.5 \%$ & $16.5 \%$ \\
$\begin{array}{c}16 \text { Oct. 2003 } \\
\text { MODIS }\end{array}$ & $69.8 \%$ & $18 \%$ & $9.7 \%$ & $2.5 \%$ \\
16 Oct. 2003 & $71.5 \%$ & $22 \%$ & $6.3 \%$ & $0.2 \%$ \\
\hline
\end{tabular}




\subsection{Discussion}

\subsubsection{Comparison from soil moisture perspective}

The mismatch between SWDI and AMSR-E soil moisture are located in different geographic/landscape characteristics. Several reasons may account for poor correlation data points. Firstly, there can be decoupling between AMSR-E signal (responding to the top $5 \mathrm{~cm}$ ) whereas surface-energy-balance measurement can be impacted by transpiration or diffusion of deeper soil water. This can be the causes leading to some discrepancies between surface soil moisture and SEBS derived SWDI as shown in Fig. 4-3. Secondly, the AMSR-E soil moisture has a spatial resolution of $25 \mathrm{~km}$ while that of AVHRR and MODIS is about $1 \mathrm{~km}$. Although the SEBS derived SWDI has been aggregated to $25 \mathrm{~km}$, some information may be lost during this process. Thirdly, it's almost impossible to select cloud-free images for the study area. There are more or less cloud remained in the selected images. Therefore, cloud cover would impact the correlation between SWDI and AMSR-E soil moisture.

Chen et al (2013) pointed out four GLDAS models tend to systematically underestimate the surface soil moisture $(0-5 \mathrm{~cm})$ while well simulating the soil moisture for $10-40 \mathrm{~cm}$ layer. Thus, the soil moisture at $10-40 \mathrm{~cm}$ depth from GLDAS Noah is used to make a comparison with SEBS SWDI. However, all of them show poor correlation between GLDAS soil moisture and SEBS SWDI. As the land surface of TP is heterogeneous ( $M a$ et al. 2011; Ma et al. 2012) and the location of our study area is totally different from that of Chen et al. (2013), this means whether the results from $1^{\circ} \times 1^{\circ}$ can be applied to the whole TP area is questionable. In other words, the accuracy of GLDAS soil moisture at 20-40 cm depth needs more comparison and validation.

\subsubsection{Determination of SWDI from AVHRR and MODIS data by using SEBS algorithm}

The spatio-temporal SWD conditions have been identified by applying SEBS algorithm with satellite data and meteorological data as input data. The derived SWD has a discontinuous and patchy distribution, which is consistent with Li et al. (1999), Dong et al. (1999) and Shen et al. (2012). However, none of the former studies revealed the diurnal and seasonal SWD variations with different satellite sensors which have similar spatial resolution. Application of both AVHRR and MODIS data provides new insights into the situation of SWD on the same day. They can also be validated by each other to some extent. Some human activities may account for the SWD in the study area. The YZR and its two tributaries are the activity center of the Tibetan people and local cultivated land is mainly in the valley. Local population has doubled since 1950s (Shen et al. 2012). As the orientation of 
the river valley is nearly parallel to the wind direction, the mountainous terrains greatly rise the wind velocity. Thus, the YZR valley has favorable environmental conditions that are necessary for the development of aeolian sand landforms. With the impact of excessive use of valley land and special terrain and vegetation conditions, the land desertification trend has become increasing serious (Shen et al. 2012). The bare sand area including migratory dune cover about 112,000 hectares which is almost equivalent to two-thirds of the arable land in YZR and its two tributaries. Besides, natural factors (such as the arid and windy climate, sparse vegetation conditions, and abundant surface sand source) are also important driving forces for the SWD (Dong et al. 1999; Shen et al. 2012).

In the past decades, different satellite based approaches were established to monitor soil water deficit or drought conditions. Examples are the use of vegetation indices (Gutman 1990; Gosh 1997), land surface temperature (Kalma et al. 2008; Kogan 1997), a combination of both (Kogan 1995; McVicar and Jupp 1998), the microwave backscatter signal (Zhang and Jia 2013), or energy balance models with remote sensing data and meteorological data as the input data (Niemeyer and Vogt 1998; Kalma et al. 2008). However, the most common satellite based indicators like NDVI, Vegetation Condition Index ( VCl) and Temperature Condition Index ( $\mathrm{TCl}$ ) are difficult to interpret in heterogeneous terrain (Niemeyer and Vogt, 1998). Although the energy balance models have distinct physical mechanism, fixed values are used for the roughness height for heat transfer in most models. In fact, the roughness height for heat transfer can vary in several orders of magnitude for large scale heterogeneous surfaces (Su et al. 2003). A model for the determination of the roughness length for heat transfer has been built in SEBS. Therefore, SEBS derived SWDI have great advantages than other methods in determination of soil water stress for large-scale heterogeneous study areas. It should be noted that some similarities exist between SWDI and NDTI. Both indexes are based on energy balance at limiting cases. There are also some differences. For the SWDI, a model for the determination of the roughness length for heat transfer over heterogeneous land surface is applied for the determination of sensible heat flux. This is not found in NDTI.

\subsection{Conclusion}

From the surface energy balance perspective, the surface SWD conditions for YZR and its two tributaries in spring and autumn have been monitored from both the AVHRR and MODIS data on the same day by applying the SEBS algorithm. Firstly, remote sensing products of LST, surface albedo, NDVI, LAI and emissivity in the middle reaches of $Y Z R$ and its two tributaries have been derived from AVHRR and MODIS data. Together with conventional meteorological data from nine stations as the input data, the SWDI are then 
derived from SEBS algorithm. The indices were compared against volumetric soil moisture status retrieved from AMSR-E data. The results showed that the SWDI from both satellites was capable of detecting SWD over regional scales, and indicated overall consistent patterns in space and time for YZR and its two tributaries. The main conclusions can be summarized as follows:

(1) Through comparison with microwave remote sensing soil moisture data, the spatio-temporal variations of SWDI are found to have inverse correlation with soil moisture status. On the other hand, the intercomparison between AVHRR and MODIS results on the same day also confirms the validity of the SWD monitoring method in the study area. Although the SWD patterns derived from both satellites on the same day show some similar properties, there are some differences between them. These differences are especially obvious in spring with much more severe SWD happening in MODIS image. This is due to the different satellite overpass time and the resulting melting of frozen soil. The results of this study also illustrate that in landscapes SWD conditions may change diurnally, exhibit freeze-thaw processes, which is consistent with diurnal soil moisture variations.

(2) The derived SWDI show a south-high and north-low spatial patterns and the severe SWD usually occurs along the river valley and has a patchy distribution. Satellite SWD monitoring proved that local crops are experiencing severe spring SWD. Furthermore, the SWD conditions are much more serious on 14 April than 16 October. The contradiction of less supply (low river runoff) and large demand of water resources cause the spring SWD.

Our results demonstrated the potential of remote sensing based approaches to monitor SWD in the TP area: a harsh and challenging environment. However, the coarse spatial resolution of AMSR-E data and the different satellite overpass time for microwave and optical remote sensing data led to some discrepancies between SWDI and soil moisture values. Although nine meteorological stations locate in the study area, there is no observation for soil moisture. Establishing more comprehensive observation stations for the in-situ validation is urgently needed. 


\section{Chapter 5}

\section{Assessment of Vegetation Dynamics and Their Response to Variations in Precipitation and Temperature in the Tibetan Plateau}

\footnotetext{
${ }^{*}$ This chapter is based on

Zhong, L., Y. Ma, M. S. Salama, and Z. Su, 2010, Assessment of vegetation dynamics and their response to variations in precipitation and temperature in the Tibetan Plateau. Climatic Change, 103: 519-535.
} 


\section{ABSTRACT}

The Tibetan Plateau is a region sensitive to climate change, due to its high altitude and large terrain. This sensitivity can be measured through the response of vegetation patterns to climate variability in this region. Time series analysis of Normalized Difference Vegetation Index (NDVI) imagery and correlation analyses are effective tools to study land cover changes and their response to climatic variations. This is especially important for regions like the Tibetan Plateau, which has a complex ecosystem but lacks a lot of detailed in-situ observation data due to its remoteness, vastness and the severity of its climatic conditions. In this research a time series of 315 SPOT VEGETATION scenes, covering the period between 1998 and 2006, has been processed with the Harmonic ANalysis of Time Series (HANTS) algorithm in order to reveal the governing spatiotemporal pattern of variability. Results show that the spatial distribution of NDVI values is in agreement with the general climate pattern in the Tibetan Plateau. The seasonal variation is greatly influenced by the Asian monsoon. Interannual analysis shows that vegetation density (recorded here by the NDVI values) in the entire Tibetan Plateau has generally increased. Using a $1 \mathrm{~km}$ resolution land cover map from GLC2000, seven meteorological stations, presenting monthly data on near surface air temperature and precipitation, were selected for correlation analysis between NDVI and climate conditions in this research. A time lag response has also been found between NDVI and climate variables. Except in desert grassland (Shiquanhe station), the NDVI of all selected sites showed strong correlation with air temperature and precipitation, with variations in correlation according to the different land cover types at different locations. The strongest relationship was found in alpine and subalpine plain grass, the weakest in desert grassland.

Keywords: Spot vegetation, HANTS, GLC2000, Responses, the Tibetan Plateau 


\subsection{Introduction}

There is compelling evidence to suggest that strong interactions between terrestrial ecosystems and climate variability exist (Cao and Woodward 1998; Pielke et al. 1998). Climate change affects the existence of the ecosystem and its evolution. On the other hand, land ecosystems can influence the climate system through various physical, physiological, and chemical feedback processes (Zhou et al. 2007). As a matter of fact, it has been reported that changes in terrestrial vegetation can modify local, regional, and global climate at a diurnal, seasonal, and long-term scale (Kaufmann et al. 2003). Vegetation is regarded as an intermediate link in the pedosphere, atmosphere and hydrosphere of the earth's system. Therefore, monitoring vegetation dynamics and analyzing their relationship with climate variability is becoming an important aspect of global climate change research (Rees et al. 2001).

The unique ecological environments of the Tibetan Plateau have survived under extreme geographical and climatic conditions. The Tibetan Plateau is a sensitive region in terms of climate change and is also known to be an ecologically fragile region. On the other hand, the Tibetan Plateau has an important feedback effect on the climate system of China, East Asia and even the globe (Wang 2006). Due to the unique landscape and lack of human activity, it is often regarded as the 'natural laboratory' for analyzing climate change (Zhou et al. 2007).

Remote sensing provides an effective tool for monitoring surface parameters of a large and complex ecosystem like the Tibetan Plateau (e.g. Wen and Su 2004; Ma et al. 2006; Oku et al. 2007; Zhong 2007). Amongst remotely sensed surface parameters, the Normalized Difference Vegetation Index (NDVI), defined below, is widely used as an indicator of vegetation growth status, spatial density distribution and phenology of vegetation.

$$
N D V I=(N I R-\operatorname{Re} d) /(N I R+\operatorname{Re} d)
$$

where, NIR and Red are the surface reflectance in the infrared and red spectral regions, respectively.

Satellite data have been increasingly used to link vegetation indices to climatic parameters (Roerink et al. 2003). Since the 1980s, a number of analyses have explored the relationship between NDVI and climate factors in different geographic areas and ecosystems. Most of these studies have used NDVI derived from the Advanced Very High Resolution Radiometer (AVHRR) for study at national or global scale (e.g. Azzaliand Menenti 2000; Zhou et al. 2001; GurgelandFerreira 2003; Roerink et al. 2003; Piao et al. 2006). Although such information is appropriate for large scale analysis, due to its 
long time series, it has coarse spatial resolutions, which are inappropriate for resolving the regional spatial variations. On the contrary, SPOT-4 and SPOT- 5 satellites provide improved spatial and temporal resolution, which facilitate the detection of vegetation response to climate changes at a regional scale (Immerzeel et al. 2005). Furthermore, climate variability has a large heterogeneous impact on the ecosystem, i.e. the impact is not the same for every region and for every type of land cover (Roerink et al. 2003).

Scientific research on vegetation response to climatic conditions in the Tibetan Plateau is rather scarce. This research chapter is a first step towards filling this gap. Based on the SPOT VEGETATION data and in-situ meteorological data from the China Meteorological Administration (CMA), this research aims to quantify the spatial and temporal response of vegetation dynamics to climate variability in the Tibetan Plateau. Since NDVI images are often influenced by clouds and other conditions unfavorable for observation (large viewing angles, atmospheric haze, etc.), reconstructing a cloud free NDVI time series would be the first preprocessing step to facilitate the analysis of vegetation response to climate conditions in the Tibetan Plateau.

Firstly, this chapter focuses on reconstructing a NDVI time series by applying the Harmonic ANalysis of Time Series (HANTS) algorithm (Verhoef 1996). The seasonal cycle, interannual development of NDVI and comparison between reconstructed NDVI and original data will be shown. Secondly, seven different meteorological stations with different land cover types will be used for correlation analysis between NDVI and climate variables (air temperature and precipitation) in order to find the response of different vegetation types to climate fluctuations in the Tibetan Plateau.

\subsection{Material and Methods}

\subsubsection{Study area}

The Tibetan Plateau, located in southwest China, extends over the latitudelongitude domain of $26-40^{\circ} \mathrm{N}, 73-105^{\circ} \mathrm{E}$, has a size of about one-quarter of the Chinese territory and a mean elevation of more than $4000 \mathrm{~m}$ above sea level (Fig. 1-1). Surface elevation changes rapidly across the boundaries of the Plateau (especially at the southern boundary) and strong contrasts exist between the western and eastern parts in terms of land surface features, vegetation, and meteorological characteristics (e.g. Ye and Gao 1979; Smith and Shi 1995). The general climate conditions in the Tibetan Plateau are characterized by strong solar radiation, low air temperature, high daily temperature differences and low annual temperature differences. However, due to the influence of the Asian monsoon, there is a clear demarcation between the dry and rainy season. As such, about $90 \%$ of the total 
precipitation falls in the rainy season and average air temperature ranges

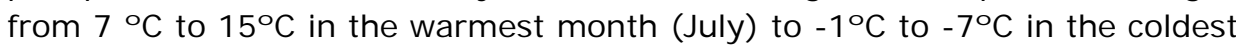
month (January). A decreasing trend in both temperature and precipitation has also been observed from the south-east to the north-west (Immerzeel et al. 2005).

\subsubsection{Datasets}

The NDVI data were obtained from 1998 to 2006, using SPOT VEGETATION products. The VEGETATION programme has been developed jointly by France, the European Commission, Belgium, Italy and Sweden, and was formed in order to allow daily monitoring of terrestrial vegetation cover through remote sensing from regional to global scales. The instruments and associated ground services for data archival, processing and distribution have been operational since April 1998. Each ten-day synthesis (S10) was obtained through the compilation of the daily syntheses of ten consecutive days. They were computed using all passes acquired at each location during 10 day periods. The periods were defined as from the 1st to the 10th, from the 11th to the 20th, and from the 21st to the end of each month. 10-Day syntheses were generated with the 'best' measurement for the entire period, i.e. the maximum NDVI value. The $1 \mathrm{~km}$ spatial resolution was nearly constant across the whole $2,250 \mathrm{~km}$ swath covered, which meant that there was almost no distortion at the image edge (Maisongrande et al. 2004).

The land cover map of the Tibetan Plateau was obtained from the global land cover database for the year 2000 (GLC 2000)(Fig. 5-1). GLC 2000 contains two levels of land cover information, namely: regionally optimized land cover legends for each continent and a less thematically detailed global legend that harmonizes regional legends into one consistent product. The land cover map with regionally optimized land cover legends was used in this research. There were twenty-one vegetation types scattered throughout the Tibetan Plateau (see Fig. 5-1 and Fig 5-2) in total. The three dominant land cover types were: alpine and subalpine meadow, alpine and subalpine plain grass and desert grassland, which made up $28 \%, 23 \%$ and $11 \%$ of the total landscape, respectively (Fig. 5-2). 
Table 5-1 The selected meteorological stations with their corresponding land cover types

\begin{tabular}{|c|c|c|c|c|}
\hline Station & Longitude(우) & Latitude(우) & Altitude(m) & Land cover \\
\hline Shiquanhe & 80.08 & 32.5 & 4278 & Desert grassland \\
\hline Dangxiong & 91.1 & 30.48 & 4274 & $\begin{array}{l}\text { Alpine and subalpine } \\
\text { meadow }\end{array}$ \\
\hline Linzhi & 94.33 & 29.67 & 2990 & $\begin{array}{l}\text { Evergreen needleleaf } \\
\text { forest }\end{array}$ \\
\hline Chaqia & 99.08 & 36.78 & 3088 & Meadow \\
\hline Maduo & 98.22 & 34.92 & 4272 & $\begin{array}{l}\text { Alpine and subalpine plain } \\
\text { grass }\end{array}$ \\
\hline Jiulong & 101.5 & 29 & 3987 & Slope grassland \\
\hline Tuotuohe & 92.43 & 34.22 & 4533 & Plain grassland \\
\hline
\end{tabular}

Monthly data from ninety-one meteorological stations distributed in the Tibetan Plateau were obtained from the Chinese National Meteorological Centre. The data included monthly mean surface air temperature and monthly total precipitation. The variability of NDVI with respect to the climate was analyzed using seven different meteorological stations. These stations were selected to represent the seven major land cover types in the Tibetan Plateau (Table 5-1). The stations, located at different altitudes, covered a large portion of the Tibetan Plateau from south to north and from east to west. Note that meteorological stations over other land cover types, such as broadleaf forest, farmland, and deciduous needleleaf forest were not available for this study. 


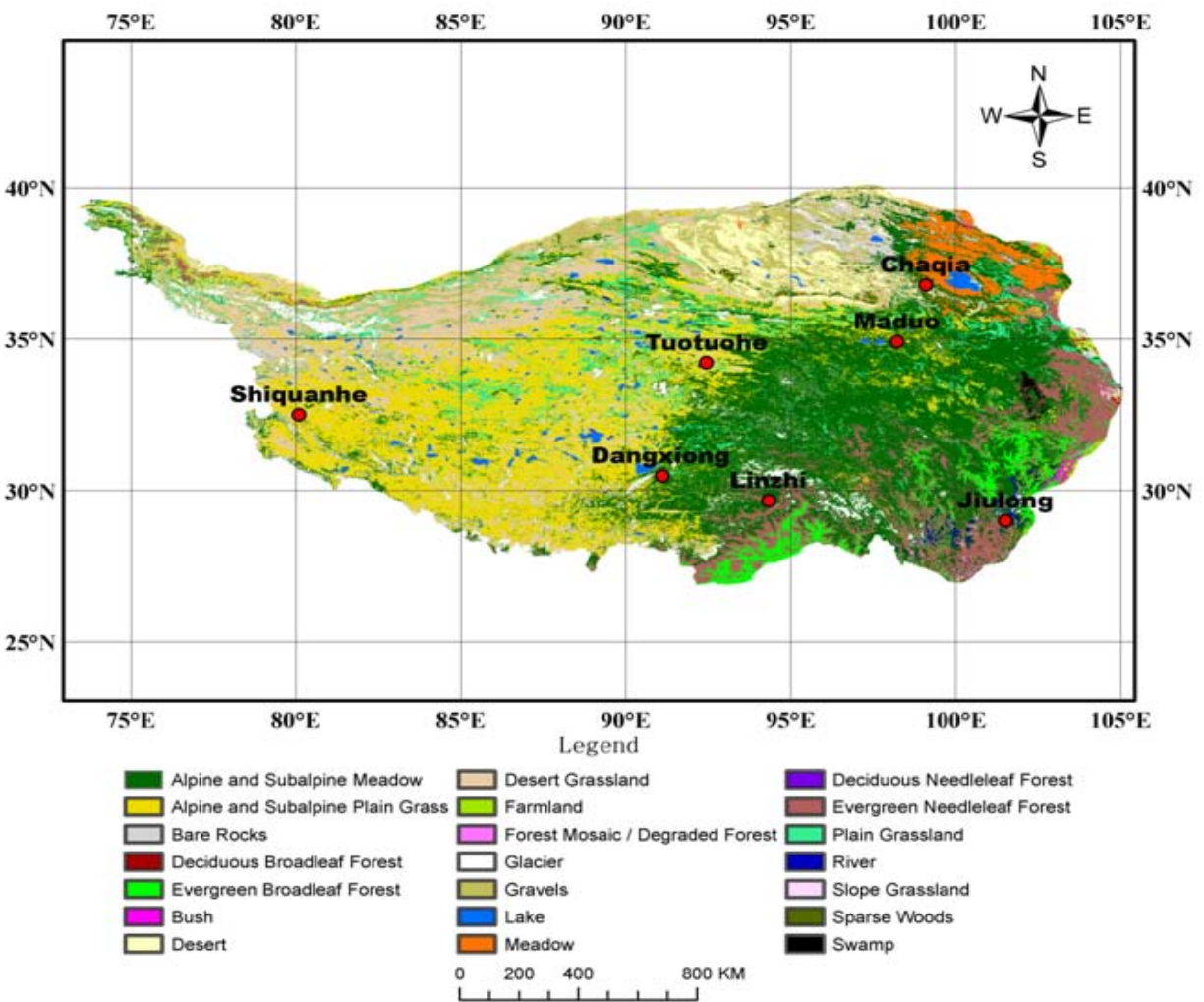

Fig. 5-1 Map of vegetation cover types in the Tibetan Plateau

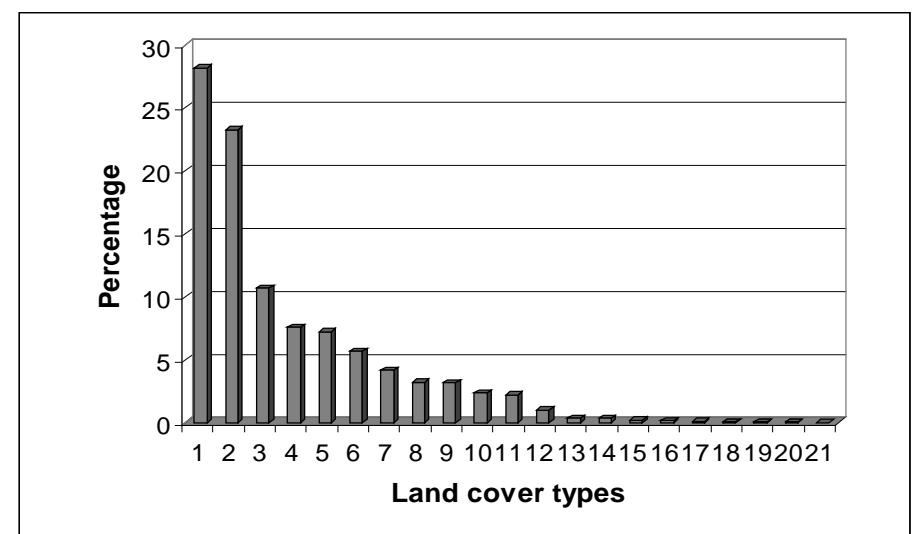

Fig. 5-2 Proportions of land cover in the Tibetan Plateau (1 Alpine and Subalpine Meadow, ASM; 2 Alpine and Subalpine Plain Grass, ASPG; 3 Desert Grassland, DG; 4 Evergreen Needleleaf Forest, ENF; 5 Gravels, Gr; 6 Plain Grassland, PG; 7 Bare Rocks, BR; 8 Desert, D; 9 Glacier, Gl; 10 Meadow, M; 11 Evergreen Broadleaf Forest, EBF; 12 Lake, L; 13 Farmland, F; 14 River, R; 15 Slope Grassland, SG; 16 Swamp, S; 17 Bush, B; 18 Sparse Woods, SW; 19 Deciduous Broadleaf Forest, DBF; 20 Deciduous Needleleaf Forest, DNF; 21 Forest Mosaic/ Degraded Forest, FM/ DF) 


\subsubsection{HANTS algorithm}

Cloud cover on satellite images is a tremendous problem with respect to the application of optical remote sensing in monitoring land surface properties. Fortunately, several methods have been developed to remove cloud cover. For instance, Maximum Value Composition (MVC) can be applied to derive reasonable NDVI values and has been used in research on vegetation dynamics (Holben 1986; Myneni et al. 1997). Nevertheless, experience has shown that artifacts, related to residual cloud cover and atmospheric haze, remain visible in MVC-processed time series (Verhoef et al. 2005). The Fourier Transform is another method, which can be used to remove cloud contamination by curve-fitting, using observational samples in a finite discrete time series. However, one problem is that observations must be relatively error free and equidistant in time (Menenti et al. 1993). To overcome this problem, the HANTS (Verhoef 1996) algorithm has been developed. In the HANTS algorithm, invalid data are removed by associating them with a weighting function of zero, changing the original curve-fitting problem into a weighted least squares curve fitting process. The smooth curve the data are aligned with, is described by means of an average value plus a short series of harmonic (cosine) functions, each of which is defined by its amplitude and phase. As the HANTS algorithm is superior to the other two methods, it has been adopted in our research to reconstruct gapless time series of NDVI. The HANTS algorithm can also be applied to time series analysis of other surface parameters like surface albedo, temperature and evapourative fraction (Su et al. 2001; Wen et al. 2004; Julien et al. 2006).

\subsection{Results}

\subsubsection{Validation of HANTS algorithm}

Due to the Tibetan Plateau's very high elevation and convective weather conditions, it was almost impossible to get any cloud free NDVI images covering the whole area. Therefore, the first step was to reconstruct NDVI images without cloud contamination. A total of 315 SPOT VEGETATION S10 images (from April 1998 to December 2006) have been processed with the HANTS algorithm for each year separately. The results were validated using two validation sites: Maduo(98.217으, $\left.34.917^{\circ} \mathrm{N}\right)$ and Chaqia(99.083으, $\left.36.783^{\circ} \mathrm{N}\right)$, located over meadow, and alpine and subalpine plain grass, respectively. The original NDVI data were generated with the MVC method and suffered cloud contamination as depicted by the bars in Figure 5-3. Also, note that there were some extremely low NDVI values in summer. For Maduo, there was a sudden decrease in NDVI from day 160 to 170 and day 220 to 240 (Fig. 5-3a). This also occurred in Chaqia between day 220 and 230 (Fig. $5-3 b)$. Since it is unlikely that the surface vegetation would change at such a rapid rate during that season, it was concluded that these images must be all 
contaminated by clouds. However, after being processed by the HANTS algorithm, the seasonal curve of the NDVI became smoother, as shown by the curves in Figure 5-3, as the NDVI gaps were filled with newer values. However, it should be emphasized that the use of the HANTS algorithm implies that the NDVI is a smooth and continuous function of time, i.e. a sudden decrease in NDVI values is attributed to cloud contamination. Using the HANTS algorithm to smooth the NDVI time series may also accidentally remove abrupt changes. Some abrupt changes could be characteristic for an ecosystem collapse caused by external pressures (e.g. fire or drought). In fact, the actual signals are not purely periodic, but yet the periodic model can be applied successfully, because it allows one to obtain more insight into the dynamics of land surface processes. Moreover, the use of a long time series of land cover and metrological parameters will facilitate detecting the changes in prominent patterns with relation to climate conditions.
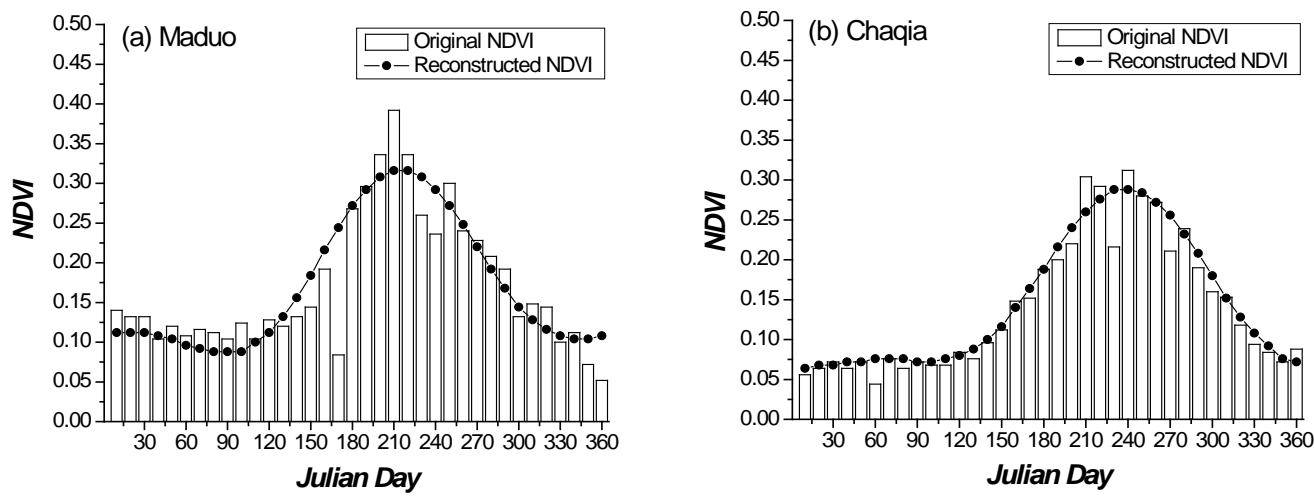

Fig. 5-3 Comparison of original and reconstructed NDVI (Maduo: 98.2170E, $34.917 \circ \mathrm{N}$, alpine and subalpine plain grass; Chaqia: $99.083^{\circ} \mathrm{E}, 36.783^{\circ} \mathrm{N}$, meadow)

\subsubsection{Spatial, seasonal and inter-annual changes in NDVI}

Based on the NDVI images processed by the HANTS algorithm, a clear seasonal NDVI cycle has been derived (see Fig. 5-4). Under the influence of the Asian monsoon, the rainy season began in May. From then on the vegetation started to grow, leading to an increase in the green area and a maximum NDVI value in August. In the post-monsoon period, the green area started to shrink and NDVI values tended to decrease gradually. Figure 5-4 shows that the vegetation cover was relatively high in the southeastern part of the Plateau. It reflects the fact that the climate was warm and wet in this region. On the other hand, the vegetation growth in the northwestern region was limited, resulting in a low NDVI value, which indicates that this region was very cold and dry. On average, for the whole Tibetan Plateau area, the duration of sunshine increased together with air temperature and 
precipitation from May to August. Accordingly, NDVI increased from 0.15 to 0.28. After that, the NDVI tended to decrease to 0.15 in December (Fig. 5-5). Note that the mean NDVI value for the Tibetan Plateau was about 0.19.

To investigate inter-annual change in NDVI, a tendency correlation analysis was applied to study the geographically dependent behaviour of the plateau NDVI (Xu 2004). Herein, the tendency correlation was evaluated by the correlation coefficient $r_{x t}$ between NDVI and time.

$$
r_{x t}=\frac{\sum_{i=1}^{n}\left(x_{i}-\bar{x}\right)(i-\bar{t})}{\sqrt{\sum_{i=1}^{n}\left(x_{i}-\bar{x}\right)^{2} \sum_{i=1}^{n}(i-\bar{t})^{2}}}
$$

where $\mathrm{n}$ is the total number of years (9), $x_{i}$ is the NDVI value in the ith

year, and $\bar{x}=\frac{1}{n} \sum_{i=1}^{n} x_{i}, i=1,2,3, \ldots, n ; \bar{t}=\frac{1}{n} \sum_{i=1}^{n} i$

When $r_{x t}$ is positive (negative), the NDVI tends to increase (decrease) linearly.

The results are presented in Table 5-2. Non-vegetation land cover types, such as desert, glacier, gravels etc., were not included in this table. In general, vegetation activity was enhanced from 1998 to 2006 . NDVI increased in $49.87 \%$ of the total Plateau territory, while about $29.86 \%$ of the total area showed a decrease. The inter-annual variability was different for the various land cover types. The largest increase in NDVI (10.45\%) was found in alpine and subalpine plain grass, which is the second most common vegetation type on the Tibetan Plateau. The main land cover type (alpine and subalpine meadow) was second on the list of NDVI increases (2.45\%). Of all the land cover types, only deciduous needleleaf forest showed a decrease in NDVI. Since the Tibetan Plateau is hardly influenced by anthropogenic activities (e.g. overgrazing and deforestation) the changes in vegetation density are closely related to climate variation in the Tibetan Plateau. However, the climate variation in the Tibetan Plateau itself is a complicated issue. The Plateau's warming trends have been reported in many scientific publications (Liu et al. 2006; Zhang et al. 2006; You et al. 2008). The influences of the Tibetan Plateau warming trend are two-folds. On the one hand, the increasing temperature will prolong the growing period of vegetation. On the other hand, the temperature increasing trend will also exacerbate the demand of vegetation for water. Therefore, under such circumstance, the vegetation condition will deteriorate if the regional 
precipitation decreases. However, trends concerning the overall precipitation for the whole Tibetan Plateau remain unclear. These trends could harbor fundamental reasons for an increase or decrease in NDVI and require further investigation in future studies.

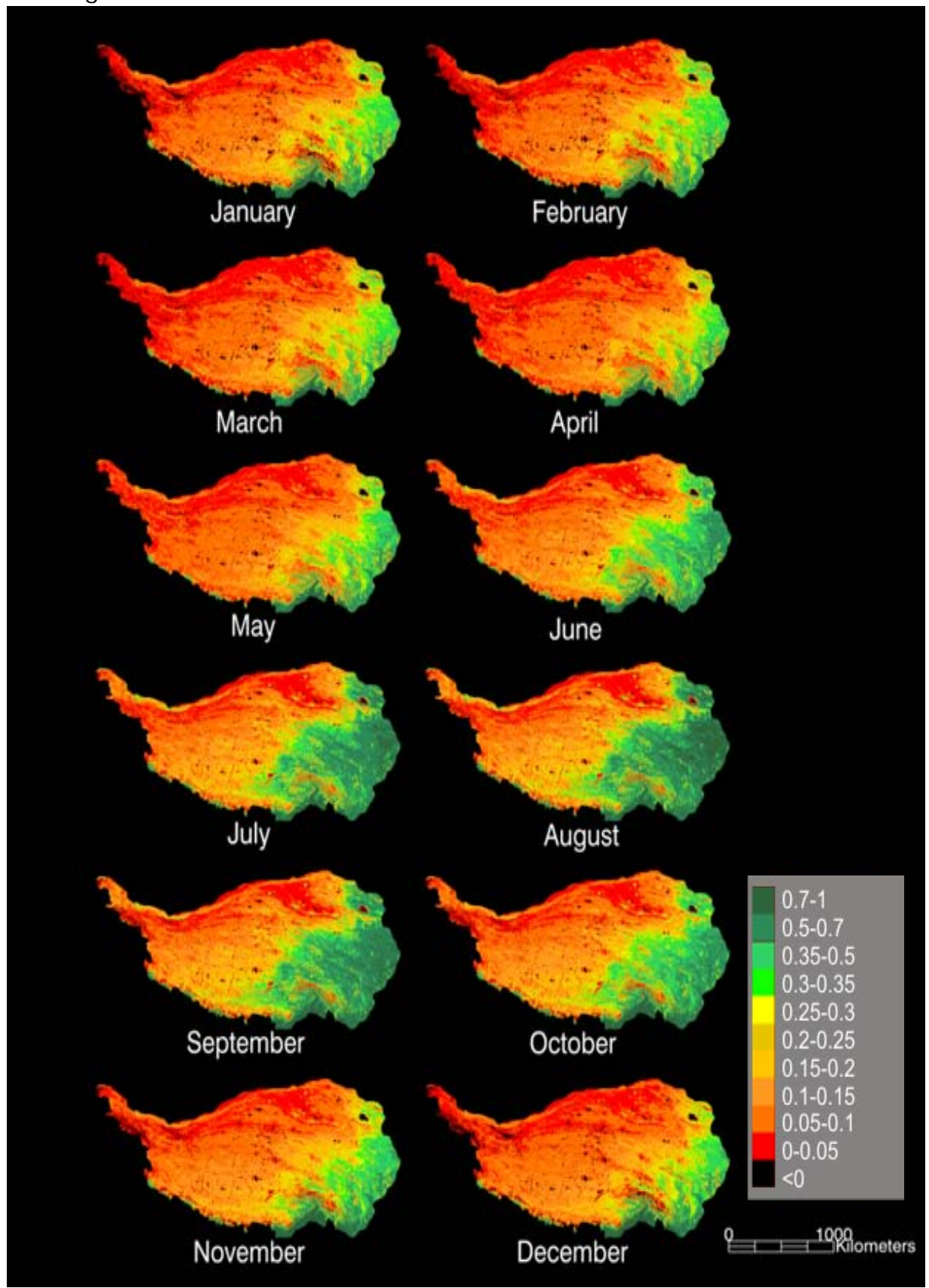

Fig. 5-4 Average seasonal mean NDVI variations in the Tibetan Plateau 


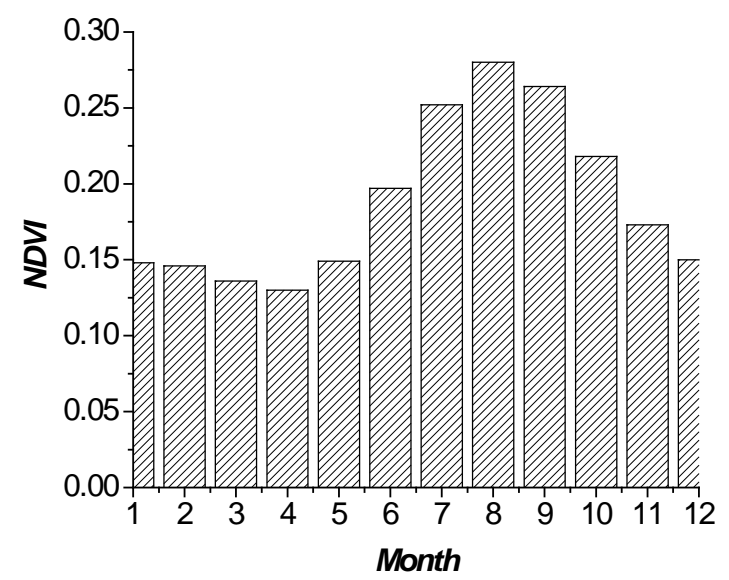

Fig. 5-5 Reconstructed time series of NDVI in the Tibetan Plateau

Table 5-2 I nterannual NDVI variation trend for different land cover types from 1998 to 2006

\begin{tabular}{cccc}
\hline Land covers* & Proportion of increasing & Proportion of decreasing & Difference \\
\hline ASPG & 16.69 & 6.24 & 10.45 \\
ASM & 15.2 & 12.75 & 2.45 \\
ENF & 4.62 & 2.9 & 1.72 \\
DG & 6.02 & 4.37 & 1.65 \\
PG & 3.6 & 1.98 & 1.62 \\
EBF & 1.66 & 0.54 & 1.12 \\
M & 1.5 & 0.86 & 0.64 \\
F & 0.26 & 0.11 & 0.15 \\
SG & 0.16 & 0.05 & 0.11 \\
B & 0.1 & 0.01 & 0.09 \\
SW & 0.03 & 0.02 & 0.01 \\
DBF & 0.02 & 0.01 & 0.01 \\
DNF & 0.01 & 0.02 & -0.01 \\
Total & 49.87 & 29.86 & 20.01 \\
\hline
\end{tabular}

*abbreviations as in Fig. 5-2

\subsubsection{NDVI development in different land cover types and its response to climate variables}

In order to find relationships between NDVI and meteorological data, NDVI values at the pixel nearest to each surface station listed in Table 5-1 were selected, as shown in Figure 5-6. All seven sites had a clear NDVI seasonal cycle. The vegetation density at Jiulong and Linzhi was relatively high, because the climatic conditions were much warmer and wetter than at the other sites and the elevation of these two sites was relatively low. The average NDVI values for these two sites were 0.6 and 0.56 , respectively 
(Table 5-3). Furthermore, the vegetation at these two sites started to grow in about April, or about one month earlier than at the other five sites. They all reached a maximum value in August, which may mean the growing season at Jiulong and Linzhi is one month longer than at the other sites. For the Tuotuohe and Shiquanhe sites, the vegetation density was lower because of their very high elevation (Tuotuohe4533 m, Shiquanhe4278 m) and cold and dry climate conditions. The maximum NDVI value at these two stations was not more than 0.1 during the whole year. The Dangxiong site had the largest range in annual NDVI. The second largest was at Maduo, followed by Linzhi, Jiulong, Chaqia, Tuotuohe and Shiquanhe, respectively.

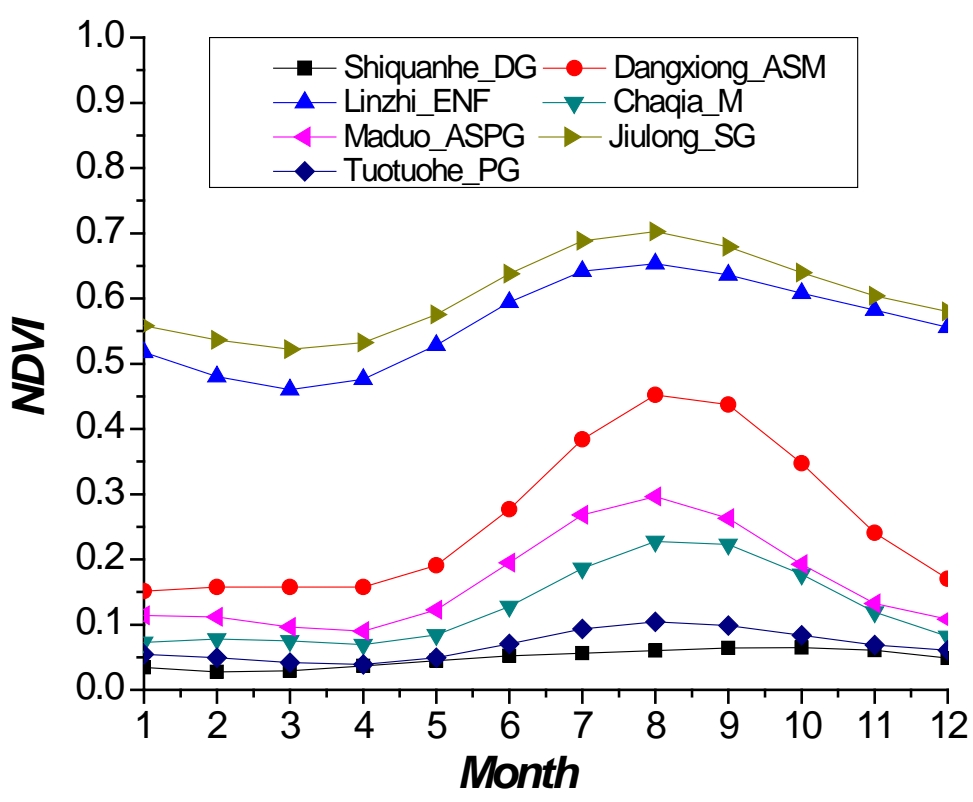

Fig. 5-6 Comparison of seasonal NDVI variations for different land cover types (land cover abbreviations as in Fig. 5-2)

Table 5-3 Monthly maximum, minimum, difference between the maximum and minimum, and average NDVI values for different land cover types (land cover abbreviations as in Fig. 5-2)

\begin{tabular}{llllllll}
\hline NDVI & $\begin{array}{l}\text { ASM } \\
\text { (Dangxiong) }\end{array}$ & $\begin{array}{l}\text { ASPG } \\
\text { (Maduo) }\end{array}$ & $\begin{array}{l}\text { ENF } \\
\text { (Linzhi) }\end{array}$ & $\begin{array}{l}\text { SG } \\
\text { (Jiulong) }\end{array}$ & $\begin{array}{l}\text { M } \\
\text { (Chaqia) }\end{array}$ & $\begin{array}{l}\text { PG } \\
\text { (Tuotuohe) }\end{array}$ & $\begin{array}{l}\text { DG } \\
\text { (Shiquanhe) }\end{array}$ \\
\hline Maximum & 0.45 & 0.3 & 0.65 & 0.7 & 0.23 & 0.1 & 0.06 \\
Minimum & 0.15 & 0.09 & 0.46 & 0.52 & 0.07 & 0.04 & 0.03 \\
Average & 0.26 & 0.17 & 0.56 & 0.6 & 0.13 & 0.07 & 0.05 \\
Max-Min & 0.3 & 0.21 & 0.19 & 0.18 & 0.16 & 0.06 & 0.03 \\
\hline
\end{tabular}


Figure 5-7 shows the different relationships between four vegetation types and climate variables (precipitation and temperature). The figures for the other three vegetation types are not shown, because their characteristics matched one of the four other types (e.g. Linzhi and Jiulong; Shiquanhe and Tuotuohe; Chaqia and Maduo). The response of the different vegetation types to climate variability in the area could mainly be attributed to the Asian monsoon. The Asian monsoon usually started in May, bringing the first rain. The air temperature rose above $0^{\circ} \mathrm{C}$ and kept on increasing, almost in time with the monsoon's breakout. All these factors promoted vegetation growth from May onwards. After the start of the rainy season, both temperature and NDVI values increased, and then decreased again towards the end of the rainy season. Slope grassland (Jiulong) and evergreen needleleaf forest (Linzhi), however, followed a different trend. At these two stations, the rainy season started in April and the air temperature stayed above $0^{\circ} \mathrm{Call}$ year round. NDVI increased from May onwards, and reached a maximum around August. A common time lag of one month between temperature and NDVI can be found in Figure 5-7. For all land cover types, NDVI reached its maximum one month later than the temperature did. But the lag between precipitation and NDVI was more complicated. There was a two-month lag for slope grassland while the one-month lag existed for the land cover types: plain grassland, alpine and subalpine plain grass and meadow. No time lag was found for other land cover types. The relationships between monthly NDVI and the climate variables (temperature and precipitation), were assessed by performing correlation analyses. Pearson correlation coefficients were calculated for each of the selected stations (Table 5-4). Over the course of nine years, in total 108 samples from 108 different months were used to calculate the correlation coefficients. Different land cover types showed different strengths in correlation between NDVI and climate variables. In desert grassland (Shiquanhe station), the small amount of precipitation ( 80.5 $\mathrm{mm}$ ) occurring during a whole year greatly limited vegetation growth (Table 5-5). The low air temperature there (annual mean temperature $1.65^{\circ} \mathrm{C}$ ) was another limiting factor. Therefore, correlation was very weak and the vegetation hardly grew, even in the growing season. For the other land cover types, there was a strong correlation between NDVI and climate parameters. Our results did not support previous analysis, which suggested that vegetation variability in the Tibetan Plateau might be mainly driven by thermal impacts, with the impact of precipitation being less clear (Zhou et al. 2007). Zhou et al. (2007) examined the vegetation-climate correlation by comparing GIMMS NDVI values with time series of temperature and precipitation from 56 meteorological stations over the entire Plateau. Their study was performed on coarse temporal (yearly mean) and spatial $\left(0.25^{\circ} \times 0.25^{\circ}\right)$ scales and did not consider the variation of land cover. The coarse spatial and temporal resolutions of NDVI and meteorological observations hindered resolving the fine-scale variability of land cover as 
response to metrological forcing. Our results further showed no strong relationship in either the evergreen needleleaf forest or the slope grassland, which have plenty of rain with relatively high air temperatures. On the other hand, alpine and subalpine plain grass had correlation coefficients of more than 0.7 for precipitation and temperature. This suggests that climate variables in alpine and subalpine plain grass area were the main limiting factors for vegetation growth, whereas evergreen needleleaf forest and slope grassland area were less influenced by the variability in temperature and precipitation. 

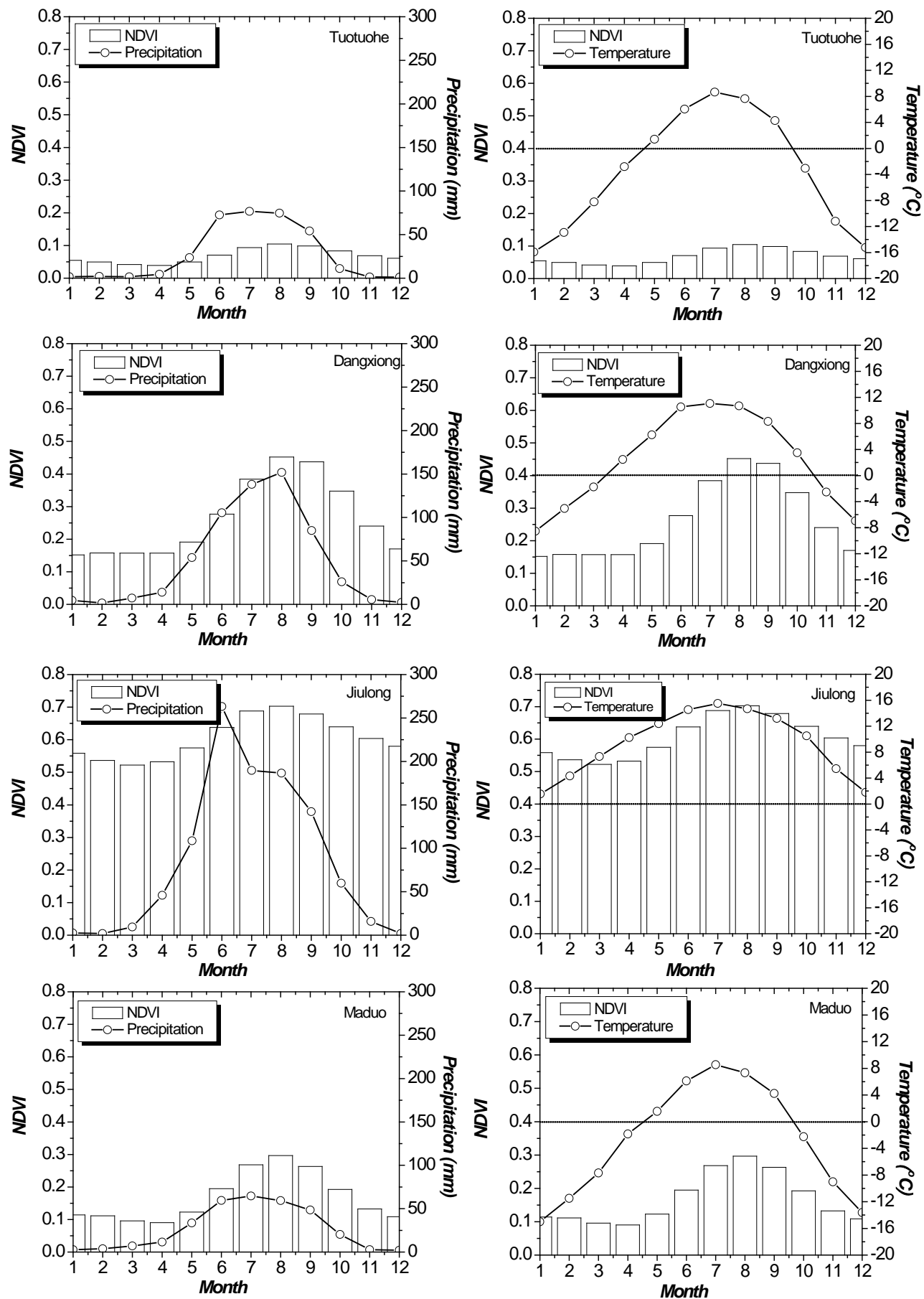

Fig. 5-7 Changes in seasonal NDVI, precipitation and temperature at different vegetation types 
Table 5-4 Correlation coefficients of NDVI versus precipitation (P) and NDVI versus temperature $(T)$ of different vegetation types

\begin{tabular}{lll}
\hline Vegetation types & NDVI vS P & NDVI VS T \\
\hline Desert grassland (Shiquanhe) & 0.168 & 0.482 \\
Alpine and subalpine meadow (Dangxiong) & 0.698 & 0.711 \\
Evergreen needleleaf forest (Linzhi) & 0.543 & 0.561 \\
Meadow (Chaqia) & 0.592 & 0.607 \\
Alpine and subalpine plain grass (Maduo) & 0.769 & 0.745 \\
Slope grassland (J iulong) & 0.534 & 0.485 \\
Plain grassland (Tuotuohe) & 0.596 & 0.585 \\
\hline
\end{tabular}

Table 5-5 Annual mean NDVI, precipitation and temperature of different vegetation types

\begin{tabular}{llll}
\hline Vegetation types & $\begin{array}{l}\text { Annual } \\
\text { mean } \\
\text { NDVI }\end{array}$ & $\begin{array}{l}\text { Annual } \\
\text { mean } \\
\text { precipitation }(\mathrm{mm})\end{array}$ & $\begin{array}{l}\text { Annual } \\
\text { mean } \\
\text { temperature }\left({ }^{\circ} \mathrm{C}\right)\end{array}$ \\
\hline $\begin{array}{l}\text { Desert grassland (Shiquanhe) } \\
\text { Alpine and subalpine meadow } \\
\text { (Dangxiong) }\end{array}$ & 0.048 & 80.5 & 1.65 \\
$\begin{array}{l}\text { Evergreen needleleaf forest } \\
\text { (Linzhi) }\end{array}$ & 0.26 & 594.6 & 2.33 \\
Meadow (Chaqia) & 0.561 & 772.8 & 9.38 \\
$\begin{array}{l}\text { Alpine and subalpine plain grass } \\
\text { (Maduo) }\end{array}$ & 0.127 & 222.4 & 2.81 \\
Slope grassland (J iulong) & 0.166 & 315.7 & -2.76 \\
Plain grassland (Tuotuohe) & 0.605 & 1027.5 & 9.29 \\
\hline & 0.068 & 325 & -3.44 \\
\hline
\end{tabular}

\subsection{Discussion}

\subsubsection{HANTS algorithm}

The results of the HANTS algorithm were validated for two different vegetation sites in order to compare reconstructed cloud-free time series with the original series. They showed satisfactory correspondence. Our result demonstrated that the HANTS algorithm forms an effective tool for removing cloud contamination of satellite images, especially in challenging areas like the Tibetan Plateau. Although the HANTS algorithm is superior to most other methods in time series data processing, it does have some drawbacks and does not perform well, for instance, when there are large gaps in the data.

\subsubsection{Spatiotemporal variations of NDVI}

The time series analysis revealed the spatial pattern and temporal variation in vegetation dynamics in the Tibetan Plateau on a seasonal and inter-annual time scale. The vegetation density was generally much higher in the southeastern part of the Tibetan Plateau and gradually decreased towards the northwestern part. This was in accordance with the climatic conditions of the Plateau, which made the southeastern part more suitable for vegetation growth, than the northwestern part. The inter-annual vegetation cycle was analyzed using tendency correlation. In general, for the entire Tibetan 
Plateau, the vegetation density increased in $49.87 \%$ of the total area, while in $29.86 \%$ of the total area the vegetation density decreased between 1998 and 2006. Different trends could be observed for the different land cover types. The dominant three land cover types of alpine and subalpine meadow, alpine and subalpine plain grass and desert grassland increased in density by $10.45 \%, 2.45 \%$ and $1.65 \%$, respectively. We believe that the variability in land cover conditions in the Tibetan Plateau is related to its climatic warming. However, more research will be necessary.

\subsubsection{The response of different land cover types to climate variables}

The seasonal NDVI variations of seven land cover types showed some similar characteristics. They were characterized by a one peak pattern. Under the influence of the Asian monsoon, all vegetation started to grow in April or May and reached a maximum in August. After August, vegetation began to decrease. However, for each separate location with its own climatic conditions, the amplitude and peak value of the NDVI curve differed. Slope grassland (Jiulong) had the largest peak value, while desert grassland (Shiquanhe) had the smallest peak value and amplitude. Alpine and subalpine meadow (Dangxiong) had the largest amplitude. Considering monthly temperatures and precipitation, we found that, except for desert grass, all the other six land cover types showed a high correlation between climate variables and NDVI.

A time lag of one month could be observed between NDVI and temperature. NDVI usually started to increase when the temperature rose above $0^{\circ} \mathrm{C}$ and reached its maximum a month later than temperatures reached their maximum. There was a lag of one to two months between NDVI and precipitation. In most cases, NDVI began to increase after the first rainfall and reached its peak value later than precipitation peaked. Different land cover types showed different correlation strength between NDVI and climate variables (precipitation and temperature) during a season. The strength of the relationship varied depending on the land cover type being evaluated. Strongest correlation was observed in alpine and subalpine plain grass and weakest correlation in desert grassland.

\subsubsection{Limitations}

The SPOT VEGETATION used in this study formed a good data source, because of its high spatial resolution and because it could be matched to the land cover map (GLC2000) and the meteorological data. However, the time coverage of about nine years was relatively short. There are still other ecoclimatological factors, such as solar radiation, soil moisture, and snow melt, which have not been explored in this study, but may also account for 
variability in vegetation growth in the Tibetan Plateau. Therefore, longer time series satellite data are needed in order to investigate interactions at different spatial and temporal scale and to predict the response of land cover to climatic impacts.

In addition, the limitation of using the HANTS algorithm for processing, especially at the beginning and end of the annual cycle, forms another source and uncertainty.

\subsection{Conclusions}

In this study, nine-year time series of SPOT NDVI images were processed with the HANTS algorithm, in order to reconstruct cloud free images of the entire Tibetan Plateau area. Spatial and temporal vegetation changes were investigated. The data were then linked to observed monthly climatic data of precipitation and temperature, to infer the vegetation response of different land cover types to climate variability. From the presented analysis and results we concluded:

(1) HANTS algorithm is an effective tool for removing cloud contamination from satellite images, especially in challenging areas like the Tibetan Plateau.

(2) The vegetation density was generally much higher in the southeastern part of the Tibetan Plateau and decreased gradually towards the northwestern part, which is in accordance with the general climate pattern (temperature and precipitation variations) in the Tibetan Plateau. The Asian monsoon had a great impact on the seasonal variation in NDVI.

(3) In general, for the entire Tibetan Plateau, the vegetation density had been increasing in $49.87 \%$ of the total area, according to the interannual analysis.

(4) Certain time lags were found between NDVI and climate variables. The land cover types showed differing correlations between NDVI and climate variables. Strongest correlation was found in alpine and subalpine plain grass and weakest correlation in desert grassland. 


\section{Chapter 6}

\section{Accelerated Changes of Environmental Conditions on the Tibetan Plateau Caused by Climate Change}

\footnotetext{
${ }^{*}$ This chapter is based on

Zhong, L., Z. Su, Y. Ma, M. S. Salama, and J. A. Sobrino, 2011, Accelerated changes of environmental conditions on the Tibetan Plateau caused by climate change. Journal of
} Climate, 24: 6540-6550. 


\section{ABSTRACT}

Variations of land surface parameters over the Tibetan Plateau have great importance on local energy and water cycles, the Asian monsoon and climate change studies. In this chapter, The NOAA/NASA Pathfinder AVHRR Land (PAL) dataset is used to retrieve the land surface temperature (LST), Normalized Difference Vegetation Index (NDVI) and albedo, from 1982 to 2000. Simultaneously, meteorological parameters and land surface heat fluxes are acquired from the European Centre for Medium-Range Weather Forecasts (ECMWF) 40 Years Re-Analysis data (ERA-40) and Global Land Data Assimilation System (GLDAS), respectively. Results show that from 1982 to 2000 both the LST and the surface air temperature increased on the Tibetan Plateau (TP). The rate of increase of the LST was $0.26 \pm 0.16 \mathrm{~K}$ per decade and that of the surface air temperature was $0.29 \pm 0.16 \mathrm{~K}$ per decade, which exceeded the increase in the Northern Hemisphere $(0.054 \mathrm{~K}$ per decade). The plateau-wide annual mean precipitation increased at $2.54 \mathrm{~mm}$ per decade, which indicates that the TP is becoming wetter. The 10 meter wind speed decreased at about $0.05 \pm 0.03 \mathrm{~ms}^{-1}$ per decade from 1982 to 2000 , which manifests a steady decline of the Asian monsoon wind. Due to the diminishing ground-air temperature gradient and subdued surface wind speed, the sensible heat flux showed a decline of $3.37 \pm 2.19 \mathrm{Wm}^{-2}$ per decade. The seasonal cycle of land surface parameters could clearly be linked to the patterns of the Asian monsoon. The spatial patterns of sensible heat flux, latent heat flux and their variance could also be recognized.

Keywords: Land surface parameters, PAL, Climate change, the Tibetan Plateau 


\subsection{Introduction}

Land-atmosphere interaction in the TP, especially through energy and water cycles, has great influence on the Asian monsoon, east Asian atmospheric circulation and even global climate change (Ye and Gao 1979; Ye 1981; Ye and Wu 1998; Ma and Tsukamoto 2002; Zhong et al. 2010a). The history of observations on the TP is rather short and mainly based on scarce field measurements. Ground observation sites were limited in their spatial coverage and unevenly distributed over the TP. Therefore, little was known about the surface characteristics of the TP until recently. Current scientific efforts are focusing on obtaining systematic observations of surface biogeophysical parameters and of the exchange of energy fluxes at the landatmosphere interface of the TP. Considerable amounts of valuable atmospheric and land surface data are being collected through new research projects, e.g. the GEWEX Asia Monsoon Experiment on the Tibetan Plateau (GAME/Tibet) and the Coordinated Enhanced Observing Period (CEOP) AsiaAustralia Monsoon Project on the Tibetan Plateau (CAMP/Tibet). Some results have been achieved relating to characteristics of land surface parameters on the TP (Yang et al. 2001; Ma et al. 2002; Yang et al. 2002; Yang et al. 2003; Yang et al. 2004; Ma and Ma 2006; Ma et al. 2008; Zhong et al. 2009). All these results are, however, based on observational sites which can only be representative on a point scale. This kind of information is useful but not sufficient to be able to understand the energy and water cycles over the whole TP area. Over the last three decades, the fast development of remote sensing techniques provided appropriate data for studying the regional surface characteristics on the TP area. Land surface parameters for the TP such as land surface temperature (LST), Normalized Difference Vegetation Index (NDVI) and surface albedo dynamics were derived from data obtained from different sensors, e.g. Landsat, Advanced Very High Resolution Radiometer (AVHRR), and Moderate Resolution Imaging Spectroradiometer (MODIS)( Ma et al. 2002; Oku and I shikawa 2004; Ma and Ma 2006; Ma et al. 2006; Ma et al. 2007; Oku et al. 2007; Wang et al. 2007). Most of these studies were at local-patch-level or meso-scale and their time scales were too short to be able to understand the effect of climatic changes on the TP. In addition, the focus of these studies was on the development of retrieval algorithms for surface parameters (J ulien et al. 2006), rather than analyzing the interrelationships between climatic and land surface parameters in the area.

This study aims to verify the long-term variations in land surface parameters on the TP and their relation to the strength of the Asian monsoon by using satellite images and reanalyzing climatic data. In section 6.2 the datasets and the retrieval algorithms for land surface parameters are introduced. Then analyses of long-term variation trends for surface parameters are presented 
over the TP as a whole, and their influence on the heating source of sensible heat flux as well as their relationship to the Asian monsoon. Based on these results, conclusions are drawn on how climate changes affect accelerated variations of environmental conditions on the Tibetan Plateau.

\subsection{Data and algorithm}

\subsubsection{Datasets}

The NOAA/NASA Pathfinder AVHRR Land (PAL) data set has been processed to derive the land surface parameters in this study. The PAL data set is a global land surface data set, derived from the AVHRR, on the NOAA polar orbiting satellite series, and provides a continuous daily and 10-day composite data set from July 1981 through to 2001. The 10-day Maximum Value Composition (MVC) method selects the highest value for each pixel during each 10-day period, thus eliminating most of the cloudy pixels (Holben, 1986; Julien et al. 2006). The resulting composite data sets provide a time series of uniform, nearly cloud free, data sets providing highly repetitive, synoptic coverage of all global land areas. Parameters include NDVI, Channels $1 \& 2$ reflectances and Channels 3 through 5 brightness temperatures.

Another data source which will be used in this study is the European Centre for Medium-Range Weather Forecasts (ECMWF) 40 Years Re-Analysis (ERA40) dataset. The ERA-40 uses a variational data assimilation system to make a new synthesis of the in-situ and remotely sensed measurements made over the period since mid-1957, when a major improvement was made to the atmospheric observing system in preparation for 1958, the International Geophysical Year (Kållberg et al. 2004). The selected data have a spatial resolution of 2.5 degrees. The parameters which will be used in our study are: 2 meter air temperature, precipitation and 10 meter wind speed.

The surface sensible and latent heat flux with a spatial resolution of 1 degree are obtained from the Global Land Data Assimilation System (GLDAS). The goal of the GLDAS is to ingest satellite- and ground-based observational data products, using advanced land surface modeling and data assimilation techniques, in order to generate optimal fields of land surface states and fluxes (Rodell et al. 2004). The monthly results obtained from the Community Land Model (CLM 2.0) covering 1982 to 2000 will be used in this study. The Community Land Model (CLM) has added complexity in order to satisfy a wide variety of applications. Some extensive offline tests were carried out by using a variety of observational data by Dai (2003). Those tests have demonstrated that CLM can reasonably simulate land surface processes. Offline studies presented demonstrate that CLM can realistically 
simulate the key state variables and fluxes. Thus GLDAS reanalysis could be used to analyze the interannual surface flux variability over the TP.

\subsubsection{Retrieval algorithms for satellite images}

The NDVI is routinely calculated from visible $(0.585$ to $0.68 \mu \mathrm{m})$ and nearinfrared (NIR) ( 0.73 to $1.1 \mu \mathrm{m}$ ) data acquired by the NOAA series of Advanced Very High Resolution Radiometer (AVHRR) sensors:

$$
N D V I=(N I R-\operatorname{Re} d) /(N I R+\operatorname{Re} d)
$$

where, NIR and Red are the surface reflectance in the infrared and red regions, respectively.

As a critical variable affecting the earth's climate (Cess, 1978; Dickinson, 1983), land surface broadband albedo is estimated by adopting the algorithm by Liang (2000). Liang (2000) applied an approach that decouples surface reflectance spectra from the real-time radiative transfer simulations so that many different surface reflectance spectra and the atmospheric conditions can be effectively incorporated.

$\alpha_{\text {short }}=-0.3376 \alpha_{1}^{2}-0.2707 \alpha_{2}^{2}+0.7074 \alpha_{1} \alpha_{2}+0.2915 \alpha_{1}+0.5256 \alpha_{2}+0.0035$ (6-2)

where $\alpha_{\text {short }}$ is total shortwave albedo, and $\alpha_{1}$ and $\alpha_{2}$ are AVHRR spectral albedos of band 1 and band 2, respectively.

The split window algorithm was first introduced to estimate ocean surface temperature. Since then, after thirty years' development, it has been proved simple with high efficiency (Zhong et al. 2010b). The retrieval method from Sobrino and Raissouni(2000) had been proved effective to derive LST over the TP by Ma et al. (2003). Therefore, the split window algorithm by Sobrino and Raissouni(2000) is applied to derive the land surface temperature $\left(T_{s}\right)$ :

$T_{s}=T_{4}+1.40 \cdot\left(T_{4}-T_{5}\right)+0.32 \cdot\left(T_{4}-T_{5}\right)^{2}+0.83+(57-5 W) \cdot(1-\varepsilon)-(161-30 \mathrm{~W}) \cdot \Delta \varepsilon(6-3)$

where $T_{4}$ and $T_{5}$ are AVHRR's radiometric temperature in channel 4 and channel $5, W$ is the total amount of total atmospheric water vapour, $\varepsilon$ is the mean effective emissivity and $\Delta \varepsilon$ is the spectral variation of emissivity. $\varepsilon$ and $\Delta \varepsilon$ are estimated to be functions of the NDVI values, according to Sobrino and Raissouni(2000). The total atmospheric water vapour is estimated using the method developed by Sobrino et al. (1999).

\subsubsection{Validation}

Four observation sites in CAMP/Tibet area, AMDO, D105, BJ and NPAM, were used to make the validation. The derived LST from satellite data was 
compared with field measurements at four sites. As LST from PAL dataset are 10-day maximum value composition, the in situ observation values are corresponding 10-day maximum values measured at satellite passing time. The differences are shown in Fig 6-1., together with a 1:1 line. As can be seen from the figure, the derived LST from satellite images was close to in situ measurements. The percentage error (PE) was applied to measure quantitatively the difference between the derived results and the in situ values:

$$
\mathrm{PE}=\frac{\left|V_{\text {derived }}-V_{\text {measured }}\right|}{V_{\text {measured }}}
$$

The average LST PE derived from four sites was about $1 \%$ which proves that the retrieval methods can be applied to the TP. Although the derived results were generally in agreement with field measurements, there were some discrepancies. These may be due to 1 ) the pixel scale itself is usually not homogeneous and the component temperature was not taken into account; 2) the impact of topography on LST calculation having been omitted.

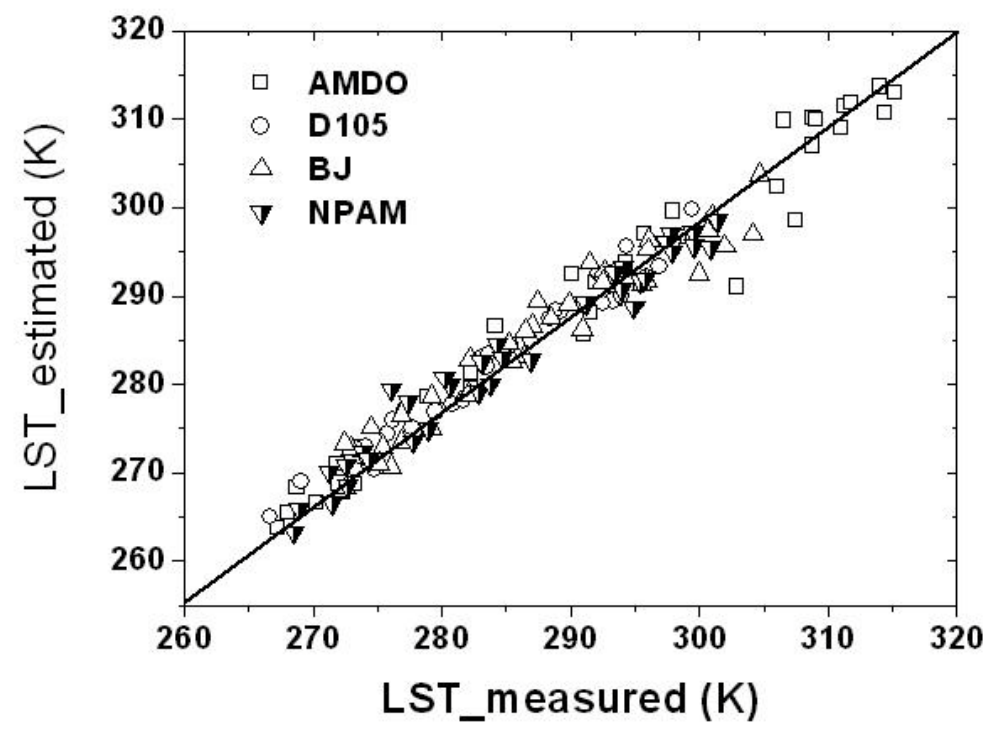

Fig. 6-1 Validation of derived PAL land surface temperature against field measurements. Not all time series data but cases in year 2000 are shown here.

\subsection{Recent variation trends in land surface parameters across the Tibetan Plateau}

Monthly and annual averages of LST, NDVI and albedo from satellite images were calculated from every pixel across the TP. The area-averaged air 
temperature, precipitation and wind speed for the TP were derived from grid values for each month from 1982 to 2000 . As can be seen from time series of monthly mean LST (Fig. 6-2a) and annual mean LST (Fig. 6-2b), there is a clear warming trend across the land surface of the TP as a whole. The annual average LST on the plateau increased by $0.26 \pm 0.16 \mathrm{~K}$ per decade, which is very close to the in-situ measurements by Li et al. (2005). They found that the TP had been warming at $0.3 \mathrm{~K}$ per decade over the past 20 years. The warming trend on the TP is also in accordance with the remote sensing results from the Geostationary Meteorological Satellite 5 (GMS-5)(Oku and Ishikawa, 2004). There is no dominant pattern in the spatial distribution of the LST. However, it was observed that the 18-year average LST was much higher in the northeastern, eastern and southwestern areas of the TP than in other parts of the TP (Fig. 6-2c). The variance map of the LST shows that the northwestern part of the TP has the greatest anomalies (Fig. 6-2d).
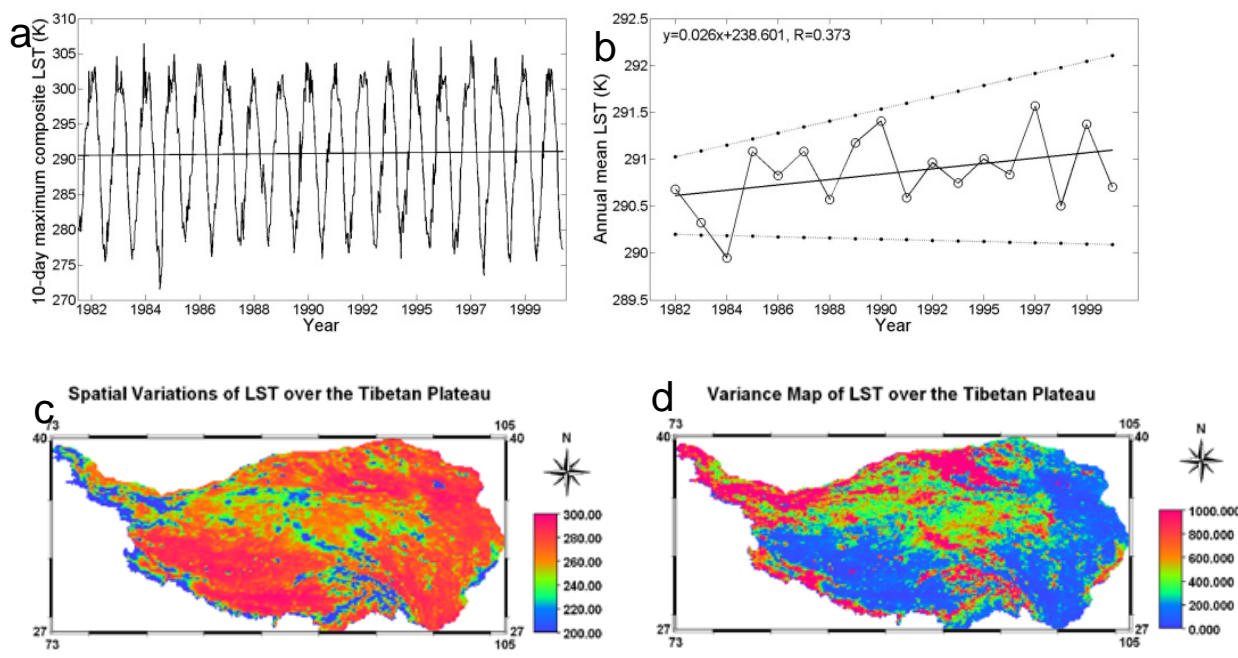

Fig. 6-2 Temporal variations and spatial distribution of LST over the TP. (a) Time series of 10-day maximum LST of the TP from 1982 to 2000 . (b) Variations of annual mean PAL LST from 1982 to 2000 . The bold straight line represents the linear fit result. Dash-dot lines are confidential lines for the linear trend at $95 \%$ confidence level. (c) Spatial distribution of LST; (d) Spatial distribution of LST variance. The LST data in 1994 is not complete and it has been excluded.

As the land surface directly heats the atmosphere above, the surface air temperature is also rising (Fig. 6-3a and Fig. 6-3b). Both monthly and annual developments of surface air temperature recorded by the ERA-40 show an increase from 1982 to 2000 . The warming rate is about $0.29 \pm 0.16 \mathrm{~K}$ per decade, which is a little higher than the increase in LST derived from PAL and also higher than the results obtained by Liu and Chen (2000), who employed all records from the 97 TP stations to obtain a TP-wide temporal evolution for 
seasonal and annual average surface air temperature anomalies from 1955 to 1996. Liu and Chen (2000) found the increase in the linear rates of the allplateau temperature during 1955-1996 to be about $0.16 \mathrm{~K}$ per decade for the annual mean, which exceeds the increase in the Northern Hemisphere $(0.054$ $\mathrm{K}$ per decade).
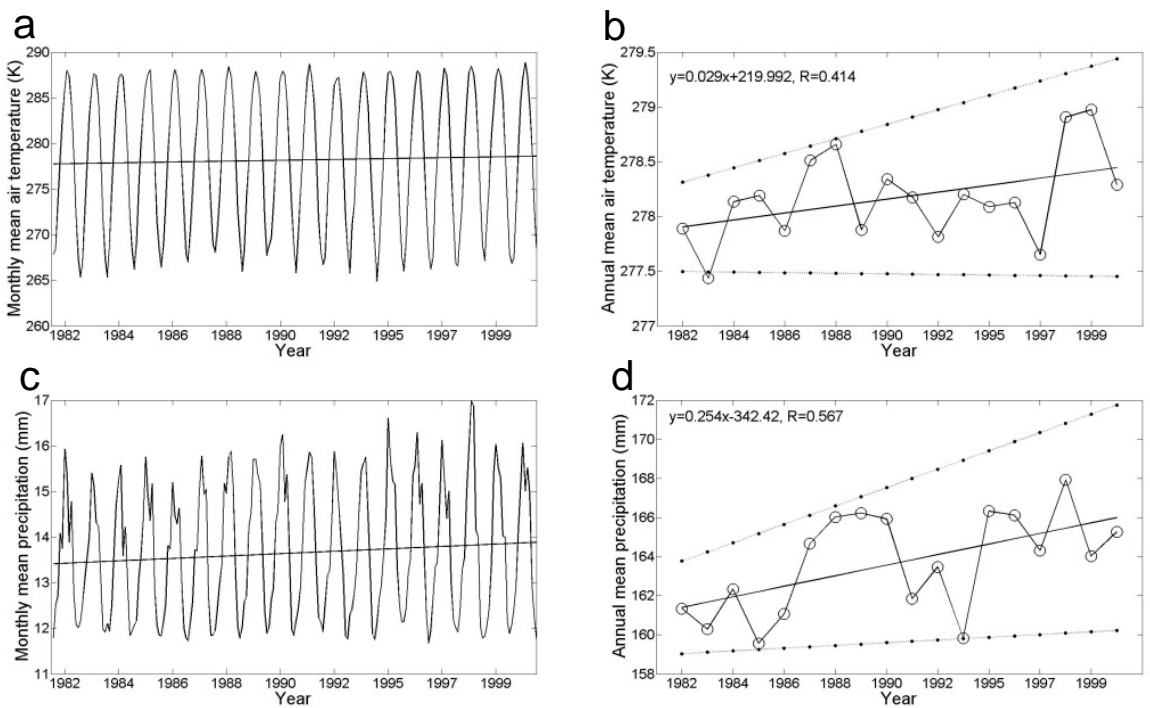

Fig. 6-3 Air temperature and precipitation variations over the TP. (a) Time series of monthly mean air temperature at $2 \mathrm{~m}$ from ERA-40. (b) Variations of ERA-40 annual mean air temperature from 1982 to 2000. (c) Time series of monthly mean precipitation from ERA-40. (d) Variations of ERA-40 annual mean precipitation from 1982 to 2000 . The bold straight line represents the linear fit result. Dash-dot lines are confidential lines for the linear trend at $\mathbf{9 5 \%}$ confidence level.

The warming of the TP will inevitably affect the upward motion of airflow in the atmosphere and thus influence precipitation variability. As shown in Fig.6-3c and Fig. 6-3d, there are general upward trends for both monthly and annual precipitation. The plateau-wide annual mean precipitation increased at $2.54 \mathrm{~mm}$ per decade, which indicates that the TP has become wetter during the past 18 years. This significant change can also be observed in the spatial pattern of monthly mean precipitation and variance (Fig. 6-4). The precipitation data from the ERA-40 were divided into four groups. In Fig. 6$4 a, c, e$, and $g$ the increasing changes in precipitation on the TP are clearly shown. A gradual decrease in precipitation can usually be seen from the southern TP to the northern TP. There is also a maximum precipitation belt located around the Himalayas. The warm and humid Indian monsoon always brings a large amount of water vapour from the Indian Ocean in summer. When this encounters the Himalayas, the air has to flow upwards, causing large amounts of precipitation. From the variance maps (Fig. 6-4b, d, f, and 
h), it can be seen that large precipitation anomalies are located in a special area (84으-99으, 27N-30N) in the southern TP.
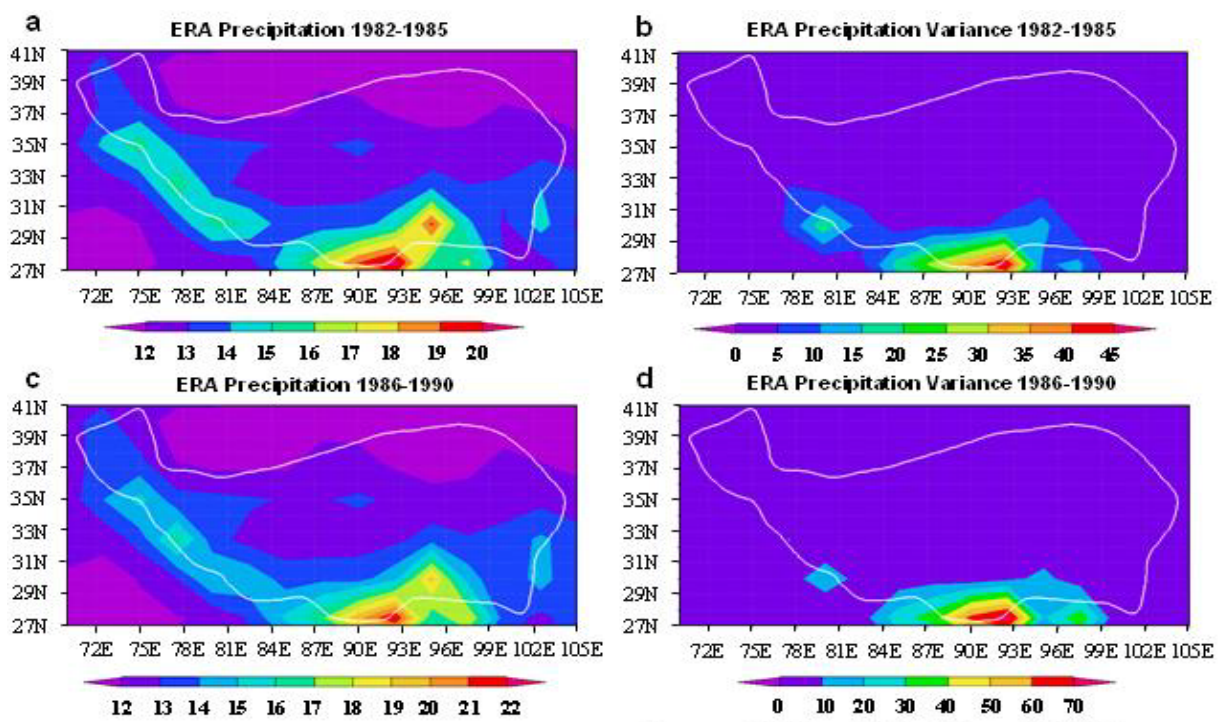
ERA Precipitation 1991-1995
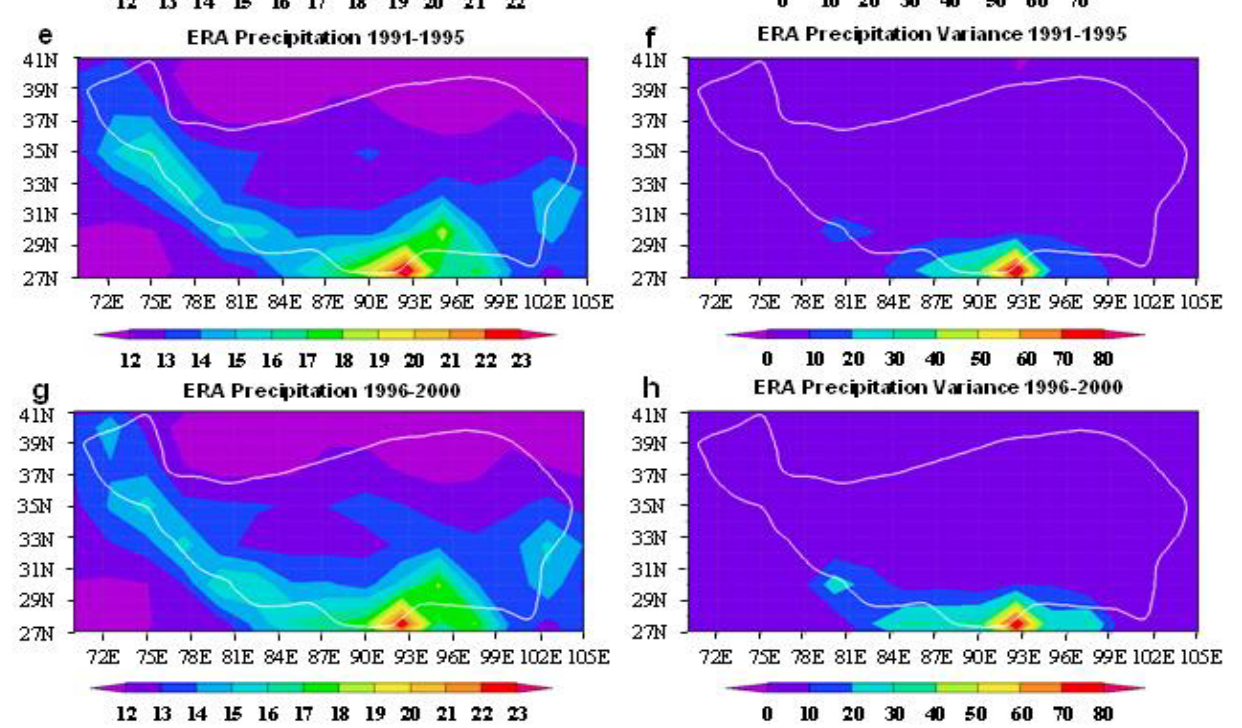

Fig. 6-4 Monthly mean precipitation and variance. (a) and (b) are generated from 1982 to 1985 . (c) and (d) are from 1986 to 1990. (e) and (f) are from 1991 to $1995 .(\mathrm{g})$ and (h) are from 1996 to 2000. The white line represents contour of $\mathbf{3 0 0 0}$ meters.

With the warming of the TP, the NDVI has shown an upward trend and the albedo a downward trend (Fig. 6-5a, b, c, and d). The rate of increase of the NDVI is about $0.01 \pm 0.003$ per decade, while the albedo decreases at $0.004 \pm 0.003$ per decade (Fig. 6-5b, and d). For the TP as a whole, the 10 
meter wind speed decreased from 1982 to 2000 with a rate of $0.05 \pm 0.03 \mathrm{~ms}$ ${ }^{1}$ per decade (Fig. 6-5e, and f), which is consistent with the steady decline of the East Asian monsoon winds ( $X u$ et al., 2006). As the TP is greatly influenced by the Asian monsoon, the land surface parameters show a clear seasonal cycle in accordance with the monsoon. As the Asian monsoon develops, the LST, surface air temperature and NDVI usually increase, while wind speed and albedo decrease. After the monsoon retreats, wind speed and albedo increase again, while LST, surface air temperature and NDVI show a decrease. For example, from the pre-monsoon season to the monsoon season, the LST, NDVI, and surface air temperature tend to increase, respectively, from $293.4 \mathrm{~K}, 0.1$, and $279.09 \mathrm{~K}$ to $301.3 \mathrm{~K}, 0.19$, and $288.1 \mathrm{~K}$. Simultaneously, the values for albedo and wind speed decrease from, respectively, 0.24 and $0.95 \mathrm{~ms}^{-1}$ to 0.19 and $0.33 \mathrm{~ms}^{-1}$.

The climatic warming of the TP has to be accompanied by a change in the atmospheric heating source (sensible heat flux, $H_{s}$ ) and therefore has to be related to the strength of the Asian monsoon. According to a widely used bulk aerodynamic method, $H_{s}$ can be derived (Ye and Gao 1979; Chen et al. 1985; Duan and Wu 2008) as follows:

$$
H_{s}=C_{p} \rho C_{D H} V_{0}\left(T_{s}-T_{a}\right)
$$

where $C_{p}\left(=1005 \mathrm{~J} \mathrm{~kg}^{-1} \mathrm{~K}^{-1}\right)$ is the specific heat of dry air at constant pressure, $\rho$ is the air density, $C_{D H}$ is the drag coefficient for heat transfer, and $V_{0}$ is the mean wind speed measured at $10 \mathrm{~m}$ above ground. At each specific position variations in $\rho$ and $C_{D H}$ will have been negligible during the study period from 1982 to 2000, meaning $H_{s}$ is mainly determined by $V_{0}$ and $T_{s}-T_{a}$. Based on the 10-day maximum value of LST, we made a further calculation to get the monthly average values of LST. Both $T_{a}$ and $V_{0}$ are all monthly mean values from ERA-40. Thus $H_{s}$ also represents a monthly value. As stated above, there was a downward trend for wind speed and an upward trend for both LST and surface air temperature, with the rate of increase in surface air temperature being a little higher than that of the LST. Therefore, the ground-air temperature difference $\left(T_{s}-T_{a}\right)$ has to have decreased during the study period. Based on the decrease in $V_{0}$ and $T_{s}-T_{a}$, the sensible heat flux should also decrease. This is in accordance with the trend of decrease in surface sensible heat flux from GLDAS (Fig. 6-6a, and b). The rate of decrease in sensible heat flux is about $3.37 \pm 2.19 \mathrm{Wm}^{-2}$ per decade. This is in agreement with calculations from in-situ measurements 
(Duan and $\mathrm{Wu}, 2008$ ). There is a clear spatial pattern in the distribution of sensible heat flux across the TP. The northern, northeastern and southwestern parts of the TP usually have a much higher sensible heat flux (Fig. 6-6c). The variation in sensible heat flux increases gradually from the southeast to the northwest part of the TP (Fig. 6-6d).

The increase in precipitation, LST, and NDVI and the decrease in albedo contribute to an increase in surface latent heat flux (Figures not shown here). The surface latent heat flux derived from the GLDAS shows a rate of increase of about $0.9 \mathrm{Wm}^{-2}$ per decade. The spatial distribution of the latent heat flux exhibits a very clear pattern, consistent with the general climatic patterns on the TP. As the climatic conditions in the southeastern part of the TP are usually warmer and wetter than in the northwestern part, the latent heat flux tends to decrease from southeast to northwest.

As a major source of heating leading up to the rainy season, the TP has a great influence on the Asian monsoon. The trend in sensible heat flux to decrease may explain the recent atmospheric and rainfall anomalies in China, especially in the eastern part of China. There are many debates on the specific impact the TP heat has on precipitation in China, and further investigation is needed. 
a

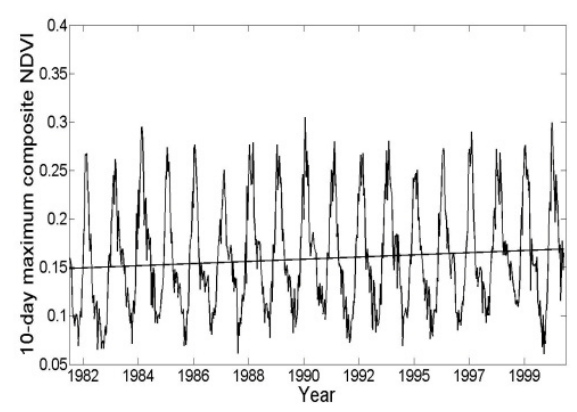

C

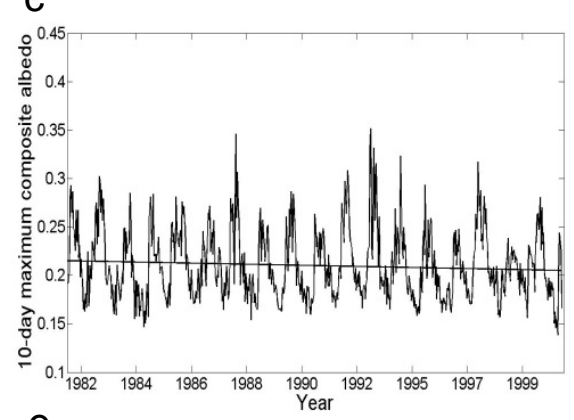

e

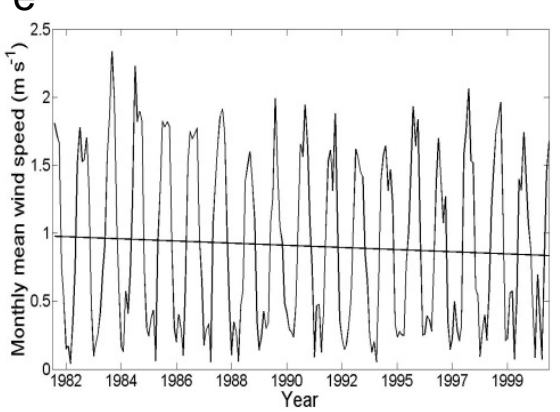

b
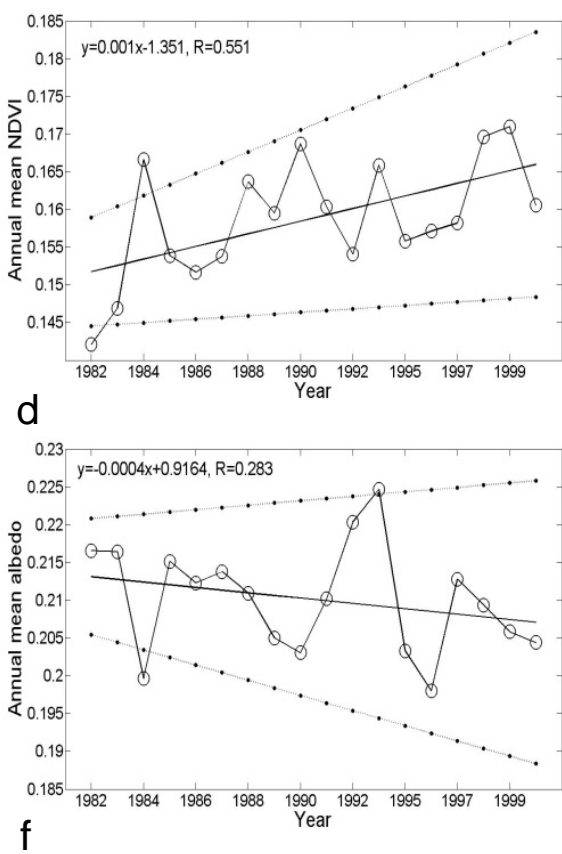

f

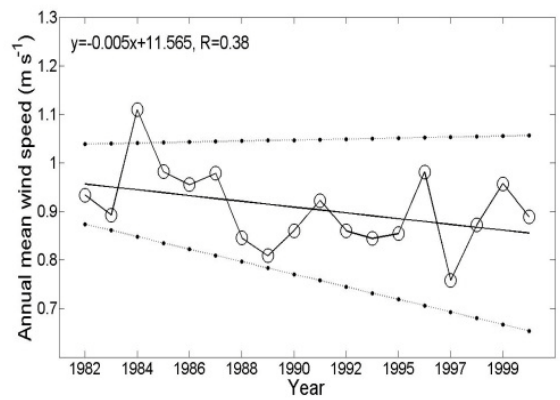

Fig. 6-5 NDVI albedo and wind speed variations over the TP. (a) Time series of 10-day maximum NDVI derived from PAL. (b) Variations of annual mean PAL NDVI from 1982 to 2000. (c) Time series of 10-day maximum albedo derived from PAL. (d) Variations of annual mean PAL albedo from 1982 to 2000. (e) Time series of monthly mean wind speed at $10 \mathrm{~m}$ from ERA-40. (f) Variations of ERA-40 annual mean wind speed from 1982 to 2000 . The bold straight line represents the linear fit result. Dash-dot lines are confidential lines for the linear trend at $\mathbf{9 5 \%}$ confidence level. 

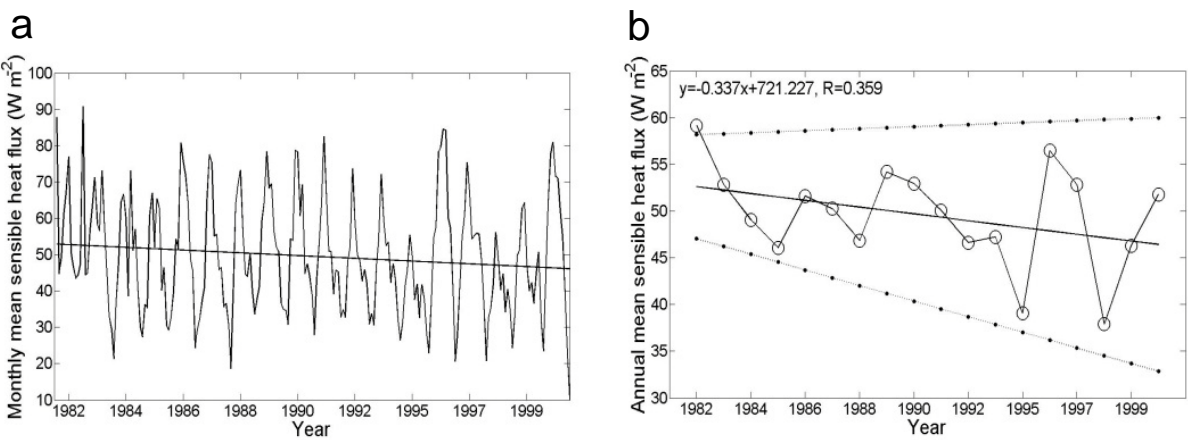

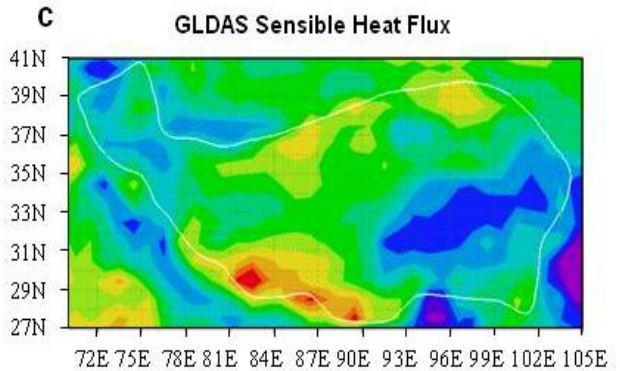

$1020 \quad 30 \quad 4050 \quad 60 \quad 7080 \quad 90 \quad 100110120$

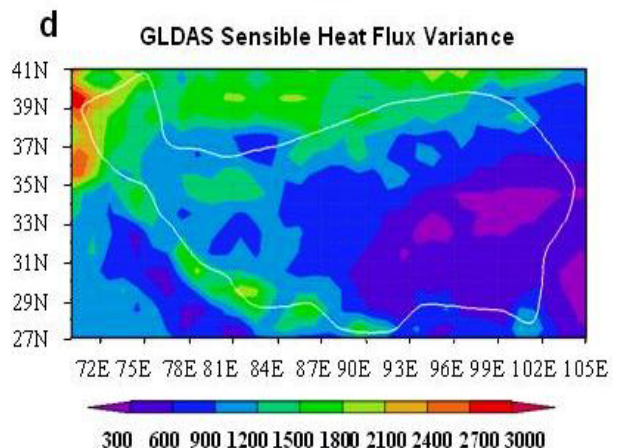

Fig. 6-6 Temporal variations and spatial distribution of sensible heat flux over the TP. (a) Time series of monthly mean surface sensible heat flux from GLDAS. (b) Variations of GLDAS annual mean sensible heat flux from 1982 to 2000. The bold straight line represents the linear fit result. Dash-dot lines are confidential lines for the linear trend at $95 \%$ confidence level. (c) Spatial distribution of sensible heat flux; (d) Spatial distribution of sensible heat flux variance. The white line represents contour of $\mathbf{3 0 0 0}$ meters.

\subsection{Conclusions and discussion}

Based on the PAL dataset, ERA-40, and GLDAS re-analysis data, time series of land surface parameters have been developed for the TP as a whole. The results have been compared with other relevant studies and are clearly consistent. The main conclusions can be summarized as follows:

(1) The TP is becoming warmer. Both the LST and the surface air temperature on the TP show an increase from 1982 to 2000. The rate of increase of the surface air temperature is about $0.29 \pm 0.16 \mathrm{~K}$ per decade, which is larger than that of the LST $(0.26 \pm 0.16 \mathrm{~K}$ per decade). Therefore, the ground-air temperature difference is diminishing.

With the TP warming up, regional precipitation is likely to increase. The plateau-wide annual mean precipitation increased at $2.54 \mathrm{~mm}$ per decade, which indicates that the TP has become wetter during the past 18 years, especially in the southeastern and southwestern part. 
A maximum precipitation belt located around the Himalayas can clearly be identified.

An upward trend in NDVI and downward trend in albedo have been observed together with an increase in temperature and precipitation on the TP. The linear variation rates in NDVI and albedo are $0.01 \pm 0.003$ per decade and $0.004 \pm 0.003$ per decade, respectively. The 10 meter wind speed shows a decrease of about $0.05 \pm 0.03 \mathrm{~ms}^{-1}$ per decade from 1982 to 2000, which indicates a steady decline of the Asian monsoon wind.

(4) Clear seasonal cycles exist for the land surface parameters. LST, surface air temperature and NDVI usually increase from the premonsoon to the monsoon season, and then decrease from the monsoon to the post-monsoon season. On the other hand, albedo and wind speed first show a decrease from the pre-monsoon season to the monsoon season, before increasing again from the monsoon to the post-monsoon season.

(5) There are clear spatial patterns for the surface sensible heat flux, latent heat flux and their variance distribution. The variation in sensible heat flux usually decreases gradually from the southeast to the northwest. The largest variation in latent heat flux is found in the north, northeast, and southwest of the TP.

(6) Because of the decreasing wind speed and the diminishing ground-air temperature difference, the sensible heat flux on the TP has been decreasing at a rate of $3.37 \pm 2.19 \mathrm{Wm}^{-2}$ per decade according to a bulk aerodynamic method. However, the latent heat flux tends to increase at a rate of $0.9 \mathrm{Wm}^{-2}$ per decade.

In fact, the warming of the TP will inevitably accelerate the melting of snow, ice and permafrost. For this aspect, the Nam Co Lake, which is the largest lake in the Tibet Autonomous Region, can be a good example. According to a recent study result from Zhu et al. (2010), the increased glacier melting water accounted for about $50.6 \%$ of augment of the Nam Co Lake volume, which suggested that the increased glacier melting water was the main reason for the quickly enlargement of the Nam Co Lake under the continuous temperature rising. The increase in soil moisture will have consequences, affecting evapotranspiration and subsequent precipitation, perhaps leading to periods of excessive drought and floods. The increase in variability in precipitation might be linked to regional changes in snow cover, soil moisture and precipitation. This could be an important issue, but needs more study.

The recent warming trend in the TP has exceeded that of the Northern Hemisphere. The TP can be regarded as one of the areas most sensitive to 
global change. Consequently, temperature changes in high-elevation regions such as the TP could be used for detection or monitoring of global warming.

As sensible heat flux is a major source of heat, its decrease should have a large influence on atmospheric circulation in the northern hemisphere, even the globe. Its impact on the Asian monsoon and precipitation in China needs further investigation. 


\section{Bibliography}

Allen, R., L. Pereira, D. Raes, and M. Smith, 1998: Crop evapotranspirationGuidelines for computing crop water requirements-FAO Irrigation and Drainage Paper 56, FAO, Rome, I taly.

Ashcroft, P. and F. Wentz, 2003: AMSR-E/Aqua L2A Global SwathSpatiallyResampled Brightness Temperatures (Tb) V001, September to October 2003, Natl. Snow and Ice Data Cent., Boulder, Colo.

Azzali, S. and M. Menenti, 2000: Mapping vegetation-soil-climate complexes in southern Africa using temporal Fourier analysis of NOAA-AVHRR NDVI data. International J ournal of Remote Sensing, 21, 973-996.

Bartholome, E. and A. Belward, 2005: GLC2000: a new approach to global land cover mapping from Earth observation data. International Journal of Remote Sensing, 26, 1959-1977.

Bastiaanssen, W. G. M., M. Menenti, R. A. Feddes, and A. A. M. Holtslang, 1998: A remote sensing surface energy balance algorithm for land (SEBAL): 1. Formulation. J ournal of Hydrology, 212-213, 198-212.

Becker, F. and Z. L. Li, 1990: Towards a local split window method over land surface. International J ournal of Remote Sensing, 11, 369-393.

Becker, F. and Z. L. Li, 1995: Surface temperature and emissivity at various scales: definition, measurement and related problems. Remote Sensing Review, 12, 225-253.

Bian, L. G., X. D. Xu, L. G. Lu, Z. Q. Gao, M. Y. Zhou, and H. Z. Liu, 2003: Analyses of turbulence parameters in the near-surface layer at Qamdo of the Southeastern Tibetan Plateau. Advances in Atmospheric Sciences, 20, 369-378.

Bolle, H. J., J. C. Andre, and J. L. Arrue, 1993: EfEDA: The European field experiment in a desertification threatened area, Annual Geophysics, II: 173-189.

Cao, M. and F. I. Woodward, 1998: Dynamic responses of terrestrial ecosystem carbon cycling to global climate change. Nature, 393, 249252.

Cao, Y., 2006: The inversion theory and method for snow cover parameters over the Tibetan Plateau based on MODIS and AMSR-E data. Dissertation submitted to Graduate University of Chinese Academy of Sciences ed. PhD thesis.

Carlson, T. N. and D. A. Ripley, 1997: On the relation between NDVI, fractional vegetation cover and leaf area index. Remote Sensing of Environment, 62, 241-252.

Cess, R. D., 1978: Biosphere-albedo feedback and climate modeling. Journal of the Atmospheric Sciences, 35, 1765-1768.

Chamaille-Jammes, S., H. Fritz, and F. Murindagomo, 2006: Spatial patterns of the NDVI-rainfall relationship at the seasonal and interannual time scales in an African savanna. International J ournal of Remote Sensing, 
27, 5185-5200.

Chen, L. X., E. Reiter, and Z. Q. Feng, 1985: The atmospheric heat source over the Tibetan Plateau: May-August 1979. Monthly Weather Review, 113, 1771-1790.

Chen, Y., K. Yang, J. Qin, L. Zhao, W. Tang, and M. Han, 2013: Evaluation of AMSR-E retrievals and GLDAS simulations against observations of a soil moisture network on the central Tibetan Plateau. J ournal of Geophysical Research, 118, 4466-4475. DOI: 10.1002/jgrd.50301.

Choi, T. J., J. K. Hong, J. Kim, H. C. Lee, J. Asanuma, H. Ishikawa, O. Tsukamoto, Z. Q. Gao, Y. M. Ma, K. Ueno, J. M. Wang, T. Koike, and T. Yasunari, 2004: Turbulent exchange of heat, water vapour, and momentum over a Tibetan prairie by eddy covariance and flux variance measurements. J ournal of Geophysical Research-Atmospheres, 109.

Coll, C. and V. Caselles, 1997: A split-window algorithm for land surface temperature from advanced very high resolution radiometer data: Validation and algorithm comparison. Journal of Geophysics Research, 102, 16697-16713.

Coll, C., V. Caselles, J. A. Sobrino, and E. Valor, 1994: On the atmospheric dependence of the split-window equation for land surface temperature. International J ournal of Remote Sensing, 15, 105-122.

Cracknell, A. P., 1997: The Advanced Very high Resolution Radiometer (AVHRR). Taylor and Francis, $534 \mathrm{pp}$.

Dente, L., Z. Vekerdy, J. Wen, and Z. Su, 2012: Maqu network for validation of satellite-derived soil moisture products. International Journal of Applied Earth Observation and Geoinformation, 17, 55-65.

Dickinson, R. E., 1983: Land surface processes and climate-surface albedos and energy balance. Advances in Geophysics, 25, 305-353.

Dickinson, R. E., 1995: Land processes in climate models. Remote Sensing of Environment, 55, 27-38.

Ding, L., Z. Qin, and K. Mao, 2005: A research of split window algorithm based on MODIS image data and parameter determination. Remote Sensing Technology and Application, 20, 284-289.

Ding, M., Y. Zhang, L. Liu, W. Zhang, Z. Wang, and W. Bai, 2007: The relationship between NDVI and precipitation on the Tibetan Plateau. J ournal of Geographical Sciences, 259-268.

Ding, M., Y. Zhang, Z. Shen, L. Liu, W. Zhang, Z. Wang, W. Bai, and D. Zheng, 2006: Land cover change along the Qinghai-Tibet Highway and Railway from 1981 to 2001. Journal of Geographical Sciences, 16, 387-395.

Dong, Y. X., S. Li, and G. R. Dong, 1999: Tentative study on the status and the causes of desertification in Yarlung-Zangbo River basin. Scientia Geographica Sinica, 19, 35-41. (in Chinese with English abstract)

Donohue, R. J., M. L. Roderick, T. R. McVicar, and G. D. Farquhar, 2013: Impact of $\mathrm{CO} 2$ fertilisation on maximum foliage cover across the globe's warm, arid environments. Geophysical Research Letters, 


\section{0,DOI: $10.1002 / \mathrm{grl} .50563$.}

Duan, A. and G. Wu, 2008: Weakening trend in the atmospheric heat source over the Tibetan Plateau during recent decades. Part I: observations. J ournal of Applied Meteorology, 21, 3149-3164.

European Commission, Joint Research Centre, 2003: GLC2000, http://bioval.jrc. ec. europa.eu/products/glc2000/glc2000.php.

França, G. B. and A. P. Cracknell, 1994: Retrieval of land and sea surface temperature using NOAA-11 AVHRR data in northeastern Brazil. International J ournal of Remote Sensing, , 15, 1695-1712.

François, C. and C. Ottlé, 1996: Atmospheric corrections in the thermal infrared: Global and water vapour dependent split-window algorithmapplications to ATSR and AVHRR data. IEEE Transactions on Geoscience and Remote Sensing, 34, 457-470.

GAME International Science Panel, 1998: GEWEX Asian Monsoon Experiment (GAME) Implementation Plan, March, pp136.

Gao, F., J. Wang, X. Li, T. Koike, and Y. Ma, 2004: Retrieving of land surface parameters over the Tibetan Plateau with passive microwave remote sensing. Journal of Lanzhou University (Natural Science Edition), 40, 8691. (in Chinese with English abstract)

Gosh, T. K., 1997: Investigation of drought through digital analysis of satellite data and geographical information systems. Theoretical and Applied Climatology 58, 105-112.

Goutorbe J. P., T. Lebel, and A. Tinga, 1994: A large scale study of landatmosphere interaction in the semi-arid tropics (HAPEX-Sahel), Annual Geophysics, 12: 53-64.

Gurgel, H. C. and N. J. Ferreira, 2003: Annual and interannual variability of NDVI in Brazil and its connections with climate. International Journal of Remote Sensing, 24, 3595-3609.

Gutman, G. G., 1990: Towards monitoring drought from space. Journal of Climate, 3, 282-295.

Hall, F. G. and P. J. Sellers, 1993: M Apps BOREAS: Boreal Ecosystem Atmosphere Study, IEEE Geosciences Remote Sensing Society Newsletter, March: 9-17.

He, Y., P. Shi, and L. Xu, 2009: Biomass of fine root in different community type on the Tibetan vegetation transect. Scientia Silvae Sinicae, 45, 148151. (in Chinese with English abstract)

Holben, B., 1986: Characteristic of maximum value composite images for temporal AVHRR data. International Journal of Remote Sensing, 7, 1417-1434.

Hong, J., T. Choi, H. Ishikawa, and J. Kim, 2004: Turbulence structures in the near-neutral surface layer on the Tibetan Plateau. Geophysical Research Letters, 31, DOI : 10.1029/2004GL019935.

Hou, Y., J. Zhang, and Y. He, 2005: Intra- and inter-annual variation patterns of NDVI in Tibet based on AVHRR remote sensing data. Chinese Journal 
of Ecology, 24, 1273-1276. (in Chinese with English abstract)

Houghton, J. T., Y. Ding, D. J. Griggs, M. Noguer, P. J. v. d. Linden, and D. Xiausu, 2001: Climate Change 2001: The Scientific Basis Cambridge University Press, 944 pp.

Hu, Y., Y. Gao, J. Wang, G. Ji, Z. Shen, L. Cheng, J. Chen, and S. Li, 1994: Some achievements in scientific research during HEIFE, Plateau Meteorology, 13: 225-236. (in Chinese with English abstract)

IGBP, 1992: Global Change: Reducing Uncertainties, Publicized by Royal Swedish Academy, ISBN 91-630-1086-0.

I qbal, M., 1983: An introduction to solar radiation. Academic Press.

Immerzeel, W., R. Quiroz, and S. Jong, 2005: Understanding precipitation patterns and land use interaction in Tibet using harmonic analysis of SPOT VGT-S10 NDVI time series. International Journal of Remote Sensing, 26, 2281-2296.

Jang, Y., 2009: China's water scarcity. Journal of Environmental Management, 90, 3185-3196.

JSC, 1994: Report of $15^{\text {th }}$ Session of the Joint Scientific Committee of WCRP, WMO/TD, No.632, WMO, Geneva, pp136.

Julien, Y., J. A. Sobrino, and W. Verhoef, 2006: Changes in land surface temperatures and NDVI values over Europe between 1982 and 1999. Remote Sensing of Environment, 103, 43-55.

Jupp, D. L. B., G. Tian, T. R. McVicar, Y. Qin, and F. Li, 1998: Monitoring Soil Moisture and Drought Using AVHRR Satellite Data I: Theory. CSIRO Earth Observation Centre Technical Report, 98.1, Canberra, ACT.

Kållberg, P., A. Simmons, S. Uppala, and M. Fuentes, 2004: The ERA-40 archive, $31 \mathrm{pp}$.

Kalma, J. D., T. R. McVicar, and M. F. McCabe, 2008: Estimating land surface evapouration: A review of methods using remotely sensed surface temperature data. Surveys in Geophysics, 29, 421-469, DOI : 10.1007/s10712-008-9037-z.

Kaufman, Y. J. and G. B. Cai, 1992: Remote Sensing of Water Vapour in the Near IR from EOS/MODIS. IEEE Transactions on Geoscience and Remote Sensing, 5, 871-884.

Kaufmann, R. K., L. Zhou, R. B. Myneni, C. J. Tucker, D. Slayback, N. V. Shabanov, and J. Pinzon, 2003: The effect of vegetation on surface temperature: A statistical analysis of NDVI and climate data. Geophysical Research Letters, 30,DOI: 10.1029/2003GL018251.

Kerr, Y. H., J. P. Lagouarade, and J. Imbernon, 1992: Accurate land surface temperature retrieval from AVHRR data with use of an improved split window algorithm. Remote Sensing of Environment, 41, 197-209.

Kogan, F. N., 1995: Droughts of the late 1980s in the United States as derived from NOAA Polar-orbiting satellite data. Bulletin of the American Meteorological Society, 76, 655-668.

Kogan, F. N., 1997: Global drought watch from space. Bulletin of the 
American Meteorological Society, 78, 621-636.

Koike, T., 2002: CEOP starts-A step for predictability improvement of the water cycle and water resources, CEOP News Letter, 1: 1-2.

Koike, T., T. Yasunari, J. Wang, and T. Yao, 1999: GAME-Tibet IOP summary report. Proc. First International Workshop on GAME-Tibet, Xi'an China, 1-2.

Li, D., Q. Wu, and M. Tang, 2005: The time-space variety characteristics of the surface temperature over the Qinghai-Tibet Plateau. Science and Review Technology, 18-22.

Li, S., G. R. Dong, J. Y. Shen, P. Yang, X. W. Liu, Y. Wang, H. L. J in, and Q. Wang, 1999: Formation mechanism and development pattern of aeolian sand landform in Yarlung-Zangbo River valley. Science in China Series D: Earth Sciences, 42, 272-281.

Li, S., Y. Wang, S. Ha, P. Yang, H. J in, and J. Zhang, 1997: Classification and development of aeolian sand landform in the Yurlung Zangbo Valley. Journal of Desert Research, 17, 342-350.

$\mathrm{Li}, \mathrm{X}$. and T. Koike, 2003: Frozen soil parameterization in SiB2 and its validation with GAME-Tibet observations. Cold Regions Science and Technology, 36, 165-182.

Li, X. and P. Shi, 2000: Sensitivity analysis of variation in NDVI, temperature and precipitation in typical vegetation types across China. Acta Phytoecologica Sinica, 24, 379-382. (in Chinese with English abstract)

Liang, S., 2000: Narrowband to broadband conversions of land surface albedo I Algorithms. Remote Sensing of Environment, 76, 213-238.

Liang, S., J. C. Shuey, A. L. Russ, H. Fang, M. Chen, C. L. Walthall, C. S. T. Daughtry, and R. H. J r., 2002: Narrowband to broadband conversions of land surface albedo: II. validation. Remote Sensing of Environment, 84, 25-41.

Liu, X. and B. Chen, 2000: Climatic warming in the Tibetan Plateau during recent decades. International journal of Climatology, 20, 1729-1742.

Liu, X., Z. Yin, X. Shao, and N. Qin, 2006: Temporal trends and variability of daily maximum and minimum, extreme temperature events, and growing season length over the eastern and central Tibetan Plateau during 1961-2003. Journal of Geophysical Research, 111, doi: 10.1029/2005J D006915.

Loew, A., T. Holmes, and R. d. Jeu, 2009: The European heat wave 2003: early indicators from multisensoral microwave remote sensing? J ournal of Geophysical Research, 114, D05103.

Lu, D., 1997: Mongolia semi-arid grassland soil-vegetation-atmosphere interaction (IMGRASS), Global Change News Letter, 31,4-5.

$\mathrm{Ma}, \mathrm{W}$. and Y. Ma, 2006: The annual variations on land surface energy in the northern Tibetan Plateau. Environmental Geology, 50, 645-650.

Ma, W., M. Hafeez, H. Ishikawa and Y. Ma, 2013: Evaluation of SEBS for estimation of actual evapotranspiration using ASTER satellite data for 
irrigation areas of Australia. Theoretical and Applied Climatology, 112, 609-616, DOI 10.1007/s00704-012-0754-3.

Ma, W., Y. Ma, L. Zhong, D. Chu, and C. Bianba, 2010: Land surface variables estimated from ASTER remote sensing data in 'Three Rivers' area of Tibetan Plateau. Plateau Meteorology, 29, 1351-1355. (in Chinese with English abstract)

Ma, Y., 2006: Determination of regional surface heat fluxes over heterogeneous landscapes by integrating satellite remote sensing with boundary layer observations, PhD dissertation (ISBN 90-8504-483-9), Wageningen, The Netherlands, pp203.

Ma, Y., S. Fan, H. Ishikawa, O. Tsukamoto, T. Yao, T. Koike, H. Zuo, Z. Hu, and Z. Su, 2005: Diurnal and inter-monthly variation of land surface heat fluxes over the central Tibetan Plateau area. Theoretical and Applied Climatology, 80, 259-273.

Ma, Y., H. Ishikawa, O. Tsukamoto, M. Menenti, Z. Su, J. Wang, T. Yao, T. Koike, and T. Yasunari, 2003: Regionalization of surface fluxes over heterogeneous landscape of the Tibetan Plateau by using satellite remote sensing data. Journal of the Meteorological Society of Japan, 81, 277-293.

Ma, Y., M. Menenti, and R. Feddes, 2010: Parameterization of heat fluxes at heterogeneous surfaces by integrating satellite measurements with surface layer and atmospheric boundary layer observations Advances in Atmospheric Sciences, 27, 328-336.

Ma, Y., M. Menenti, R. Feddes, and J. Wang, 2008: Analysis of the land surface heterogeneity and its impact on atmospheric variables and the aerodynamic and thermodynamic roughness lengths. Journal of Geophysical Research, 113,DOI: 10.1029/2007J D009124.

Ma, Y., M. Song, H. Ishikawa, K.Yang, T.Koike, L.Jia, M. Menenti, and Z. Su, 2007: Estimation of the regional evapourative fraction over the Tibetan Plateau area by using Landsat-7 ETM data and the field observations. J ournal of Meteorological Society of Japan, 85A, 295-309.

Ma, Y., Z. Su, Z.-L. Li, T. Koike, and M.Menenti, 2002: Determination of regional net radiation and soil heat flux densities over heterogeneous landscape of the Tibetan Plateau. Hydrological Processes, 16, 29632971.

Ma, Y., O. Tsukamoto, J. Wang, H. Ishikawa, I. Tamagawa, and 2002: Analysis of aerodynamic and thermodynamic parameters over the grassy marshland surface of Tibetan Plateau. Progress in Nature Science, 12, 36- 40.

Ma, Y. and O. Tsukaoto, 2002: Combining Satellite Remote Sensing with Field Observations for Land Surface Heat Fluxes over Inhomogeneous Landscape. China Meteorological Press, 172 pp.

Ma, Y., L. Zhong, Z. Su, H. Ishikawa, M. Menenti, and T. Koike, 2006: Determination of regional distributions and seasonal variations of land 
surface heat fluxes from Landsat-7 Ehanced Thematic Mapper data over the central Tibetan Plateau area. Journal of Geophysical Research, 111, doi: 10.1029/2005J D006742.

Ma, Y., L. Zhong, H. Tian, F. Sun, Z. Su, and M. Menenti, 2006: Study on the regional land surface heat fluxes over heterogeneous landscape of the Tibetan Plateau area. Journal of Remote Sensing, 10, 542-547. (in Chinese with English abstract)

Ma, Y., L. Zhong, B. Wang, W. Ma, X. Chen, and M. Li, 2011: Determination of land surface heat fluxes over heterogeneous landscape of the Tibetan Plateau by using the MODIS and in situ data. Atmospheric Chemistry and Physics, 11, 19617-19638.

Ma, Y., L. Zhong, Y. Wang, and Z. Su, 2012: Using NOAA/AVHRR data to determine regional net radiation and soil heat fluxes over the heterogeneous landscape of the Tibetan Plateau. International J ournal of Remote Sensing, 33, 4784-4795.

Maisongrande, P., B. Duchemin, and G. Dedieu, 2004: VEGETATION/SPOT: an operational mission for the Earth monitoring; presentation of new standard products I nternational J ournal of Remote Sensing, 25, 9-14.

Mao, K., Z. Qin, J. Shi, and P. Gong, 2005a: A practical split-window algorithm for retrieving land-surface temperature from MODIS data. International J ournal of Remote Sensing, 26, 3181-3204.

Mao, K., Z. Qin, J. Shi, and P. GONG, 2005b: The research of Split-Window Algorithm on the MODIS. Geomatics and Information Science of Wuhan University, 30, 703-707.

Menenti, M., 1984: Physical aspects and determination of evapouration in deserts applying remote sensing techniques Report 10 (Special issue), Institute for Land and Water Management Research (ICW), The Netherlands, 202 pp.

Menenti, M. and B. J. Choudhury, 1993: Parameterization of land surface evapotranspiration using a location dependent potential evapotranspiration and surface temperature range. In: Bolle et al. (eds) Exchange processes at the land surface for a range of space and time scales. IAHS, Oxfordshire. No. 212. 561-568.

McMillin, L. M., 1975: Estimation of sea surface temperature from two infrared window measurements with different absorption. Journal of Geophysical Research, 36, 5113-5117.

McVicar, T. R. and C. Körner, 2013: On the use of elevation, altitude and height in the ecological and climatology literature. Oecologia, 171, 335337. DOI : 10.1007/s00442-012-2416-7.

McVicar, T. R. and D. L. B. Jupp, 1998: The current and potential operational uses of remote sensing to aid decisions on drought exceptional circumstances in Australia: a review. Agricultural Systems, 57, 399-468.

McVicar, T. R. and D. L. B. Jupp, 2002: Using covariates to spatially interpolate moisture availability in the Murray-Darling Basin A novel 
use of remotely sensed data. Remote Sensing of Environment, 79, 209-212.

McVicar, T. R., D. L. B. Jupp, X. Yang, and G. Tian, 1992: Linking regional water balance models with remote sensing. In Proceedings of the 13th Asian Conference on Remote Sensing, Ulaanbaatar, Mongolia, B.6.1B.6.6.

McVicar, T. R., M. L. Roderick, R. J. Donohue, L. T. Li, T. G. Van Niel, A. Thomas, J. Grieser, D. Jhajharia, Y. Himri, N. M. Mahowald, A. V. Mescherskaya, A. C. Kruger, S. Rehman, and Y. Dinpashoh, 2012: Global review and synthesis of trends in observed terrestrial near-surface wind speeds: Implications for evapouration. Journal of Hydrology, 416-417, 182-205.

Myneni, R., C. Keeling, C. Tucker, G. Asrar, and R. Nemani, 1997: Increased plant growth in the northern high latitudes from 1981 to 1991. Nature, 386, 698-702.

Niemeyer, S. and J. V. Vogt, 1998: Towards monitoring drought conditions in Sicily using an energy balance approach. Proceedings 7th International Conference for Computer Technology in Agriculture (ICCTA), Florence, Italy, 459-466.

Oku, Y. and H. Ishikawa, 2004: Estimation of land surface temperature over the Tibetan Plateau using GMS data. Journal of Applied Meteorology, 43, 548-561.

Oku, Y., H. Ishikawa, and Z. Su, 2007: Estimation of land surface heat fluxes over the Tibetan plateau using GMS data. In: Journal of applied meteorology and climatology. Journal of Applied Meteorology and Climatology, 46, 183-195.

Ottlé, C. and D. Vidal-Madjar, 1992: Estimation of land surface temperature with NOAA-9 Data. Remote Sensing of Environment, 40, 27-41.

Owe, M., R. d. Jeu, and T. Holmes, 2008: Multisensor historical climatology of satellite-derived global land surface moisture. Journal of Geophysical Research, 113, doi: 10.1029/2007J F000769

Padhi, J., R. K. Misra and J. O. Payero, 2012: Estimation of soil water deficit in an irrigated cotton field with infrared thermography. Field Crops Research, 126, 45-55.

Peel, M. C., B. L. Finlayson, and T. A. McMahon, 2007: Updated world map of the Koppen-Geiger climate classification. Hydrology and Earth System Sciences, 11, 1633-1644.

Piao, S., A. Mohammat, J. Fang, Q. Cai, and J. Feng, 2006: NDVI-based increase in growth of temperate grasslands and its responses to climate changes in China. Global Environmental Change, 16, 340-348.

Prata, A. J., 1993: Land surface temperature derived from the Advanced Very High Resolution Radiometer and the Along-Track Scanning Radiometer 1. Theory. . J ournal of Geophysical Research, 98, 16689-16702.

Prata, A. J. and M. Platt, 1991: Land surface temperature measurements 
from the AVHRR. In Proceedings of the 5th AVHRR data Users' Meeting. Tromso (NORWAY), EUMETSAT, Darmstadt, 433-438.

Price, J. C., 1984: Land surface temperature measurements from the split window channels of the NOAA 7 Advanced Very High Resolution Radiometer. J ournal of Geophysical Research, 89, 7231-7237.

$\mathrm{Pu}, \mathrm{S}$. and J. Fang, 2001: Dynamic vegetation cover change over the last 18 years in China. Quaternary Sciences, 21, 294-302. (in Chinese with English abstract)

Qin, Z. and A. Karnieli, 1999: Progress in the remote sensing of land surface temperature and ground emissivity using NOAA-AVHRR data. International J ournal of Remote Sensing, 20, 2367-2393.

Qin, Z., G. D. Olmo, and A. Karnieli, 2001: Derivation of split window algorithm and its sensitivity analysis for retrieving land surface temperature from NOAA-advanced very high resolution radiometer data. J ournal of Geophysics Research, 106, 22655-22670.

Qiu, J., 2008: The third pole. Nature, 454, 393-396.

Rahman, H. and G. Dedieu, 1994: SMAC: a simplified method for the atmospheric correction of satellite measurements in the solar spectrum. International J ournal of Remote Sensing, 15, 123-143.

Rees, M., R. Condit, M. Crawley, S. Pacala, and D. Tilman, 2001: Long-term studies of vegetation dynamics. Science, 293, 650-655.

Rodell, M., P. R. Houser, U. Jambor, J. Gottschalck, K. Mitchell, C. J. Meng, K. Arsenault, B. Cosgrove, J. Radakovich, M. Bosilovich, J. K. Entin, J. P. Walker, D. Lohmann, and D. Toll, 2004: The Global Land Data Assimilation System. Bulletin of the American Meteorological Society, 85, 381-394.

Roerink, G. J., M. Menenti, W. Soepboer, and Z. Su, 2003: Assessment of climate impact on vegetation dynamics by using remote sensing. Physical and Chemistry of the Earth, 28, 103-109.

Roerink, G. J., Z. Su, and M. Menenti, 2000: S-SEBI: a simple remote sensing algorithm to estimate the surface energy balance. Physics and Chemistry of the Earth, Part B: Hydrology, Oceans and Atmosphere, 25, 147-157.

Roger, A. P., S. , I. A. Ron, R. Michael, A. J. Dolman, Z. Xubin, and A. S. Denning, 1998: Interactions between the atmosphere and terrestrial ecosystems: influence on weather and climate. Global Change Biology, 4, 461-475.

Rosegrant, M. W., C. Ringler and Zhu T, 2009: Water for agriculture: Maintaining food security under growing scarcity. Annual Review of Environment and Resources, 34, 205-222, DOI: 10.1146/annurev.environ.030308.090351.

Rouse, J. W., R. W. Hass, J. A. Schell, D. W. Deering, and J. C. Harlan, 1974: Monitoring the vernal advancement and retrogradiation (green wave effect) of natural vegetation, NASA/GSFCT Type III Final Report. 
Greenbelt, MD, USA.

Schmugge, T. J. and J. C. Andre, 1991: Land surface evapouration measurement and parameterization, Springer Verlag, New York, 424.

Sellers, A. H., and F. G. Hall, 1992: FIFE special Issue, Journal of Geophysics Research, 97(D17): 18343-19109.

Sellers, P. J., C. A. Norbre, D. J. Fitjarrald, 1993: LAMBADA-BATERISTA: A preliminary science plan for a large scale biosphere-atmosphere field experiment in Amazon Basin, ISLSCP, IGPO Washington D.C., 49.

Shahabfar, A., A. Ghulam, and J. Eitzinger, 2012: Drought monitoring in Iran using the perpendicular drought indices International Journal of Applied Earth Observation and Geoinformation, 18, 119-127.

Shen, W., H. Li, M. Sun, and J. Jiang, 2012: Dynamics of aeolian sandy land in the Yarlung-Zangbo River basin of Tibet, China from 1975 to 2008. Global and Planetary Change, 86-87, 37-44.

Smith, E. and L. Shi, 1995: Reducing discrepancies in atmospheric heat budget of Tibetan Plateau by satellite-based estimates of radiative cooling and cloud-radiation feedback. Meteorology and Atmospheric Physics, 56, 229-260.

Sobrino, J. A., V. Caselles, and F. Becker, 1990: Significance of the remotely sensed thermal infrared measurements obtained over a citrus orchard. ISPRS Photogrammetric Engineering and Remote Sensing, 44, 343-354.

Sobrino, J. A., C. Coll, and V. Caselles, 1991: Atmospheric correction for land surface temperature using NOAA-11AVHRR channels 4 and 5. Remote Sens. Environ., 38, 19-34.

Sobrino, J. A., Z. L. Li, M. P. Stoll, and F. Becker, 1994: Improvements in the split-window technique for land surface temperature determination. IEEE Transaction of Geoscience and Remote Sensing, 32, 243-253.

Sobrino, J. A. and N. Raissouni, 2000: Toward remote sensing methods for land cover dynamic monitoring: application to Morocco. International J ournal of Remote Sensing, 21, 353-366.

Sobrino, J. A., N. Raissouni, J. Simarro, F. Nerry, and F. Petitcolin, 1999: Atmospheric water vapour content over land surfaces derived from the AVHRR data: Application to the Iberian Peninsula. IEEE, Transactions on Geoscience and Remote Sensing, 37, 1425-1434.

Song, M., Y. Ma, Y. Zhang, M. Li, W. Ma and F. Sun, 2011: Climate change features along the Brahmaputra Valley in the past 26 years and possible causes. Climatic Change, 106, 649-660.

Son, N. T., C. F. Chen, C. R. Chen, L. Y. Chang, and V. Q. Minh, 2012: Monitoring agricultural drought in the Lower Mekong Basin using MODIS NDVI and land surface temperature data. International Journal of Applied Earth Observation and Geoinformation, 18, 417-427.

Sun, F., M. L. Roderick, and G. D. Farquhar, 2012: Changes in the variability of global land precipitation. Geophysical Research Letters, 39, DOI : 10.1029/2012GL053369. 
Su, Z., 2002: The Surface Energ Balance System (SEBS) for estimation of turbulent heat fluxes. Hydrology and Earth System Sciences, 6, 85-99.

Su, Z., Y. Abreham, W. J un, R. Gerbert, H. Yanbo, G. Benhu, B. Hendrik, and V. D. Cees, 2003: Assessing relative soil moisture with remote sensing data:theory, experimental validation, and application to drought monitoring over the North China Plain. Physics and Chemistry of the Earth, 28, 89-101.

Su, Z., G. Roerink, and C. Jacobs, 2001: Development of a procedure to produce time series of evapouration fractionsREPORT USP-2, 01-02, 184- $186 \mathrm{pp}$.

Tanaka, K., H. Ishikawa, T. Hayashi, I. Tamagawa, and Y. M. Ma, 2001: Surface energy budget at Amdo on the Tibetan Plateau using GAME/Tibet IOP98 data. Journal of the Meteorological Society of Japan, 79, 505-517.

Timmermans, W. and J. Kwast, 2005: Intercomparison of energy flux models using ASTER imagery at the SPARC 2004 site (Barrax, Spain). SPARC final workshop.

Ulivieri, C., M. M. Castronuovo, R. Francioni, and A. Cardillo, 1996: A splitwindow algorithm for estimating land surface temperatures from satellites. Advances in Space Research, 14, 1279-1292.

Univieri, C., M. M. C. Castronuovo, R. Francionis, and A. Cardillo, 1992: A split-window algorithm for estimating and surface temperatures from satellites. COSPAR, Comm. On Space Programs and Research, Washington, D.C.

Van Loon, A. F. and H. A. J. Van Lanen, 2013: Making the distinction between water scarcity and drought using an observation-modeling framework. Water Resources Research, 49, 1483-1502.

Verhoef, W., 1996: Application of Harmonic Analysis of NDVI Time Series (HANTS) 19-24. pp.

Verhoef, W., A. v. d. Kamp, and R. Koelemeijer, 2005: Climate Indicators from Time Series of NDVI Images (CITISEN), $30 \mathrm{pp}$.

Vidal, A., 1991: Atmospheric and emissivity correction of land surface temperature measured from satellite using ground measurements or satellite data. International J ournal of Remote Sensing, 12, 2449-2460.

Vogt, J. V., S. Niemeyer, F. Somma, I. Beaudin, and A. A. Viau, 2000: Drought Monitoring from Space. Advances in Natural and Technological Hazards Research Springer Netherlands.

Wang, B., 2006: The Asian Monsoon. Springer, 844 pp.

Wang, J. M., 1999: Land surface process experiments and interaction study in China-from HEIFE to IMGRASS and GAME-Tibet/Tipex, Plateau Meteorology, 18,280-294.

Wang, J., Y. Gao, and Y. Hu, 1993: An overview of the HEIFE experiment in the People's Republic of China, Exchange processes at the land surface for a range of space and time scales, IAHS Publication, 212: 397-403. 
Wang, K., Z. Wan, P. Wang, M. Sparrow, J. Liu, and S. Haginoya, 2007: Evaluation and improvement of the MODIS land surface temperature/emissivity products using ground-based measurements at a semi-desert site on the western Tibetan Plateau. International J ournal of Remote Sensing, 28, 2549-2565.

Wanjura, D. F. and D. R. Upchurch, 2000: Canopy temperature characterizations of corn and cotton water status. Transactions of the ASAE, 43, 867-875.

Wei, X., P. Yang, and G. Dong, 2004: Agricultural development and farmland desertification in middle 'One River and Its two branches' river basin of Tibet. J ournal of Desert Research, 24, 196-200.

Wen, J. and Z. Su, 2004: An analytical algorithm for the determination of vegetation leaf area index from TRMM-TMI data. International Journal of Remote Sensing, 25, 1223-1234.

Wen, J., L. Wang, and Z.G. Wei, 2009: An overview of the LOess Plateau mesa region land surface process field EXperiment series (LOPEXs), Hydrology and Earth System Sciences, 13:945-951.

Wen, J., Z. Su, and Y. Ma, 2004: Reconstruction of a cloud-free vegetation index time series for the Tibetan Plateau. Mountain Research and Development, 24, 348-353.

Wu, R., 1993: An analysis on "Three Rivers" water resource and its annual runoff. Sichuan Water Conservancy, 14, 26-27. (in Chinese with English abstract)

Xu, J., 2004: Mathematical Method in Contemporary Geography. Higher Education Press, $457 \mathrm{pp}$.

Xu, M., C.-P. Chang, C. Fu, Y. Qi, A. Robock, D. Robinson, and H.-m. Zhang, 2006: Steady decline of east Asian monsoon winds, 1969-2000: Evidence from direct ground measurements of wind speed. Journal of Geophysical Research, 111,DOI : 10.1029/2006J D007337.

$\mathrm{Xu}, \mathrm{X}$. and Z. Lin, 2002: Remote sensing retrieval of surface monthly mean albedo in Qinghai-Xizang Plateau. Plateau Meteorology, 21, 233-237. (in Chinese with English abstract)

Yang, H. and Z. Yang, 2006: A modified land surface temperature split window retrieval algorithm and its applications over China. Global and Planetary Change, 52, 207-215.

Yang, K., T. Koike, H. Fujii, K. Tamagawa, and N. Hirose, 2002: Improvement of suface flux parameterizations with a turbulentce-related length. Quarterly Journal of the Royal Meteorological Society, 128B, 2073-2088.

Yang, K., T. Koike, H. Ishikawa, and Y. Ma, 2004: Analysis of the surface energy budget at a site of GAME/Tibet using a singe-source model. Journal of the Meteorologicla Society of Japan, 82, 131-153.

Yang, K., T. Koike, and D. Yang, 2003: Surface flux parameterization in the Tibetan Plateau. Boundary Layer Meteorology, 116, 245-262.

Yang, K., N. Tamai, and T. Koike, 2001: Analytical solution of surface layer 
similarity equations. Journal of Applied Meteorology, 40, 1647-1653.

Yao, T. D., L. G. Thompson, V. Musbrugger, Y. M. Ma, F. Zhang, X.X. Yang, and D. Joswiak, 2011: UNESCO-SCOPE-UNEP Policy Briefs Series, Third Pole Environment, UNESCO-SCOPE-UNEP, Paris.

Ye, D., 1981: Some characteristics of the summer circulation over the Qinghai-Xizang(Tibet) Plateau and its neighborhood. Bulletin of the American Meteorological Society, 62, 14-19.

Ye, D. and Y. Gao, 1979: Meteorology of the Qinghai-Xizang (Tibet) Plateau. Science Press, $278 \mathrm{pp}$.

Ye, D. and G. Wu, 1998: The role of the heat source of the Tibetan Plateau in the General circulation. Meteorology and Atmospheric Physics, 67, 181198.

You, Q., S. Kang, N. Pepin, and Y. Yan, 2008: Relationship between trends in temperature extremes and elevation in the eastern and central Tibetan Plateau, 1961-2005. Geophyiscal Research Letters, 35,DOI: 10.1029/2007GL032669.

You, Q., S. Kang, Y. Wu, and Y. Yan, 2007: Climate change over the YarlungZangbo River Basin during 1961-2005. Journal of Geographical Sciences 17, 409-420.

Zhang, A. and G. Jia, 2013: Monitoring meteorological drought in semiarid regions using multi-sensor microwave remote sensing data. Remote Sensing of Environment, 134, 12-23.

Zhang, Q., S. Kang, and Y. Yan, 2006: Characteristics of spatial and temporal variations of monthly mean surface air temperature over Qinghai-Tibet Plateau. Chinese Geographical Science, 16, 351-358.

Zhang, Y., B. Li, and D. Zheng, 2002: A discussion on the boundary and area of the Tibetan Plateau in China. Geographical Research, 21, 1-8.

Zheng, D., \& Li, B. (1999). Progresses in studies on geographical environments of the Qinghai-Xizang Plateau. Chinese Geographical Science, 9, 289-296.

Zheng, D., Q. Yang, and Y. Liu, 1985: The Tibetan Plateau of China. Science Press, $267 \mathrm{pp}$.

Zhong, L., 2007: Ground measurement and satellite remote sensing of land surface characteristics parameters over the Tibetan Plateau area. Dissertation submitted to Graduate University of Chinese Academy of Sciences ed. PhD thesis, $124 \mathrm{pp}$.

Zhong, L., Y. Ma, W. Ma, D. Chu, and C. Bianba, 2011a: Land surface heat fluxes in the middle reaches of Yarlung-Zangbo river and its two tributaries derived from AVHRR and MODIS data. Journal of Glaciology and Geocryology, 33, 309-317. (in Chinese with English abstract)

Zhong, L., Y. Ma, W. Ma, Y. Fu, Z. Su, M. S. Salama, D. Chu, and C. Bianba, 2012: Remote sensing of land surface parameters in the middle reaches of Yarlung-Zangbo River and its two tributaries from AVHRR and MODIS data. Journal of the Meteorological Society of Japan, 90C, 75-86. 
Zhong, L., Y. Ma, M. S. Salama, and Z. Su, 2010: Assessment of vegetation dynamics and their response to variations in precipitation and temperature in the Tibetan Plateau. Climatic Change, 519-535.

Zhong, L., Y. Ma, Z. Su, X. Liu, M. Li, W. Ma, and Y. Wang, 2006: Atmospheric turbulence and land-atmosphere energy transfer characteristics in the surface layer of the northern slope of Mt. Qomolangma area Advances in Earth Science, 21, 156-166. (in Chinese with English abstract)

Zhong, L., Y. Ma, Z. Su, W. Ma, and Y. Lv, 2009: Land-atmosphere energy transfer and surface boundary layer characteristics in the Rongbu valley on the northern slope of Mt. Everest. Arctic, Antarctic, and Alpine Research, 41, 396-405.

Zhong, L., Y. Ma, Z. Su, and M. S. Salama, 2010: Estimation of Land Surface Temperature over the Tibetan Plateau Using AVHRR and MODIS Data. Advances in Atmospheric Sciences, 27, 1110-1118.

Zhong, L., Z. Su, Y. Ma, M. S. Salama, and J. A. SOBRINO, 2011b: Accelerated changes of environmental conditions on the Tibetan Plateau caused by climate change. Journal of Climate, 24, 6540-6550.

Zhong, Q. and S. Wu, 1985: A method for determing surface albedo over the Tibetan Plateau from AVHRR data Plateau Meteorology, 4, 193-203. (in Chinese with English abstract)

Zhou, D., G. Fan, R. Huang, Z. Fang, Y. Liu, and H. Li, 2007: Interannual variability of the normalized difference vegetation index on the Tibetan Plateau and its relationship with climate change. Advances in Atmospheric Sciences, 24, 474-484.

Zhou, L., C. Tucker, R. Kaufmann, D. Slayback, N. Shabanov, and R. Myneni, 2001: Variations in northern vegetation activity inferred from satellite data of vegetation index during 1981 to 1999. Journal of Geophysical Research, 106, 20069-20083.

Zhou, R., Y. Yang, and J. Fang, 2007: Responses of vegetation activity to precipitation variation on the Tibetan Plateau. Acta Scientiarum Naturalium Universitatis Pekinensis, 43, 771-775.

Zhu, C., F. Zhu, and Y. Liu, 1993: On the relationship between clear-sky planetary and surface albedos over the Qinghai-Xizang Plateau. Acta Meteorologica Sinica, 51, 57-65. (in Chinese with English abstract) 


\section{Summary}

Based on remote sensing data (such as AVHRR, MODIS, SPOT), reanalysis data (such as GLDAS, ERA-40) and available in-situ meteorological data in the atmospheric boundary layer, the spatio-temporal variations of land surface parameters (e.g. LST, Albedo, NDVI ) are, for the first time, derived over the entire TP. We also identify the vegetation dynamics and their responses to meteorological variations in the TP. Furthermore, the accelerated changes of land surface parameters on the TP are also clearly demonstrated. With the use of SEBS algorithm, the energy balance components (e.g. net radiation heat flux, sensible heat flux, latent heat flux and soil heat flux) and surface soil water deficit conditions are estimated in the YZR and its two tributaries. In conclusion, the innovative work and contribution of this thesis mainly focus on the following aspects.

\section{Retrieval of LST over the entire TP}

The distribution of the meteorological stations over the TP area, especially in the western part, is not only sparse but also uneven. This situation constrains the quantitative understanding of the energy and water cycles over the Tibetan Plateau. The development of remote sensing technology provides the possibility of acquiring large amount of global high-resolution and real-time data. Great developments have been made in the retrieval of land surface parameters and land-atmosphere energy exchanges by remote sensing data. But at the same time, it must be pointed out that the current scientific results are mainly limited to meso-scale experiment area in the northern TP or at local scale. So far it was difficult to retrieve land surface parameters and land-atmosphere fluxes for the entire TP which accounts for $25 \%$ of the Chinese territory. Based on AVHRR and MODIS data, the LST over the entire TP has been retrieved. The spatial distribution and seasonal variation characteristics have been clearly identified. The innovation of our study is that, relative to the previous studies which focus on the estimation of land surface temperature at meso-scale level, two sets of LST retrieval algorithms have been developed and validated. The regional LST retrieval has been also extended to the entire TP. And two different satellite data with similar spatial resolutions have been introduced to make a comparison in this study. The scientific significance of this innovative method is it revealed the spatial distribution and seasonal variations of the LST over the Tibetan Plateau. Thus it provides vital data that are necessary for the parameterization of the surface fluxes over the Tibetan Plateau. It also has significant meaning for the understanding of the energy and water cycles in the inner TP and even surrounding areas. 


\section{Long-term variations of land surface environment over the TP}

A wide range of surface environments can be effectively and continuously monitored by remote sensing data. However, most previous studies usually focused on algorithm development in which the regional surface parameters (e.g. entire TP) could not be acquired because of the limitation of the retrieval algorithms. Based on 20-year NOAA/NASA Pathfinder AVHRR Land (PAL) dataset, we retrieve time series of land surface parameters, such as LST, albedo, NDVI, applying validated algorithms for AVHRR data. Compared to previous studies, we have extended the PAL algorithm to the entire Tibetan Plateau. The novelty of this work is in its introduction of the ERA-40, GLDAS data and the bulk aerodynamic method to analyze the long-term variations of surface sensible and latent heat fluxes over the TP and their inner relationship with land surface parameters. This study makes contribution to the long-term variation of surface environment over the TP under climatic change.

\section{Vegetation dynamics and their responses to variation in air temperature and precipitation}

Based on SPOT data, the HANTS algorithm was applied to remove the cloud cover and reconstruct time series data. Simultaneously, GLC2000, which has the same spatial resolution of $1 \mathrm{~km}$ was also introduced into the study to retrieve the vegetation dynamics and their responses to air temperature and precipitation. The major novel idea of this part is the introduction of GLC2000 to match the high-resolution SPOT data. The other innovation is the reconstruction of the time series and cloud removal using HANTS algorithm. The main contribution of this study is to reveal the variation trends of different vegetation types over the TP in recent 10 years and their responses to climatic change.

\section{Estimation of surface energy balance components and soil water deficit in YZR and its two tributaries}

In the past decades, different satellite based approaches were established to estimate land surface heat fluxes and soil water deficit conditions. Examples are the use of vegetation indices, land surface temperature, a combination of both, the microwave backscatter signal, or energy balance models with remote sensing data and meteorological data as the input data. However, the most common satellite based indicators like the normalized difference vegetation index (NDVI), vegetation condition index $(\mathrm{VCl})$ and temperature condition index $(\mathrm{TCl})$ are difficult to interpret in heterogeneous terrain. Although the energy balance models have distinct physical mechanism, prefixed values are often used for the roughness height of heat transfer in most models. In fact, the roughness height of heat transfer can vary in several orders of magnitude for large scale heterogeneous surfaces. A model for the determination of the roughness length of heat transfer has been built in SEBS. 
Therefore, SEBS derived energy balance components and SWDI have great advantages over other methods in determination of surface heat fluxes and soil water stress for large-scale heterogeneous study areas.

\section{Perspectives for future research}

The TP plays a major role in the climatic system of Asia and the monsoon systems. It has an important influence on the regional and even global atmospheric circulations. The Himalayas and the TP exert profound thermal and dynamical influences on atmospheric circulation, through surface topography and conditions (surface roughness, snow cover, and soil moisture), including dynamics of vegetation cover. For the past several decades, scientists from all over the world have made great efforts to try to reveal the energy and water cycles in this special and important region. This thesis makes some contributions to the scientific efforts towards understanding the land-atmosphere interaction in the TP through better quantification of LSP over the whole region. Based on our results in this thesis, in cooperation with Prof.Yaoming Ma, we have retrieved the plateauscale energy balance components by applying Ma's algorithms. Several papers have been published. However, dealing with the regional surface heat fluxes over a heterogeneous landscape is not an easy task. For the time being, the parameterization method is still in the developing stage and only several satellite images at a specific time of specific days have been used. To reach more accurate regional surface heat fluxes, more satellite images need to be used and more in-situ measurements need to be established to get time series images of energy and water fluxes over the TP.

On the other hand, much more attention should be given to the water cycle part. Specific attention should be given to clouds and precipitation. Another key issue for the energy and water cycles of the Asian monsoon is cloud and precipitation processes and their interactions with large-scale atmospheric circulation. A-train satellite observations provide the opportunity and possibility for relevant studies. The formation of satellites which currently includes Aqua, CloudSat, Cloud-Aerosol Lidar and Infrared Pathfinder Satellite Observations (CALIPSO) and Aura satellites may provide better understanding of the climate system by quantifying the complex relationships that connect water in all three phases to heat exchanges between the surface, atmosphere, and space; to aerosols; and to trace gases. 


\section{Samenvatting}

In dit onderzoek worden voor het eerst, zijn de spatiale temporale variaties van de land parameters (zoals Landoppervlakte temperatuur, Albedo en NDVI) berekend over het Tibetaans plateau. Dit is gedaan met behulp van aardobservatie data (zoals AVHHR, MODIS, SPOT), re-analyse data (zoals GLDAS, ERA-40) en beschikbare meteorologische data van de atmosferische grenslaag. Wij hebben hiernaast ook de dynamiek van de vegetatie en hun reactie op meteorologische veranderingen in kaart gebracht, waarbij versnelde veranderingen in de land parameters duidelijk zijn geillustreerd. Met het gebruik van het SEBS algoritme zijn daarna de energy balans componenten (netto straling, voelbare warmte, grond warmte en latente warmte) en de water tekort berekend over de YZR rivier. Dit innovatieve werk heeft zich met name toegespitst op de volgende aspecten.

\section{Het berekenen van landoppervlakte temperaturen van het Tibetaans Plateau}

De verdeling van meteorologische stations op het Tibetaans Plateau is niet alleen erg dun, maar ook niet gelijk verdeeld, vooral in het westelijke gedeelte. Deze situatie limiteert onze kwantitatieve begrip van de energy en water cyclussen van het Tibetaans Plateau. De ontwikkeling van aardobservatie technieken is daarom van dermate belang, omdat zij ons de mogelijkheid geeft op grote hoeveelheden data op hoge resolutie near-realtime. Dit heeft geleidt tot grote ontwikkelingen in het berekenen van land parameters en de gerelateerde land-atmosfeer interacties met behulp van aardobservatie data. Er moet echter opgemerkt worden dat de huidige wetenschappelijke resultaten gelimiteerd zijn op punt van resolutie van tot lokale schaal tot meso-schaal. Tot zo ver was het daarom zeer moeilijk om de land parameters en fluxen te berekenen boven het Tibetaans Plateau (welke $25 \%$ van het Chinese grondgebied omvangt). Vandaar dat er onderzoek gedaan is naar het berekenen van de landoppervlakte temperatuur (LST) uit data van AVHHR en MODIS satelliet sensoren. Hier zijn de duidelijke spatiale en seizoenlijkse variaties duidelijk geïdentificeerd. De innovatie in dit onderzoek is dat twee LST algoritmen ontwikkeld en gevalideerd zijn met de focus op het berekenen van de landoppervlakte temperatuur at meso-schaal. De regionale LST algoritmes zijn daarnaast ook geüpdatet voor toepassing boven de gehele Tibetaans Plateau. Deze methodes zijn daarom toegepast op datasets van twee verschillende satelliet sensoren om een goede vergelijking te maken ten aanzien van de accuratesse. De wetenschappelijk significantie van deze innovatieve methodologie heeft de spatiale en seizoenlijkse veranderingen van het Tibetaans Plateau aangetoond. De methode laat dus zien de noodzakelijke input data te produceren voor het modelleren van oppervlakte fluxen boven het Tibetaans Plateau. Daarboven op zijn de vindingen significant bevonden voor een verbeterd begrip van de energie en 
water cyclussen van het Tibetaanse binnenland en zelfs rondom gelegen gebieden.

\section{Langdurige variaties van het land oppervlakte milieu op het Tibetaans Plateau}

Een grote diversiteit aan het milieu kan effectief en continu worden bemeten met behulp van aardobservatie metingen. De meeste studies, welke zijn echter gefocussed op het ontwikkelen van algoritmes, zijn gelimiteerd zodat regionale parameters niet konden worden berekend boven het Tibetaans Plateau. In deze context hebben we een langdurige tijdserie gemaakt van land parameters, zoals LST, albedo, NDVI, door gevalideerde algoritmes voor AVHRR data toe toepassen op een 20-jarige NOAA/NASA Pathfinder (PAL) dataset. Vergeleken met de vorige studies hebben we het PAL algorithme toegepast over het gehele Tibetaanse Plateau. De innovativiteit van dit onderzoek is de introductie van de ERA-40 en GLDAS data om de langdurige variaties in de (latente en voelbaar) fluxen te analyseren in vergelijking met de eerder bepaalde land parameters. Deze studie maakt daarom een grote contributie in het modelleren van de langdurige variatie van het milieu van Tibetaans Plateau.

\section{Vegetatie Dynamiek en responsiviteit op lucht temperatuur en neerslag}

In dit gedeelte van het onderzoek hebben we de vegetatie dynamiek bepaald op basis van SPOT data, welke verbeterd was met behulp van het HANTS algoritme. Samen met GLC2000 (welke de zelfde $1 \mathrm{~km}$ spatiale resolutie heeft als SPOT) is daarna de vegetatie dynamiek onderzocht op hun responsiviteit op lucht temperatuur en neerslag. De grootste contributie aan de wetenschap in dit gedeelte van de dissertatie is aan de ene kant, het reconstrueren (en verwijderen van wolk effecten) van SPOT data op basis van het HANTS algoritme, en anderzijds het matchen van GLC2000 aan deze hoge-resolutie SPOT data. De grootste resultaat van dit onderzoek betreft het karakteriseren van de trend van verschillende vegetatie types op het Tibetaans Plateau gedurende de laatste 10 jaar ten opzichte van de klimaat verandering.

\section{Berekening van de energie balans componenten en de water tekort in de YZR en haar twee stroomgebieden}

In de laatste twee decennia verschillende methodes (gebaseerd op aardobservatie) zijn gecreëerd om de warmte fluxen en water tekort te modelleren. Deze methodes verschillen in hun aanpak (empirisch, fysisch), hun invoer data (vegetatie indices, landoppervlakte temperatuur), en in het gebruik van microgolf data en meteorologische data. In heterogeen gebied zijn methodes gebaseerd op puur gebruik van vegetatie indices (zoals NDVI en $\mathrm{VCl}$ ) echter moeilijk te interpreteren. Vandaar dat energie balans methodes de voorkeur hebben in dit soort gebieden. Ondanks dat deze 
energie balans modellen puur fysische zijn gebaseerd worden a priori waarden van de aerodynamische ruwheden gebruikt in meeste gevallen. Een model voor het fysisch modelleren van deze ruwheid voor warmte transport is in SEBS ingebouwd. Dit geeft SEBS een voordeel boven andere modellen voor het berekenen van de verschillende fluxen en het water tekort (als berekend in SWDI), speciaal in heterogene gebieden.

\section{Perspectieven voor toekomstig onderzoek}

Het Tibetaans plateau speelt een zeer grote rol in het klimatologisch systeem van Azië en haar monsoen gebieden. Zij heeft een belangrijke invloed op de regionale en zelfs globale atmosferische circulaties. De Himalaya's en het Tibetaans Plateau oefenen hun grote thermodynamische invloed vooral uit op de atmosferische circulatie door middel van de topografie, oppervlakte condities (zoals ruwheid, besneeuwing en bodemvocht) en bedekkingsgraad van de vegetatie. Over de afgelopen decennia zijn daarom wetenschappers uit de hele wereld geïnteresseerd om de energie en water cyclus van dit speciale gebied te onderzoeken. Deze dissertatie maakt een bijdrage aan deze onderzoeken, speciaal op het gebied van land-atmosferische interactie en betere berekeningen voor de landoppervlakte temperaturen. Dit onderzoek, in samenwerking met Prof. Yaoming Ma, heeft de berekende energie balans componenten boven het plateau berekend, en resultaten hiervan zijn in verscheidene paper gepubliceerd. Echter er is nog steeds ruimte voor verbetering, specifiek gezien in het rekening houden van de heterogeniteit van het aardoppervlak. De gebruikte parameterizatie zijn nog steeds in ontwikkeling. Ook is er tijdens het onderzoek maar een gelimiteerd aantal satelliet beelden gebruikt. Om een betere accuratesse van de berekende fluxen te garanderen zijn meer grond metingen en satelliet observaties nodig.

Aan de andere kant moet ook meer aandacht besteed worden aan de water cyclus. Specifiek de variabiliteit in wolken en het neerslag proces met al haar atmosferische interacties met betrekking tot de Aziatische monsoen. Het Atrein concept (waarin verschillende satellieten achter elkaar rondes rond de aarde maken, zou hiervoor erg geschikt kunnen zijn. De formatie (Aqua, CloudSat, Cloud-Aerosol Lidar en InfraredPathfinderSatellite Observatie (CALIPSO) en Aura van deze satellieten zouden voor een beter begrip kunnen leiden naar het klimaat systeem door complexe relaties beten te kunnen kwantificeren. 


\section{Author's biography}

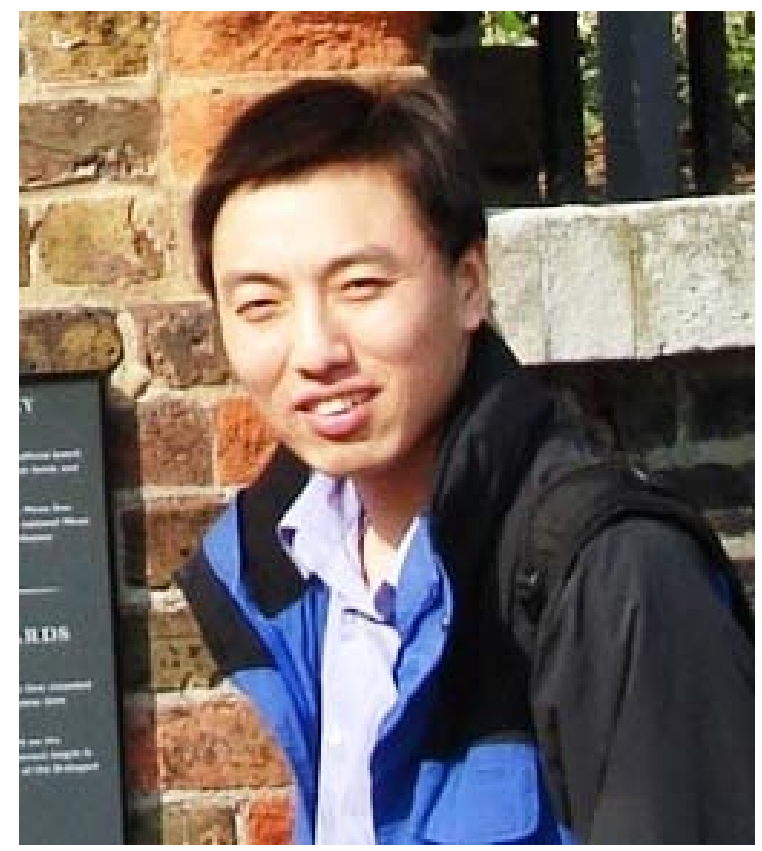

Lei Zhong was born in Wuhe County, Bengbu City, Anhui Province, China, on April 20, 1979. He went to Anhui Normal University in 1997 and obtained a Bachelor Degree in July 2001. Then he went on studying for a MSc degree at Anhui Normal University and specialized in the application of GIS and RS. After graduation in 2004, he became a Ph.D. candidate in the Institute of Tibetan Plateau Research, Chinese Academy of Sciences (ITP/CAS). In November 2006, he was awarded a scholarship by the Faculty of GeoInformation Science and Earth Observation (ITC), University of Twente to pursue a Ph.D. degree (Sandwich) in the Netherlands. In 2010, he became employed by the University of Science and Technology of China (USTC) and currently works as an associate professor in School of Earth and Space Sciences. Lei Zhong has been actively involved in some land surface processes experiments in the Tibetan Plateau, for example, Coordinated Enhanced Observing Period (CEOP) Asian-Australian Monsoon Project (CAMP) on the Tibetan Plateau (CAMP/Tibet). From March to June in 2005, he also took part in the fourth scientific expedition to Mt Everest. He was responsible for the observation of two sets of 3-D Sonic Anemometer and one set of radio sonde system at Mt. Everest Base Camp. His research focuses on application of remote sensing, land-atmosphere interaction and atmospheric boundary layer. As a scientific researcher, he is now principle investigator (PI) of 8 projects in China.

This research reported in this thesis was founded and supported by the Faculty of Geo-Information Science and Earth Observation (ITC), University of Twente through a 'sandwich' PhD fellowship, the National Natural Science Foundation of China (41275028, 91337212, 41275010, and 40905017), the China Postdoctoral Science Foundation funded project (201003163), the Fundamental Research Funds for the Central Universities and the Scientific Research Foundation for Introduced Talents, the University of Science and 
Technology of China (ZC9850290111), Specialized Research Fund for the Doctoral Program of Higher Education (Grant No. 20113402120034) and the Fundamental Research Funds for the Central Universities (Grant No. WK2080000036).

\section{First-author publications}

\section{ISI J ournal Articles}

1. Zhong, L., Y. Ma, Y. Fu, X. Pan, W. Hu, Z. Su, M.S. Salama and L. Feng, 2014, Assessment of soil water deficit for the middle reaches of YarlungZangbo River from optical and passive microwave images, Remote Sensing of Environment, 142: DOI:10.1016/j.rse.2013.11.008.

2. Zhong, L., Y. Ma, W. Ma, Y. Fu, Z. Su, M.S. Salama, D. Chu and C. Bianba, 2012, Remote sensing of land surface parameters in the middle reaches of Yarlung-Zangbo River and its two tributaries from AVHRR and MODIS data, J ournal of the Meteorological Society of Japan, 90(C): 75-86.

3. Zhong, L., Z. Su, Y. Ma, M.S. Salama and J.A. Sobrino, 2011, Accelerated changes of environmental conditions on the Tibetan Plateau caused by climate change, Journal of Climate, 24(24): 6540-6550.

4. Zhong, L., Y. Ma, M.S. Salama, and Z. Su, 2010, Assessment of vegetation dynamics and their response to variations in precipitation and temperature in the Tibetan Plateau, Climatic Change, 103: 519-535.

5. Zhong, L., Y. Ma, Z. Su, and M.S. Salama, 2010, Estimation of land surface temperature over the Tibetan Plateau using AVHRR and MODIS data, Advances in Atmospheric Sciences, 27(5): 1110-1118.

6. Zhong, L., Y. Ma, Z. Su, W. Ma, and Y. Lv, 2009, Land-atmosphere energy transfer and surface boundary layer characteristics in the Rongbu valley on the northern slope of Mt. Everest, Arctic, Antarctic, and Alpine Research, 41(3): 396-405.

\section{Other Refereed J ournal Articles}

7. Zhong, L., Y. Ma, W. Ma, D. Chu, and C. Bianba, 2011, Land surface heat fluxes in the middle reaches of Yarlung-Zangbo river and its two tributaries derived from AVHRR and MODIS data. Journal of Glaciology and Geocryology, 33(2): 309-317. (In Chinese with English abstract)

8. Zhong, L., Y. Ma, M. Li, 2007, An analysis of atmosphere turbulence and energy transfer characteristics of surface layer over Rongbu valley in Mt. Qomolangma area. Chinese Journal of Atmospheric Sciences, 31(1): 4856. (In Chinese with English abstract)

9. Zhong, L., Y. Ma, Z. Su, Y. Wang, Y. Lu, Z. Zhu, 2007, Variation characteristics of meteorological elements, radiation and energy budget components before and after the rainy season in the surface layer of Mt. Qomolangma area, Plateau Meteorology, 26(6): 1269-1275. (In Chinese with English abstract) 


\section{Co-author publications}

\section{ISI J ournal Articles}

1. Ma, Y., C. Han, L. Zhong, B. Wang, Z. Zhu, Y. Wang, L. Zhang, C. Meng, C. Xu, P. M. Amatya, 2013, Using MODIS and AVHRR data to determine regional surface heating field and heat flux distribution over heterogeneous landscape of the Tibetan Plateau, Theoretical and Applied Climatology, DOI 10.1007/s00704-013-1035-5.

2. Ma, Y., B. Wang, L. Zhong and W. Ma, 2012, The regional surface heating field over the heterogeneous landscape of the Tibetan Plateau using MODIS and in-situ data, Advances in Atmospheric Sciences, 29(1): 47-53.

3. Ma, Y., L. Zhong, Y. Wang, Z. Su, 2012, Using NOAA/AVHRR data to determineregional net radiation and soil heat fluxes over the heterogeneous landscape of the Tibetan Plateau, International Journal of Remote Sensing, 33(15): 4784-4795.

4. Salama, M.S., R. van der Velde, L. Zhong, Y. Ma, M. Ofwono and Z. Su, 2012, Decadal variations of land surface temperature anomalies observed over the Tibetan Plateau by the Special Sensor Microwave Imager SSM/I from 1987 to 2008, Climatic Change, 114 (3-4): 769-781.

5. Li, M., Y. Ma and L. Zhong, 2012, The turbulence characteristics of the atmospheric surface layer on the north slope of Mt. Everest region in the spring of 2005, Journal of the Meteorological Society of Japan, 90C: 185193.

6. Ma, Y., L. Zhong, B. Wang, W. Ma, X. Chen and M. Li, 2011, Determination of land surface heat fluxes over heterogeneous landscape of the Tibetan Plateau by using the MODIS and in situ data, Atmospheric Chemistry and Physics, DOI : 10.5194/acp-11-10461-2011.

7. Ma, Y., Y. Wang, L. Zhong, R. Wu and S. Wang, 2011, The Characteristics of atmospheric turbulence and radiation energy transfer and the structure of atmospheric boundary layer over the northern slope area of Himalaya, J ournal of the Meteorological Society of Japan, 89A: 345-353.

8. Ma, W., Y. Ma, L. Zhong, Retrieving land surface temperature from aster data using tes: a case study on the Namco area of the Tibetan Plateau, Proc. 'Dragon 2 Programme Mid-Term Results 2008-2010', Guilin City, People's Republic of China 17-21 May 2010 (ESA SP-684, October 2010).

9. Ma, Y., W. Ma, Y. Wang, L. Zhong, M. Li, and H. Ishikawa, 2009, Study of the energy and water cycle over the heterogeneous landscape of the northern Tibetan Plateau. Hydrological Modelling and Integrated Water Resources Management in Ungauged Mountainous Watersheds, Chengdu, China, IAHS, 335: 168-176.

10. Ma, W., Y. Ma, M. Li, Z. Hu, L. Zhong, Z. Su, H. Ishikawa, and J. Wang, 2009, Estimating surface fluxes over the north Tibetan Plateau area with ASTER imagery, Hydrology and Earth System Sciences, 13: 57-67.

11. Ma, Y., Y. Wang, R. Wu, Z. Hu, K. Yang, M. Li, W. Ma, L. Zhong, F. Sun, X. 
Chen, Z. Zhu, S. Wang, and H. Ishikawa, 2009, Recent advances on the study of atmosphere-land interaction observations on the Tibetan Plateau, Hydrology and Earth System Sciences, 13: 1103-1111.

12. Ma, Y., L. Zhong, Z. Su, H. Ishikawa, M. Menenti, and T. Koike, 2006, Determination of regional distributions and seasonal variations of land surface heat fluxes from Landsat- 7 Enhanced Thematic Mapper data over the central Tibetan Plateau area, Journal of Geophysics Research, 111: D10305, doi: 10.1029/2005J D006742.

\section{Other Refereed J ournal Articles}

13. Ma, W., Y. Ma, L. Zhong, D. Chu, C. Bianba, 2010, Land surface variables estimated from ASTER remote sensing data in 'Three Rivers' area of Tibetan Plateau, Plateau Meteorology, 29(5): 1351-1355. (In Chinese with English abstract)

14. Ma, Y., Y. Wang, W. Ma, L. Zhong, Z. Su, 2007, Determinating the regional distributions of surface heat fluxes over heterogeneous landscape of Mt. Qomolangma area using the satellite remote sensing and field observations, Plateau Meteorology, 26(6): 1231-1236. (In Chinese with English abstract)

15. Zhu, Z., Y. Ma, M. Li, L. Zhong, 2007, Diurnal and seasonal variations of the carbon dioxide over the alpine meadow ecosystem on the northern slope of the Qomolangma, Plateau Meteorology, 26(6): 1300-1304. (In Chinese with English abstract)

16. Ma, Y., L. Zhong, H. Tian, F. Sun, Z. Su, 2006, Study on the regional land surface heat fluxes over heterogeneous landscape of the Tibetan Plateau area, Journal of Remote Sensing, 10(4): 542-547. (In Chinese with English abstract)

17. Li, M., Y. Ma , L. Zhong, S. Lu, 2006, Preliminary analysis on near surface radiation budget in the region of Mt. Qomolangma in April and May 2005, Plateau Meteorolgoy, 25(6):1008-1013. (In Chinese with English abstract)

18. Li, M., Y. Dai, Y. Ma, L. Zhong, S. Lu, 2006, Analysis on structure of atmospheric boundary layer and energy exchange of surface layer over Mount Qomolangma region, Plateau Meteorology, 25(5): 807-813. (In Chinese with English abstract)

19. Ma, W., Y. Ma, F. Sun, M. Li, L. Zhong, J. Wang, 2007, Seasonal variations of land surface radiation budget and energy on northern slope of Mt. Qomolangma area, Plateau Meteorology, 26(6): 1237-1243. (In Chinese with English abstract) 


\section{ITC Dissertation List}

http://www.itc.nl/research/phd/phd_graduates.aspx 